\title{
The Search for Antimalarial Drugs and the Discovery of Artemisinin
}

\author{
LI Runhong 黎润红, ${ }^{1}$ ZHANG Daqing 张大庆 ${ }^{2}$
}

(The School of Health Humanities, Peking University, Beijing 100191, China)

\begin{abstract}
With its novel chemical structure, artemisinin is an antimalarial component isolated from the traditional Chinese medicine qinghao (Artemisia annua L.). Nowadays, artemisinin and its derivatives are used compatibly with new synthesized chemical antimalarial compounds to create artemisinin-based combination therapies (ACTs). These have become the first choice in treating malaria $p . f$. all over the world, providing an effective solution for the global challenge of curing drug-resistant malaria. Among the five ACTs recommended by the WHO, two were initiated in China and are used as the first-line treatment of falciparum malaria in all malaria endemic areas. As the use of artemisinin-based compound drugs have made such significant contributions to rolling back malaria, regarded as one of the great achievements globally in public health of the early twenty-first century, Tu Youyou, one of the most important researchers in the discovery of artemisinin, was made the first Nobel Prize laureate in Physiology or Medicine from the Chinese mainland. Artemisinin was discovered in a special social and cultural context through a combination of the exploration of traditional Chinese medical literature with the modern research approach of pharmaceutical sciences. This (Project 523 ) is a typical case of goal-oriented research leading to scientific advance, and the result of scientific research driven by the national needs.
\end{abstract}

Keywords: antimalarial drugs, artemisinin, artemisinin-based compound drugs, Tu Youyou

摘 要: 青蒿素是从中国传统药物青蒿 (植物黄花蒿) 中提取的全新化学结构的抗㾏药
物。目前, 青蒿素及其衍生物, 特别是与中国科学家化学合成的抗㾏新药伍用复方已成
为全球广泛应用于治疗㾏疾的首选药物, 为全球㾏疾耐药性难题提供了有效的解决方
案; 在青蒿素类复方药物的应用为 21 世纪全球公共卫生伟大成就之一的遏止㾏疾行动

Received: August 3, 2020. Revised: October 25, 2020.

The paper was translated from Chinese into English by Yu Yueyuan 俞月圆 and copyedited by John Moffett.

1 Research interests: History of medicine. Email: lirunhong@bjmu.edu.cn

2 Research interests: The cultural and social history of medicine in the nineteenth and twentieth century China, comparative history (particularly traditional Chinese medicine and Western medicine), and medical cultures since the late nineteenth century. Email: zhangdq@bjmu.edu.cn 
作出巨大贡献之时, 青蒿素发现过程中的代表人物屠呦呦成为中国本土第一位荣获诺贝 尔生理学或医学奖的科学家。青蒿素的发现是在一个特殊的社会文化环境中基于中医药 文献深入挖掘和现代药学研究手段相结合而完成的, 是一个任务 (“523”任务) 带动科 研和学科发展的典型案例, 是国家需要与科学研究相互促进的结果。

关键词: 抗疮药, 青蒿素, 青蒿素类复方药, 屠呦呦

$\mathrm{O}^{n}$

n December 7, 2015, Tu Youyou, the Chinese laureate of the Nobel Prize in Physiology or Medicine, gave her Nobel Lecture at Aula Medica, Karolinska Institutet in Stockholm, Sweden. In it she introduced the story of how Chinese scientists discovered new antimalarial drugs from traditional Chinese medicines nearly five decades ago in considerably difficult circumstances. Tu emphasized that the Nobel Prize she had received was not only an honor granted to her alone, but also a reward for so many scientists who had participated in this research. She mentioned in particular that the large-scale collaborative scientific research centering on "Project 523" had laid a solid foundation for the discovery of artemisinin and the development of artemisinin derivatives. "Without collective efforts, we would not have been able to present artemisinin . . . in such a short period of time" (The Nobel Prize Organization 2015, on page 309 of the PDF attachment titled "Artemisinin-A Gift from Traditional Chinese Medicine to the World").

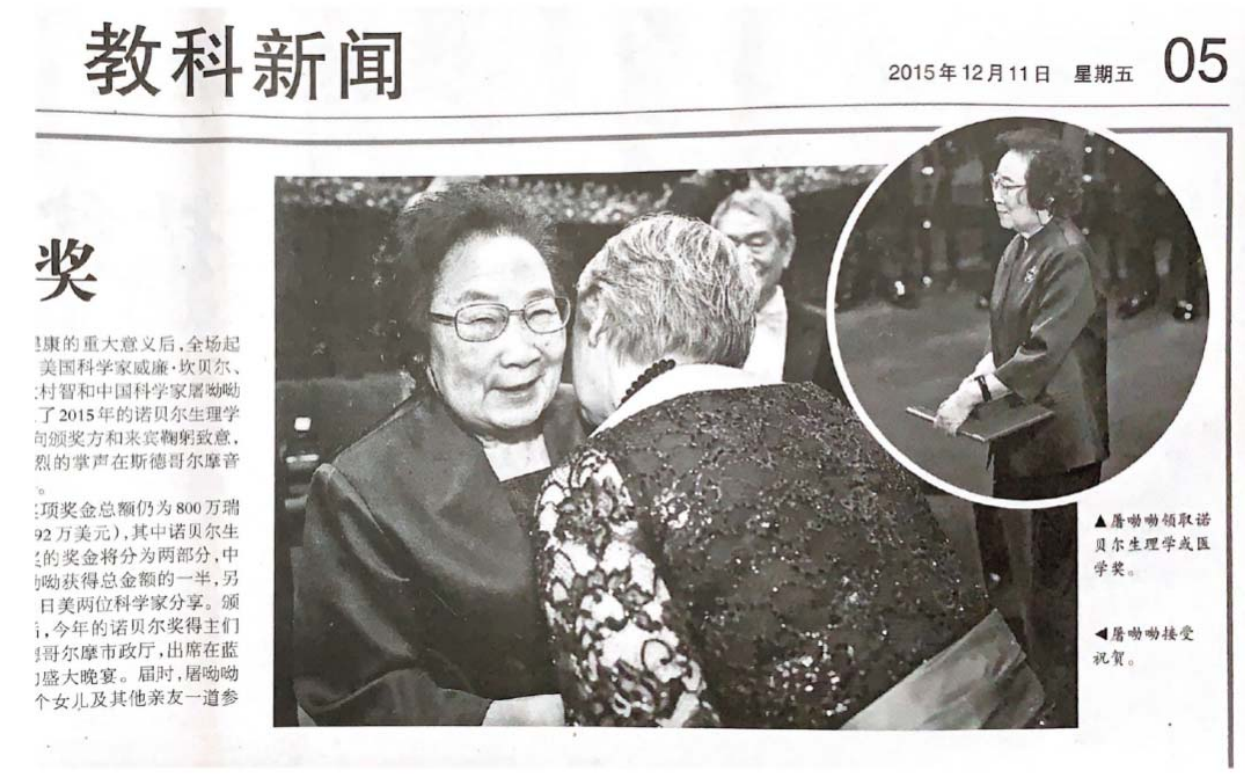

Figure 1: Tu Youyou receiving her Nobel Prize on December 10, 2015. Photo from Guangming Daily (Guangming ribao 光明日报), 5; December 11, 2015. 
Project 523 was a large-scale collaborative scientific research program organized by the Chinese government, and the story of the discovery of artemisinin is by no means pure mythology or one of epiphany. Many papers have discussed this discovery and the controversy over priority (Hsu 2009; Zhang 2009; Wang 2012; Huang and Zhu 2012). After Tu Youyou won the Nobel Prize, there were yet more papers discussing or reflecting on the research program, from a variety of angles, such as the process of the discovery or philology (Li and Zhang 2019; Su and Miller 2015; Jiang 2016; Zhou 2016; Yuan et al. 2017; Zhang H. 2018; Liu and Ling 2018). However, as the relevant archives are kept in different places, and some of these documents have not been made public, many research papers fail to offer a comprehensive picture of the research conducted on artemisinin at the time of the project. Multiple books on this topic have been published in English or in Chinese, and while each has its emphasis, reading through them one can get a relatively complete understanding of this issue. Some record oral accounts by participants, some are written from the perspective of certain individual participants, some are from the perspective of administrators, and some choose to introduce the overall situation. The authors of this paper have done their utmost to collect archives from the relevant institutions involved, and made full use of manuscripts, correspondence, and oral histories, to clarify the basic historical facts surrounding the discovery of artemisinin and the development of artemisinin-based combination drugs. For the sake of clarity, content that has been discussed in detail in previous books is included in this paper as well, but due to space limitations, some of the information is only briefly introduced. In addition to historical materials obtained recently, this paper includes an introduction to the early reviews of traditional Chinese medical literature, an examination of the origin of the widely-circulated Antimalarial Collections of Effective Recipes and Prescriptions (Kangnüe dan mi yan fang ji 抗疮单秘验方 集), and historical data on the early structural determination of artemisinin.

\section{$1 \mathrm{~A}$ mission in a special age}

Malaria is one of the oldest diseases in human history, and is still among the crucial public health issues that draw global attention. Till the early 1970s, malaria was widespread in many underdeveloped countries. Quinolines such as quinine and its homologues chloroquine and amodiaquine have played an important role in the prevention and control of malaria. However, with the long-term use of these drugs, the parasite's resistance to antimalarial medicines had strengthened, especially to chloroquine and amodiaquine, and the wait for breakthroughs in the development of malaria vaccines continued.

Malaria was also one of the major diseases that posed a serious threat to the health of the Chinese population. According to statistics, in the early 1950s, as many as 1829 
counties and cities in the country, about $70 \%$ to $80 \%$ of the total number, suffered from the malaria pandemic (The Editorial Committee 1991, 9). Statistics from eight provinces, including Yunnan, Guizhou, Guangdong, Guangxi, Jiangxi, Hunan, Sichuan, and Henan, show that in 1955 , cases of malaria accounted for around $60 \%$ of patients suffering from the nineteen listed infectious diseases (Ministry of Public Health of the People's Republic of China 1957). In 1956, the 1956-1967 National Program for Agricultural Development (Draft) (1956-1967 Quanguo nongye fazhan gangyao [caoan] 1956 1967 全国农业发展纲要[草案]) set the goal of basically eliminating all diseases, including malaria, that posed the most serious threat to people's health across the entire country. The Ministry of Public Health held the National Conference on Malaria Prevention and Control in August of that year, at which a plan for the prevention and control of malaria was formulated (Ministry of Public Health of the People's Republic of China 1957).

Chloroquine-resistant malaria p.f. (plasmodium falciparum malaria) was prevalent in Southeast Asia in the 1960s, and spread to some parts of southern China. Despite the various measures taken by the Chinese government, the disease re-emerged from time to time, resulting in around ten million malaria patients each year. As the Vietnam War escalated, both warring parties were plagued by chloroquine-resistant malaria $p . f$., which led to a significant reduction in the number of combat-ready troops available. To address this problem, the United States invested considerable manpower and material resources in the study of malaria in order to find new antimalarial drugs. Starting from the end of the 1960s, the United States' Walter Reed Army Institute of Research screened over two hundred thousand compounds.

At the request of the Vietnamese leadership, and as an important aspect of war preparations and providing emergency foreign aid, the Chinese government designated relevant departments to set up a project to solve the problem of the serious impact malaria was having on combat troops and military operations in tropical areas (Zhang J. 2018, 6). The most important goal of this project was to focus on the development in a relatively short period of time of mosquito repellents and medicines which could prevent or control drug-resistant malaria. ${ }^{3}$ From 1964 to 1966, Chinese researchers spent almost two years in Vietnam conducting field surveys and offering on-the-spot assistance, during which they learned about the urgent need for, and complexities involved in, the prevention and control of malaria. Around June 1966, Gui

3 Internal documents: Notification jointly issued by the State Scientific and Technological Commission of the People's Republic of China and the General Logistics Department of the People's Liberation Army [(67) KSZ No. 118 \& HKZ No. 388], “The Minutes of the Collaborative Conference for Research on Drugs that Prevent or Control Malaria” ( “㾏疾防治药物研究工作会 议” 纪要) and “The Collaborative Plan for Research on Drugs that Prevent or Control Malaria (1967-1970)" (疮疾防治药物研究工作协作规划 [1967 1970 年]), Attachment I, June 16, 1967. In Collection of Materials on Project 523 and Artemisinin (五二三与青高素资料汇集), edited by Zhou Keding 周克鼎, the former secretary of National Project Office of Project 523, March 2004. 
Shaozhong 桂绍忠, 4 director of the Academy of Military Medical Sciences (hereafter “the AMMS"), told Wu Zilin 吴滋霖 to accompany him to a meeting held at the General Logistics Department of the People's Liberation Army (hereafter "the General Logistics Department"). The main purpose of the meeting was for Chen Pang 陈庞, the chief of staff, to convey a task assigned by Chairman Mao Zedong, which was to prevent and control malaria among the troops in southern Vietnam during the Vietnam War. Considering that the army alone might not be able to organize a sufficiently strong research team, it was decided that the General Logistics Department and the State Scientific and Technological Commission (hereafter "the State S\&T Commission") would take the lead in organizing the cooperative research. As new strategies to prevent and control the drug-resistant malaria p.f. were an urgent need, the AMMS drafted a three-year research plan. ${ }^{5}$

On April 18, 1967, the State S\&T Commission held the "Conference on MilitaryCivilian Cooperative Research on the Prevention and Control of Malaria." On May 4, notice of a meeting to establish large-scale collaboration for the study of drugs to prevent or control malaria was issued to relevant units. On May 18, the National Leading Group for Research on the Prevention and Control of Malaria held a meeting in Beijing (Chen 2002, 960). From May 23 to May 30, after the relevant departments had discussed and approved the research plan, the State S\&T Commission and the General Logistics Department held a national cooperation meeting attended by relevant units directly under the Central Military Commission and national government ministries, leaders of relevant provinces, municipalities, autonomous regions, military regions, and relevant units. During the meeting, the three-year research plan was discussed, revised, and finalized (Zhang J. 2018). This research was regarded as an urgent war preparation task, requiring an organized and concentrated effort involving military and civilian co-operation to develop as quickly as possible mosquito repellents and medicines to prevent or control drug-resistant malaria. Based on the date of the meeting, this was named "Project 523" (or "Task 523") for short.

Project 523 was a "big science" research plan, so to speak, of modern medical research in China, featuring a clear goal, multidisciplinary efforts, cooperation between various institutions, and large investment in manpower and material resources. In order to strengthen the leadership of the project, the Chinese government set up a National Leading Group for Research on Drugs that Prevent or Control Malaria (hereafter referred to as the "Leading Group" for short), members of which included

4 Gui Shaozhong 桂绍忠 (1916-2005) was from Huoqiu 或丘, Anhui Province. He was appointed director of the AMMS and an adviser to the Department of Health under the General Logistics Department in 1966.

$5 \mathrm{Wu}$ Zilin 吴滋霖, interview by Li Runhong 黎润红, Beijing, October 7, 2009. Transcript in the database for the project of "Collecting Historic Data of Scientists' Academic life" (hereafter referred to as "the database of the Collecting Project"). 
the State S\&T Commission, the State Commission of Science and Technology for the National Defense Industry, the General Logistics Department, the Ministry of Public Health, the Ministry of Chemical Industry, and the Chinese Academy of Sciences. At first the State S\&T Commission was the group leader, and the General Logistics Department deputy leader. After the State S\&T Commission was merged with other institutions in 1970, ${ }^{6}$ the leading group was reorganized to be led by the Ministry of Public Health (as the group leader), the Department of Health under the General Logistics Department (as deputy leader), the Ministry of Chemical Industry, and the Chinese Academy of Sciences. Under this leading group was the administrative agency, members of which were mainly from the People's Liberation Army 236 Unit subordinated to the General Logistics Department (namely the AMMS; its code "236" frequently appears in documents of that time), while there was one member from the Chinese Academy of Sciences, Chinese Academy of Medical Sciences, and China National Pharmaceutical Industry Corporation, respectively. The project office, which was based in the AMMS, was in charge of daily affairs and the communication of scientific research by the time Project 523 was wound up in 1981.

In June 1967, the State S\&T Commission and the General Logistics Department jointly issued "The Minutes of the Collaborative Conference for Research on Drugs that Prevent or Control Malaria” ( “疮疾防治药物研究工作会议” 纪要) and “The Collaborative Plan for Research on Drugs that Prevent or Control Malaria (1967-1970)" (㾏疾防治药物研究工作协作规划[1967 1970 年]) to participating units. The plan made clear the target and focus of the research on antimalarial drugs. The aim of the drug was to prevent and control the drug-resistant malaria $p . f$. in tropical areas. It should be resistance-free, consistent in effect, convenient to use, and cheap in price; the treatment should be effective and quick, and the prevention should be long-lasting; the packaging should be dampproof, waterproof, heat resistant, lightproof, and shockproof. Incorporating the approaches of conducting modern medical research and extracting effective components from Chinese herbal medicines, the plan was divided into five special subjects: (1) Developing new medicines that prevent or control malaria, through synthesizing and screening chemicals; (2) research on preventing and controlling malaria through traditional Chinese medicine and acupuncture; (3) research on mosquito repellents; (4) research on the preparation and packaging of drugs that prevent or control malaria; (5) on-site observation of the effects of drugs that prevent or control malaria. For each of the subjects the plan specified the detailed research topics, the division of tasks between different units, and scheduling. In order to give full play

6 In July 1970, the State S\&T Commission was merged into the Chinese Academy of Sciences, and the new "Revolutionary Committee" of the Chinese Academy of Sciences was founded. A new State S\&T Commission was set up in September 1977, and renamed "Ministry of Science and Technology" in 1998. 
to the interests of various professions and regions and facilitate cooperation and communication between them, the participating units were divided into four cooperation groups. Two of the groups would work on the drugs: (1) The Cooperation Group on Synthesizing and Screening (合成与篮选协作组). The group leader was the AMMS, and the deputy leader were the State Institute of Pharmaceutical Industry in Shanghai and the Institute of Materia Medica, Chinese Academy of Medical Sciences (hereafter referred to as "the CAMS IMM"). (2) The Cooperation Group on Traditional Chinese Medicine (中医中药协作组). The group leader was the CAMS IMM, and the deputy leaders were the Shanghai Research Institute of Acupuncture and the AMMS.

In implementing this plan, adjustments were made to the collaboration between participating units as certain changes occurred. At first, the Cooperation Group on Traditional Chinese Medicine had three research projects, namely "Research on Antimalarial Chinese Medicines including Changshan 常山 (Dichroa febrifuga Lour.)" (常山及其他抗㾏有效中药的研究), “Focused Investigative Research on the Folk Use of Effective Antimalarial Medicines" (民间防治㾏疾有效药物的疗法的重点调查研究), and “Research on Preventing and Controlling Malaria with Acupuncture" (针尒防治㾏疾的 研究). Nearly twenty institutions participated in the work of this group. The China Academy of Chinese Medical Sciences $(\mathrm{CACMS})^{7}$ was not in the initial plan; its subordinate Institute of Chinese Materia Medica (hereafter referred to as "the CACMS ICMM") did not join the group until early in 1969. Project 523 made many accomplishments in research, including the structural transformation of febrifugine, the separation of yingzhaosu A, an effective antimalarial component isolated from the root of yingzhao 鹰爪 (Artabotrys uncinatus [L.] Merr.), and the separation of zincpolyanemine, a metallic compound, from Polyalthia nemoralis A. DC. One of the most outstanding of these achievements was the discovery made by Liang Xiaotian 梁晓天, Yu Dequan 于 德泉, and their colleagues from the CAMS IMM (Liang et al. 1979). While researching the chemical structure of yingzhaosu A, they found that it is a kind of sesquiterpene peroxide. This discovery not only provided an idea for subsequent research and synthesis of new antimalarial drugs, ${ }^{8}$ but also proved to be significant in determining

7 Founded in Beijing on December 19, 1955, the academy was under the direct leadership of the Ministry of Public Health and was then called the Academy of Traditional Chinese Medicine. At its thirtieth anniversary, it was renamed the China Academy of Traditional Chinese Medicine. It was renamed the China Academy of Chinese Medical Sciences (CACMS) in 2005.

8 Internal document: Institute of Materia Medica of Chinese Academy of Medical Sciences, Guangzhou Zhongshan School of Medicine, and the South China Botanical Garden, Chinese Academy of Sciences. "Study on the Chemical Structure of the Effective Antimalarial Component of Yingzhao" (鹰爪抗疮疾有效成分的化学结构的研究). In Selection of Achievements in Malaria Research, Compiled by the National Leading Group for Research on the Prevention and Control of Malaria (1967-1980) (全国疮疾防治研究领导小组办公室疮疾研究科研成果选编 [1967 1980]). 
the structure of artemisinin. ${ }^{9}$

At the same time, the Leading Group of Project 523 had also elicited substantial efforts from the Cooperation Group on Synthesizing and Screening. While structurally transforming febrifugine, the group finished much other work as well, obtaining remarkable results, including new functions from the effects of piperaquine phosphate, and success in synthesizing several antimalarial chemical compounds with new structures, such as pyronaridine, lumefantrine, and naphthoquine. Originating from Project 523, these drugs that had never been put on the market before continue to play a significant role in artemisinin-based combination therapy (ACT), which has turned out to be the most effective antimalarial therapy of the early twenty-first century. Lumefantrine in Coartem (artemether-lumefantrine tablets), which is known as the gold standard of ACT drugs, is the only new drug to win first prize in the State Technological Invention Awards in China (December 1990).

\section{Starting from inheriting traditional Chinese medicines}

\subsection{Reviewing traditional Chinese medical literature}

Chen Kehui's 陈克恢 extraction of ephedrine from mahuang 麻黄 (Ephedra sinica) in the 1920s established a pattern of research on traditional Chinese medicines, and the search for antimalarial drugs in traditional literature even received government support during the period of the Republic of China. For instance, changshan was commonly recorded in traditional Chinese medical literature as a treatment for malaria when used together with other medicines. Chen Guofu 陈果夫 (1892-1951), a powerful figure of the ruling Kuomintang Party, played a significant role in bringing this to scientific attention. Having been ill for a long time, Chen was interested in medical science, and according to a play he wrote, titled Treating Malaria with Changshan (Changshan zhi nüe 常山治㾏), Chen and his coworkers did clinical experiments on subjects, verifying the traditionally-recognized effects of changshan. In doing this work, they substantially cut down on the time and effort that later researchers would need to put into this stage of study (Lei 1999, 323-358). In the 1940s, Zhang Changshao 张昌绍 and his colleagues used modern scientific approaches to study changshan further, and discovered dichroine, a chemical entity that can be used to treat malaria (Rao, Li, and Zhang 2016, 232). Prior to this, no final conclusion had been reached regarding whether changshan alone could cure malaria, as it was not used on its own in standard practice of traditional Chinese medicine, while there was no modern Western scientific research to prove that it was effective on its own either (Rao 2015, 127-131). Zhang Changshao

9 Li Ying 李英 and Wu Yulin 吴毓林, interview by Li Runhong, Shanghai, July 26, 2010. Transcript in the database of the Collecting Project. 
and his collaborators established through this work the technical specifications for research on natural medicinal plants. Two associates of Zhang Changshao, Zhou Tingchong 周廷冲 from the AMMS, who had been his teaching assistant, and Fu Fengyong 傅丰永 from the CAMS IMM, who had been Zhang's student, both continued to use a modern scientific approach to study changshan's effects in treating malaria (Jang et al. 1946), and later both became planners of Project 523. Glancing over the first volume of Summary of Literature on Chinese Materia Medica (1820-1961) (Zhongyao yanjiu wenxian zhaiyao 中药研究文献摘要 $[1820 \sim 1961]$ ) compiled by Liu Shoushan 刘寿山 from the CAMS IMM, one finds a large body of research literature concerning changshan produced since the 1940s. Zhang Changshao, Fu Fengyong, and others published a series of papers in both Chinese and overseas journals (Wang, Fu, and Zhang 1945; Chou et al. 1947; Zhao et al. 1947; Chou, Fu, and Kao 1948; Fu and Jang 1948; Jang et al. 1948). Their work continued into the 1950s (Zhang and Huang 1956; Fu et al. 1956; Wu et al. 1956), which accounts for the fact that Project 523 had hoped in its first three-year plan to make a breakthrough using changshan. Unfortunately, insurmountable side effects meant that febrifugine never joined quinine and artemisinin as an important antimalarial drug deriving from natural plants.

Liu Shoushan also lists Chinese herbal medicines that can be used to treat malaria. In addition to articles on changshan, he notes literature on treating malaria with mabiancao 马鞭草 (European verbena herb, Herba Verbenae) (Hu 1958), yadanzi 鸦胆子 (java brucea fruit, Fructus Bruceae) (Wang 1950; Fan 1952; Chen 1957), and an antimalarial medicinal powder made from cangzhu 苍术 (atractylodes rhizome, Rhizoma Atractylodis), baizhi 白芷 (dahurian angelica root, Radix Angelicae Dahuricae), and chuanxiong 川芎 (Sichuan lovage rhizome, Rhizoma Ligustici Chuanxiong) (Malaria Prevention Station of Dehong Dai and Jingpo Autonomous Prefecture in Yunnan Province 1959). As Fu Fengyong and Liu Shoushan worked for the same institute, it can be speculated that mabiancao, yadanzi, and the antimalarial medicinal powder listed in the three-year plan issued by Project 523 in 1967 probably originated from Liu's work.

In the 1950s, traditional Chinese physicians Wang Songyou 王松游 and Li Weipu 李蔚普 from Jiangxi Province used qinghao 青蒿 (sweet wormwood, Artemisia annua L.) to treat malaria (Xie 2015). In 1954 during the First Conference of Representatives of Traditional Chinese Physicians in Jiangxi, Wang Songyou disclosed the simple recipe for using qinghao to treat malaria, which had been proven to be effective, and supported his claim with a clinical report based on 130 cases. In the same year, Li Weipu from the Jiangxi Institute of Traditional Chinese Medicine published "The Effect of Qinghao in Treating Malaria” (Qinghao de kangnüe liaoxiao 青蒿的抗㾏疗效) in issue No. 9 of the magazine Beijing Journal of Traditional Chinese Medicine (Beijing Zhongyi 北京中医) (Figure 2), proving that Wang Songyou's treatment was effective using a few clinical 
cases. Li also mentioned that "in my hometown (in southern Jiangxi Province), it is rather common knowledge that qinghao can be used to treat malaria" (Li 1954). ${ }^{10}$ Although the Beijing Journal of Traditional Chinese Medicine was also a source for Summary of Literature on Chinese Materia Medica, as Li Weipu's paper cites too few cases, and Wang's report of using qinghao on 130 malaria patients was given at a conference, neither made it into the book. It is indeed a pity that Wang's work, despite reporting that qinghao was effective in over $90 \%$ of the patients, was not included for the reason that it did not belong to a qualified type of research literature.

\section{青蓠的抗瘧療效 \\ 李 蔚 普}

修水王松游先生在本年六月出席汇西省首届 中醫代表大會時, 曾經公開一個單方: 用青满子

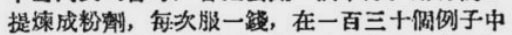
，服一次治急者佔 $60 \%$ ，服二次治湑者作 $30 \%$ 。 總絬赸來有效率在 $90 \%$ 以上。

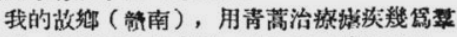
采央識, 而且用法很多栐, 有的用以煎暢洗澡,

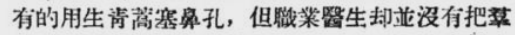

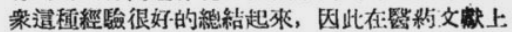

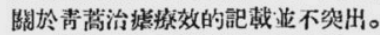

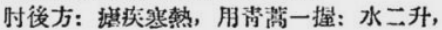
揭汁服之。

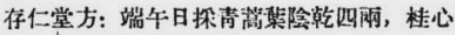
一雨经末, 未袂前酒服二箋。

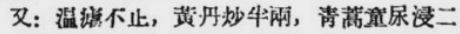
雨: 篇末每服一銭, 然多酒服, 熱多荣服。

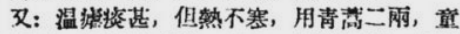
子小便浸, 婄黄丹牛两, 简来, 每服二錢, 白湯 調下。

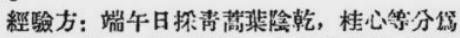

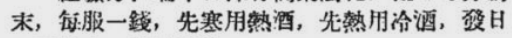
五更服之, 切忌制物。 本草網目: 青蓠主治處次寒熱。

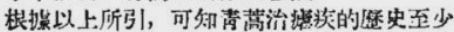

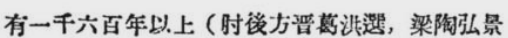

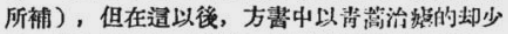
見, 古今區書集成登部全錄掼集治的力子共一

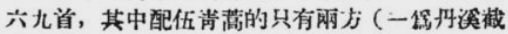

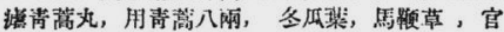
桂; 一策良方柴胡湯, 用柴胡, 常山, 知母, 鳘

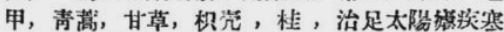

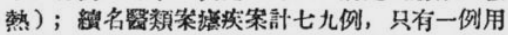

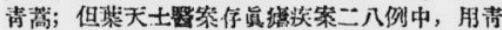
语者即有三例, 䛦明「蘇派醫生用青㵝代柴胡治 说」的說法, 是有根搌的。

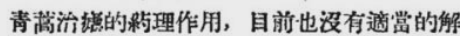

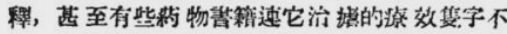

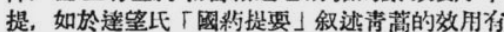

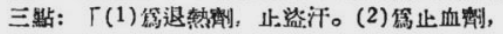

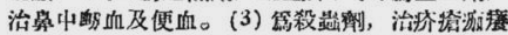
及䗋清:。1。即忽略了關於治绻的說明。但臨床

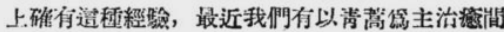
日结的病例:

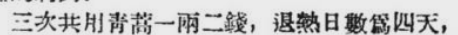

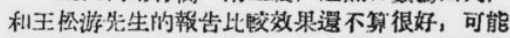

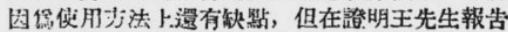
的员筫性一黑來馀，是有意绕的，希望能引起各

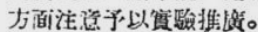

Figure 2: "The Effect of Qinghao in Treating Malaria" written by Li Weipu in 1954 (Li 1954).

Soon after the founding of the People's Republic of China, traditional Chinese medicine was incorporated into the national health administrative system, and research on Chinese materia medica became an important aspect of the development of the national health care system. In 1950, the Institute of Traditional Chinese Medicine was founded by the Central Research Institute of Health to specialize in research into traditional Chinese materia medica. In 1955, the Academy of Traditional Chinese 
Medicine was established by the national government. In October 1958, on the report to the central government on the results and experience concerning the first Off-the-Job Training Program of Traditional Chinese Medicine for Doctors Trained in Western Medicine held by the Ministry of Public Health, Mao Zedong wrote "traditional Chinese medicine is a great treasure-house. We should make great efforts to explore it and further improve it" (Literature Research Office of the CPC Central Committee 1992, 451). ${ }^{11}$ This comment became the guiding principle for the development of traditional Chinese medicine in China, and the National Working Conference on Traditional Chinese Medicine was held in Baoding at the end of that year.

In June 1959, the Ministry of Public Health issued a notice to the Health Department or Health Bureau of all the provinces, municipalities, and autonomous regions on collating, studying, and popularizing secret recipes and recipes shown to be effective by experience, so as to let these recipes play a more significant part in eliminating disease and protecting the health of the people. The practices of contributing and collecting recipes spread nationwide, leading to a great number of compilations of secret recipes, "effective" recipes (those shown to be effective through experience), and simple recipes. ${ }^{12}$ This is now regarded as the prelude to the movement of promoting Chinese herbal medicines during the "Cultural Revolution" (Zhang and Zhang 2009). During the movements of contributing recipes and promoting Chinese herbal medicines, traditional Chinese medical literature whether in the form of classical works or folk prescriptions was sorted out and collated. The two types of collating that were carried out respectively by the Shanghai Literature Institute of Traditional Chinese Medicine and the CACMS had varying degrees of influence upon the discovery of artemisinin.

Founded in 1956, the Shanghai Literature Institute of Traditional Chinese Medicine had been aware of the significance of collecting and collating folk recipes since its early years. By 1958, the institute had finished compiling the first and second selections of Selection of Effective Recipes (Yanfang xuanji 验方选辑) (Ji 2016). Starting from 1959, ten special collections on specific diseases were compiled and published, mainly based on classical works of traditional Chinese medicine through the ages. Among these collections is the Collection on Malaria (Nüeji zhuanji 疮疾专辑) (Figure 3), which was utilized by Yu Yagang 余亚纲, one of the earliest members of "Group 523" in the CACMS ICMM. The book clearly points out that the statement "Qinghao can cure malaria" (青蒿截应) is from Wang Tao's 王奉 Secret Prescriptions from the Imperial Palace

11 “中国医药学是一个伟大的宝库, 应当努力发掘, 加以提高。”

12 The development of traditional Chinese medicine was usually regional, and the knowledge and skills usually passed on within families. As medicines and the habits of making use of these medicines vary from place to place, there were a large number of such recipes circulating among the people. 
(Waitai miyao 外台秘要) ${ }^{13}$ and Ge Hong's 葛洪 Handbook of Prescriptions for Emergencies (Zhouhou fang 肘后方). ${ }^{14}$

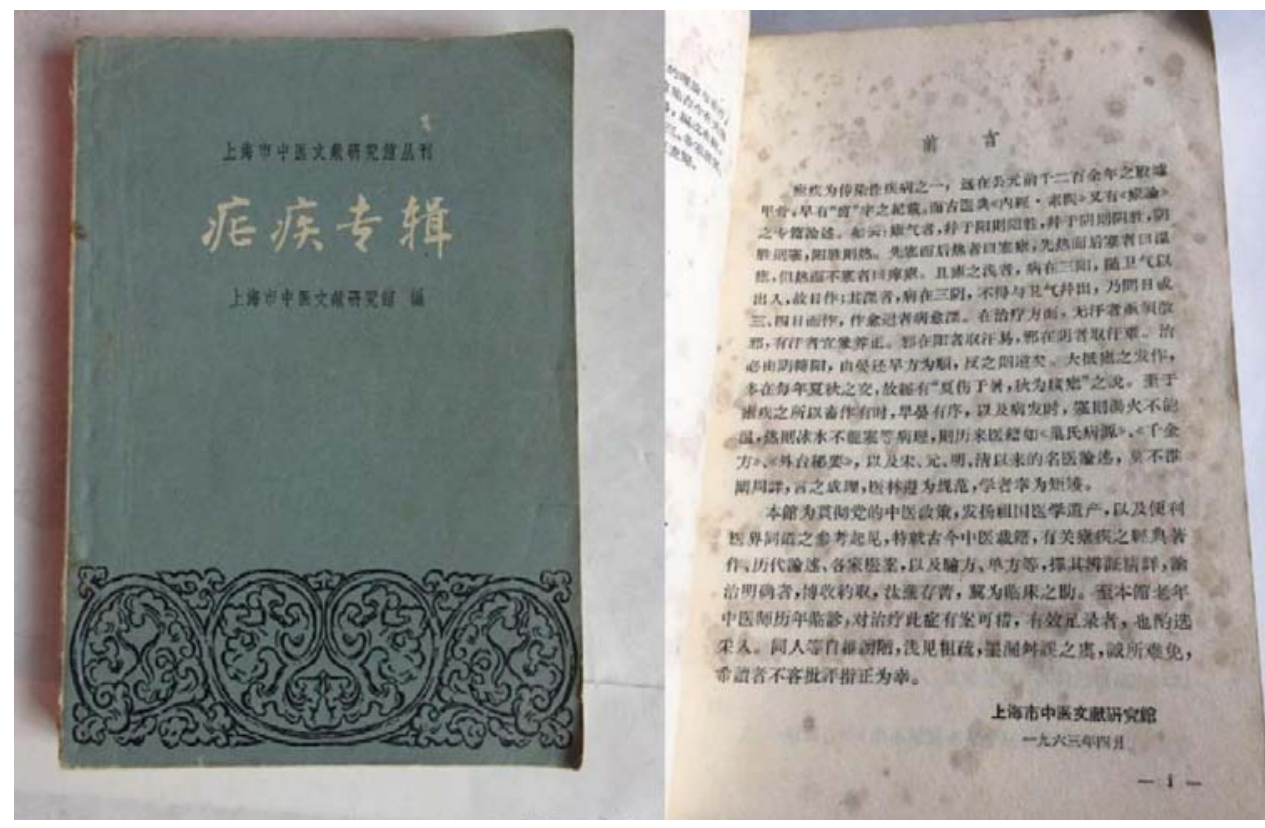

Figure 3: Collection on Malaria published in May 1965, compiled by the Shanghai Literature Institute of Traditional Chinese Medicine (Shanghai Literature Institute of Traditional Chinese Medicine 1965). Photo by Li Runhong.

According to the Ministry of Public Health's notice on collating and popularizing secret recipes and effective recipes issued in June 1959, the CACMS appointed Zhang Shaozhong 张绍重15 in charge of the "Working Group for the Research and Collation

13 Secret Prescriptions from the Imperial Palace is a comprehensive work on medicine, compiled by Wang Tao (670-755), a famous Chinese physician of the Tang dynasty. The book consists of 1104 entries and includes more than 6000 prescriptions. As many as sixty classical medical works are cited. Citing every source in detail, the book preserves a substantial amount of pre-Tang dynasty medical literature. In Chinese, the book is also called Waitai miyao fang 外台秘要方.

14 The full name in Chinese is Zhouhou beiji fang 肘后备急方. Reputedly written by Ge Hong 葛 洪 (284-364), this classical work on medicine contains many literary allusions.

15 Zhang Shaozhong 张绍重 (1930-) learned medicine from Wang Fengchun 汪逢春 and Xiao Longyou 萧龙友, two famous doctors in Beijing. In 1953, he was assigned to work as a clerk at the Research Institute for Literature and History, under the former Government Administrative Council. He was appointed Secretary of the Beijing Association of Chinese Medicine in 1956. In 1960, he was transferred to the CACMS, affiliated with the Ministry of Public Health, to do research on traditional Chinese medicine and collate classical works. Having been purged before the "Cultural Revolution," Zhang was then sent to Huining 会宁, Gansu Province in January 1970, and became a traditional Chinese doctor at Huining county hospital. He was seconded to the CACMS in 1980, and then to Gansu College of Chinese Medicine in 1984. He retired in 1991, though continued to do research for the Department of Ancient Books at the Library of Gansu University of Chinese Medicine. 
of Recipes and Prescriptions" in the CACMS ICMM. In all, the working group involved seventeen people. By March 1964, the group had collected over one thousand entries and made around 450 thousand cards that were classified according to different kinds of diseases. ${ }^{16}$ During the "Cultural Revolution," under the name of its "Revolutionary Committee," the CACMS17 successively published Selection of Effective Recipes for Common Diseases (Changjian bing yanfang xuanbian 常见病验方选编) (The "Revolutionary Committee" of the China Academy of Chinese Medical Sciences 1970a) and References for Research on Effective Recipes for Common Diseases (Changjian bing yanfang yanjiu cankao ziliao 常见病验方研究参考资料, Figure 4) (The “Revolutionary Committee" of the China Academy of Chinese Medical Sciences 1970b). The prefaces of the two books are the same. ${ }^{18}$ Considering that two years is usually needed to edit and proofread a book (Hu 2008), the compilation must have been finished by the end of 1968 . The first book does not include qinghao, but it mentions that ground pepper can be used to treat malaria. Qinghao is mentioned on page 68 of the second book: "Prescription: 5-8 qian 钱19 of qinghao. Preparation: Pound the herb to make the juice and drink it; or simmer the herb to make a decoction; or grind it into powder, and take it with boiled water; or pound the herb and apply it to the navel. Take one dose per day." 20

The majority of compilations completed during the Promoting Chinese Herbal Medicines Movement were published between 1969 and 1971. Among the over 800 booklets included in the Full-Text Database of Handbooks Compiled during the "Cultural Revolution” on Chinese Herbal Medicines for Practical Use “文革” 期间中草药实用手册全

16 Internal document: Working Group for the Research and Collation of Recipes and Prescriptions in the Institute of Chinese Materia Medica of the China Academy of Chinese Medical Sciences. 1964. "Several Thoughts concerning the Collation and Research of Simple Recipes, Secret Recipes, and Effective Recipes" (单秘验方整理研究工作中的几点体会). In A Special Collection of Materials of the Conference for the Exchange of Experiences in Conducting Traditional Chinese Medicine Research (中医研究工作经验交流会议资料专辑), edited by the Division of Scientific Research of the CACMS ICMM. The presentation was made by Zhang Shaozhong.

17 The CACMS set up an editorial office in 1955. The Research Department for Chinese Medical Literature was established in 1962. The CACMS "Revolutionary Committee" was founded at the end of 1968. In 1971, the academy planned to form a research department on the literature of medical history. The Institute for History of Chinese Medicine and Medical Literature was officially established in 1982 (Sun 2015).

18 The preface says, "Our academy preserves a large number of collections of simple recipes and effective recipes circulating among the people. Most of them were compiled and published in various places around the country based on the prescriptions collected in the Contributing Recipes Movement during the “Great Leap Forward' in 1958." ( “我院收存着大量民间单方、验方 专集, 极大部分是全国各地在一九五八年大跃进期间群众性献方运动的基础上编印的。”)

19 A traditional unit of weight. One qian equals 3.125 grams.

20 “处方: 青蒿五至八钱, 用法: 捣汁服或水煎服或研细末开水送服, 或捣烂敷脐, 每日一次。” 


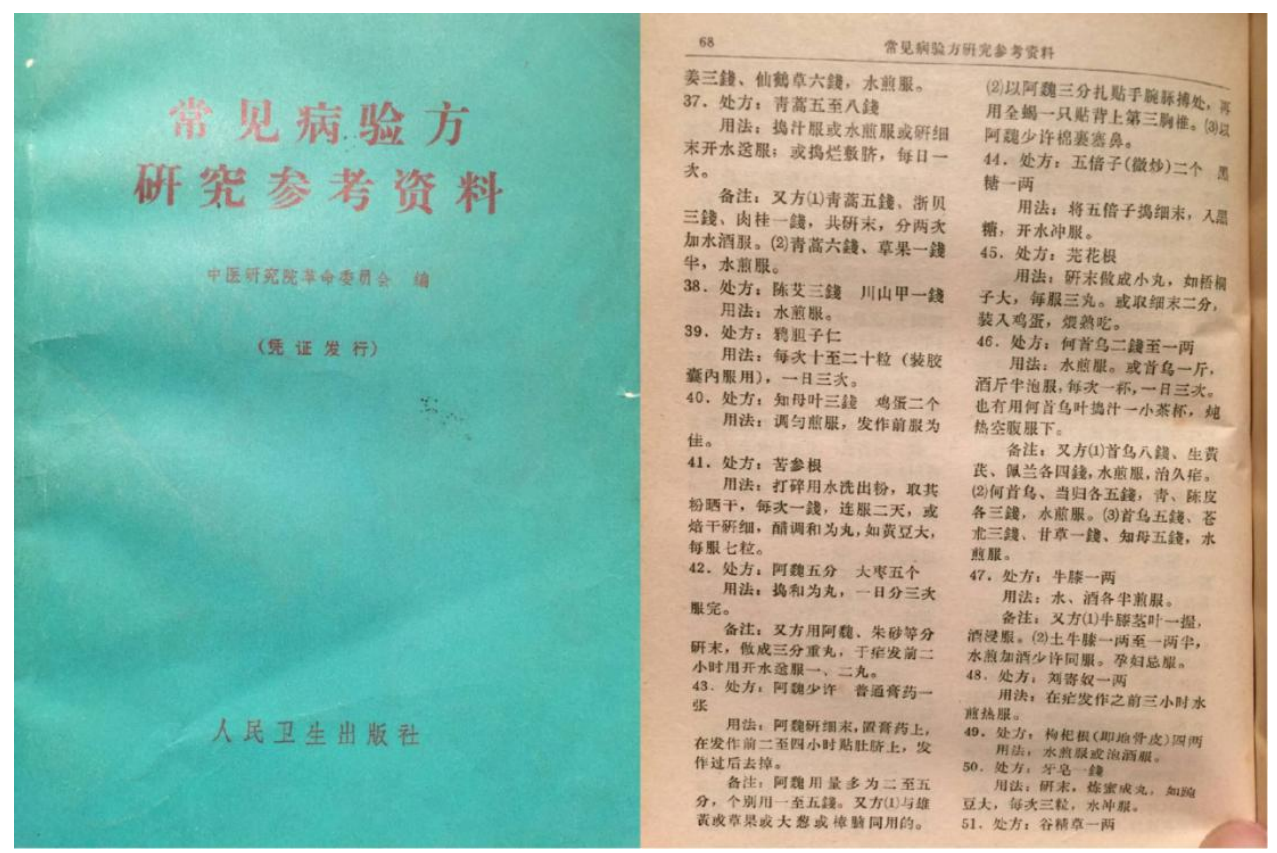

Figure 4: References for Research on Effective Recipes for Common Diseases published in May 1970, compiled by the CACMS "Revolutionary Committee." Photo by Li Runhong.

文数据库 (information provided by CACMS), ${ }^{21}$ over $70 \%$ were published in these three years. In these publications, dozens of entries explicitly state that qinghao or huanghuahao 黄花蒿 can cure malaria. For examples, on pages 32 and 33 in Jilin Herbal Medicines (Jilin Zhongcaoyao 吉林中草药), compiled by the Changchun College of Chinese Medicine "Revolutionary Committee" in April 1970, there is a record saying that with huanghuahao, "grinding the fresh qinghao to extract the juice" (鲜青蒿捣汁) would produce a cure for malaria. In Handbook of Herbal Medicines Used in Effective Recipes (Yanfang caoyao shouce 验方草药手册) compiled by the Health Bureau of the "Revolutionary Committee" in Gaoyou 高邮, Jiangsu Province, in June 1970, there are simple recipes using huanghao (the entire qinghao plant) and qinghao to treat malaria on pages 79 and 483 respectively. On page 30 in Selection of Simple Recipes and Effective Recipes of Chinese Herbal Medicines in Hunan (Hunan Zhongcaoyao danfang yanfang xuanbian 湖南中草药单方验方选编), which was compiled by the Hunan Institute of Chinese Medicine "Revolutionary Committee" and published in July of the same year, there is an account of drinking a beverage made from qinghao leaves to treat malaria.

21 China Academic Journals Electronic Publishing House Co., Ltd. Full-Text Database of Handbooks Compiled during the "Cultural Revolution" on Chinese Herbal Medicines for Practical Use. http://wgcy.cnki.net/bookweb/Default.aspx. 
The distinction between prescriptions recorded in classical works on traditional Chinese medicine and folk recipes (simple recipes, secret recipes, and effective recipes) is that the latter were circulated among ordinary people, and were usually regional. Such prescriptions are usually closely related to local epidemics or common diseases. Circulated through oral teaching, the prescriptions are always simple and their ingredients easy to prepare. Between 1967 and 1969, there was an investigation group for folk medicines consisting of members from the CAMS IMM and the AMMS, as well as researchers from Yunnan, Jiangsu, and Guangdong provinces. The group found that in Guangdong the root of the local plant yingzhao is antimalarial. In the subsequent collaboration with Guangzhou Zhongshan School of Medicine, Sun Yat-sen University, and South China Botanical Garden, Chinese Academy of Sciences, the researchers successfully separated and identified the antimalarial monomer yingzhaosu A.

\subsection{Initial screening}

The second research topic under the second special subject of Project 523, "research on preventing and controlling malaria through traditional Chinese medicine and acupuncture," is "survey and research on effective drugs and therapies used by local people to prevent or control malaria." The CAMS IMM was in charge of this topic. In the "Notes" section of the original notice issued by the State S\&T Commission and the General Logistics Department, qinghao ranked fifth among all the drugs regarded as worth studying (Figure 5).22 Cai Dingguo 蔡定国 was then an assistant researcher at the AMMS. He recalls that the research plan on qinghao in Project 523 was mapped out by Fu Fengyong from the CAMS IMM (Cai attended the collaborative conference on Project 523 in 1967 as Fu Fengyong's assistant). ${ }^{23}$ Qinghao was originally an important priority for screening, ranking after changshan, in the CAMS IMM plan. Nevertheless, the plan was held up as Fu Fengyong and Cai Dingguo were either sidelined or sent to the “May 7 cadre schools" 五七干校 during the “Cultural Revolution." To date, no mention has been found concerning the screening of qinghao in the initial screening done by any institution during the period 1967-1969. Possible reasons for this include: (1) Project 523 focused its research on changshan in the early years; (2) the on-site work of Project 523 consisted mainly of carrying out surveys while treating patients, rather than screening medicines; (3) the screening that did happen might well have been

22 Internal document: Notification jointly issued by the State Scientific and Technological Commission of the People's Republic of China and the General Logistics Department of the People's Liberation Army [(67) KSZ No. 118 \& HKZ No. 388], The Minutes of the Collaborative Conference for Research on Drugs that Prevent and Control Malaria and The Collaborative Plan for Research on Drugs that Prevent and Control Malaria (1967-1970), Attachment I, June 16, 1967. In Collection of Materials on Project 523 and Artemisinin.

23 Cai Dingguo 蔡定国, interview by Li Runhong, Shanghai, April 18, 2018. 
omitted from records if the drug's performance did not stand out. An example of this last reason is the screening for antimalarial Chinese herbal medicines by the 523 Group of Nanjing Pharmaceutical College (now China Pharmaceutical University) carried out between November 1969 and June 1973. It turned out that the inhibition rate of a decoction of huanghuahao against rodent malaria was only $15.4 \% .{ }^{24}$ Similarly, the study on the local practice in Gaoyou, Jiangsu Province, of using blanched qinghao or a simple preparation of qinghao to treat malaria, which was carried out by the Nanjing 523 Group, did not start until 1969, and was summarized and reported on after 1971. This study received attention from the Ministry of Public Health, and the paper was published in 1975 (The Medical Research Group of Gaoyou in Jiangsu Province and the Epidemic Prevention Station of Gaoyou in Jiangsu Province 1975).

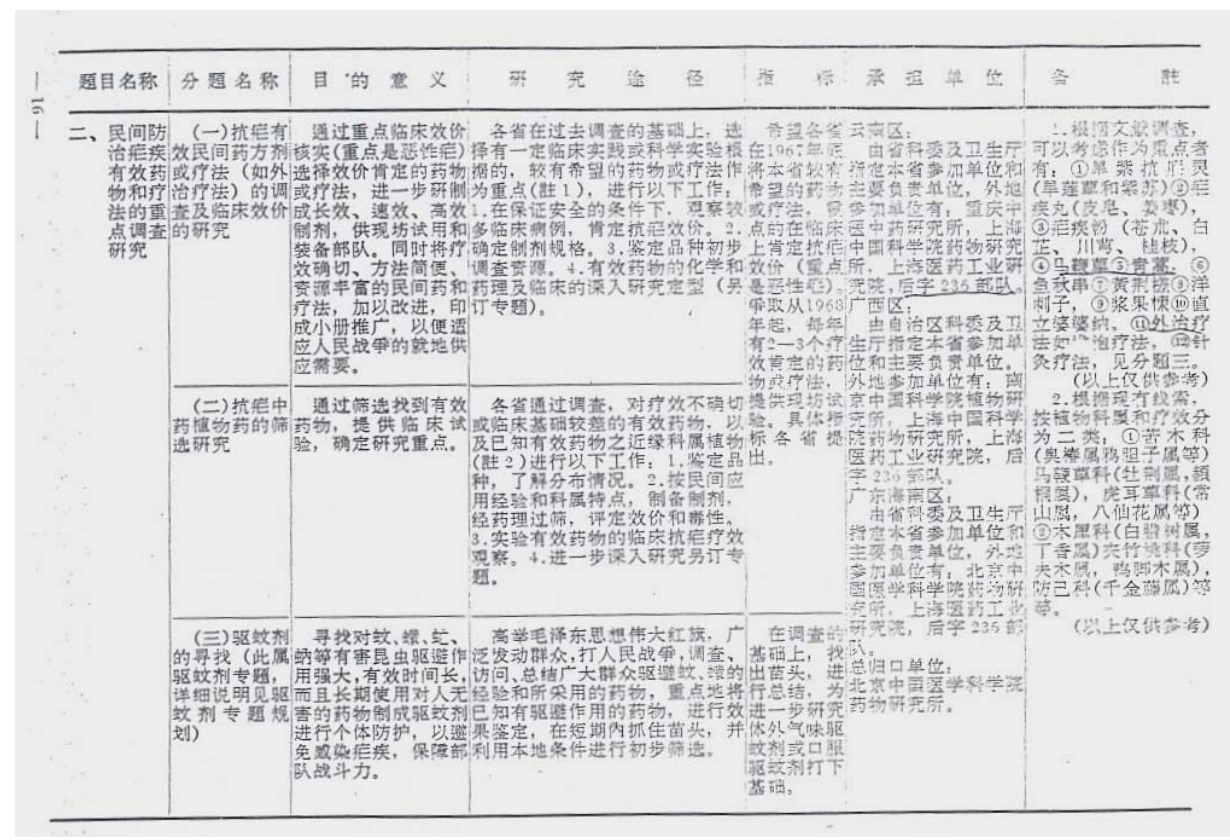

Figure 5: The second research subject in the three-year research plan for Project 523, which included qinghao as one important targets of the research.

During the early years of the "Cultural Revolution," the CACMS was so seriously impacted that its research and teaching came to a halt (Hong et al. 2005, 66). The academy was taken over by the army in August 1968, and a "Revolutionary Committee" was set up on December 24 of the same year. A special group in charge of daily work was set up affiliated with the "Revolutionary Committee." Under the

24 Internal document: The Nanjing Research Group on Antimalarial Chinese Herbal Medicines. 1974. “Summary of Screening for Antimalarial Chinese Herbal Medicines” (中草药抗㾏作用的篮 选小结). In Selection of Research Materials on Antimalarial Medicines (抗症药研究资料选编). 
suggestion of the AMMS's military representative to the CACMS (who was also a coworker of Zhang Jianfang 张剑方, one of the persons-in-charge of the National Project Office of Project 523), the National Project Office of Project 523 invited the CACMS ICMM to join the Cooperation Group on Traditional Chinese Medicine. In January 1969, the CACMS ICMM accepted the task; the earliest of its members to work on Project 523 included Tu Youyou, Yu Yagang, and Wang Fengxiang 王凤翔 (To date, none of the materials available have revealed the specific job that Wang Fengxiang did during this task) (Figure 6). ${ }^{25}$

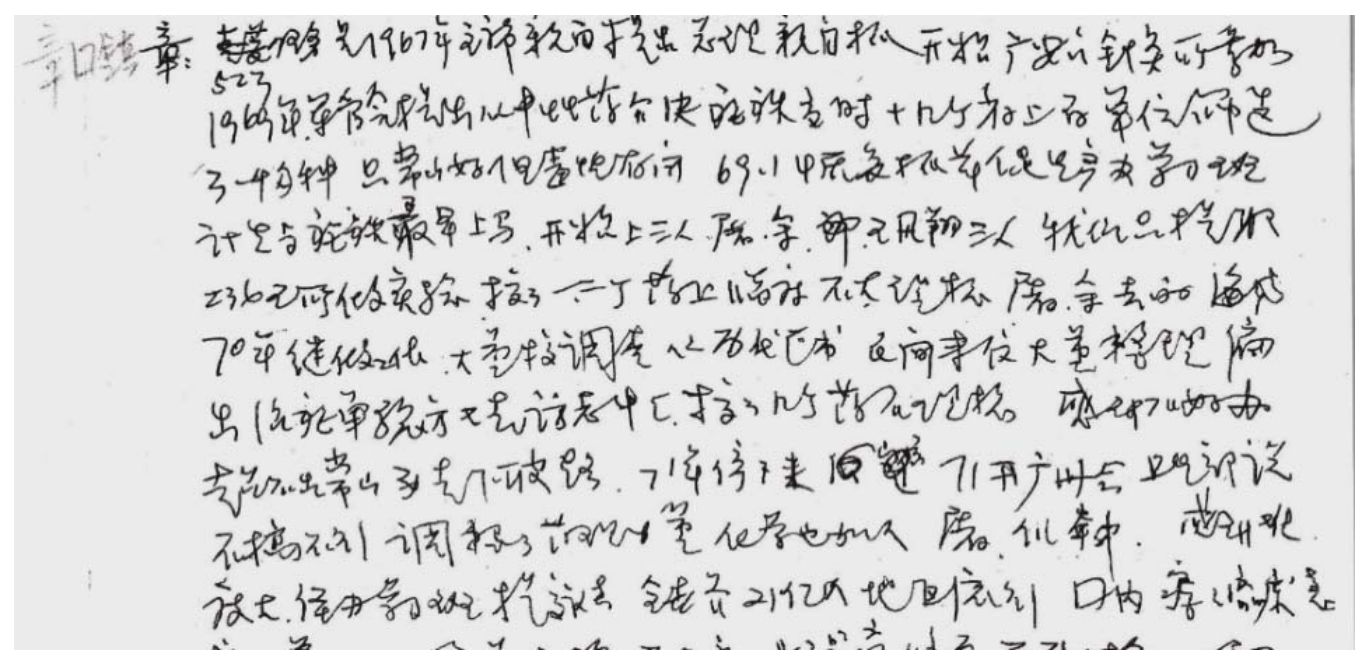

Figure 6: Transcript of a 1977 speech by Zhang Guozhen 章国镇, vice-director of the CACMS ICMM at the time. The transcript was provided by Li Zelin 李泽琳.

Born in 1930, Tu Youyou (Figure 7) was admitted to the Department of Pharmaceutics, Peking University Medical School in 1951 (renamed the Department of Pharmaceutics, Beijing Medical College in 1952 during the adjustment of schools and departments in Chinese universities and colleges). Upon graduation in 1955, she was assigned to work at the CACMS ICMM, which was then in planning. Yu Yagang was born in 1931, and was admitted to the Department of Pharmaceutics, Beijing Medical College in 1952. Having graduated in 1956, he was assigned to the CACMS ICMM. Tu and $\mathrm{Yu}$ were not only college alumni but also classmates at the third Off-the-Job Training Program of Traditional Chinese Medicine for Doctors Trained in Western Medicine (October 1959-February 1962) (Figure 8). The knowledge that they learned at the training program turned out to be of great help for their work of collecting and collating prescriptions and studying Chinese traditional medicines.

25 Internal meeting minutes of the survey meeting for Project 523, held on the morning of December 13, 1977. Provided by Li Zelin 李泽琳. 


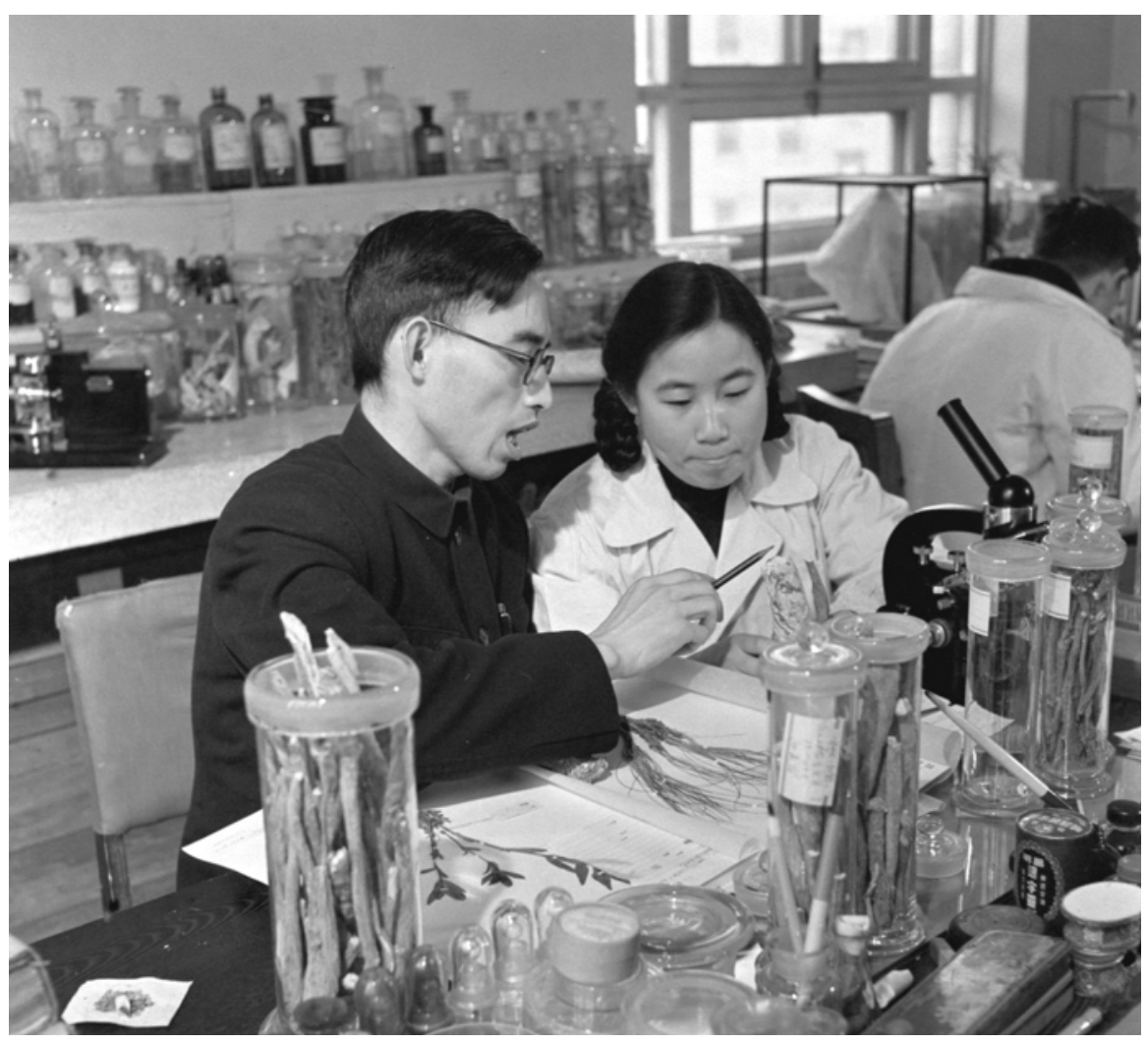

Figure 7: Tu Youyou in the 1950s (right). On the left was Associate Professor Lou Zhicen 楼之岑. Photo courtesy of Xinhua News Agency.

As has been mentioned earlier, the CACMS already had some experience in collecting and collating prescriptions for the treatment of malaria. In April 1969, in order to provide a reference source for other institutions that were looking for ways to eliminate malaria, ${ }^{26}$ the Special Group in Charge of Daily Work of the CACMS "Revolutionary Committee" selected around 640 prescriptions from those that had been collected by the institute over more than ten years, either from folk recipes nationwide or from contributions sent in by letter, thus compiling Collection of Antimalarial Recipes and Prescriptions (Nüeji dan mi yan fang ji 㾏疾单秘验方集) (Figures 9

26 When the CACMS took over another task of researching tracheitis in 1970, the Special Group in Charge of Daily Work of its "Revolutionary Committee" used the same method-they published a brochure titled Collection of Effective Recipes for Colds and Tracheitis (Youguan ganmao zhiqiguanyan yanfang huibian 有关感冒、支气管炎验方汇编) in April 1970 for other institutions to refer to. This brochure's preface is identical to that of Collection of Antimalarial Recipes and Prescriptions. 
and 10). ${ }^{27}$ Similar to other literature of the time, this collection listed prescriptions with changshan at the beginning. Qinghao appeared on page 15. "Prescription: [Take] qinghao five qian to a half jin 斤; Preparation: Pound the herb to make juice and drink it; or simmer the herb to make a decoction and drink it; or grind the herb into powder, add it to water, and drink the concoction. Origins of the prescription: Fujian, Guizhou, Yunnan, Guangxi, Hunan, and Jiangxi Provinces." 28 The book also includes thirteen recipes that are composed of qinghao and other drugs. Unlike the copy that was shown by $\mathrm{Tu}$ Youyou, the original version of the book contains neither Tu's signature, nor words in the preface saying "classical works on traditional Chinese medicine, on materia medica, and” (历代医籍、本草及), which are not consistent with the actual sources of this book (Li 2011).

27 Qinghao and Artemisinin-Based Medicines (Qinghao ji qinghaosu lei yaowu 青蒿及青蒿素类药物) (2009) compiled by Tu Youyou says: "[Tu Youyou] then starting from systematically collecting and collating classical works on traditional Chinese medicine and materia medica, based on the over two thousand prescriptions that she had learned about, compiled Collection of Antimalarial Prescriptions (Kangnüe fang yao ji 抗疮方药集), the major content of which was 640 prescriptions. After that, the screening of antimalarial medicines for rodent malaria was organized" (遂从系统 收集整理历代医籍、本草入手, 于 1969 年 4 月在收集 2 千多种方药基础上, 编辑了以 640 方药为 主的《抗疮方药集》, 继而组织鼠疮笁选抗疮药). Nevertheless, the book that she presented in public was the Collection of Antimalarial Recipes and Prescriptions (Figure 10). Her signature can be found in the bottom-left corner of the cover on a photographed copy of the mimeograph; the added “classical works on traditional Chinese medicine, on materia medica, and" (历代医籍、本草 及) in her handwriting is on the "Editor's Words" page, which was inscribed by the "Special Group in Charge of the Daily Work of the 'Revolutionary Committee' at the CACMS" (中医研究 院革委会业务组). Taking all this evidence into consideration, the Collection of Antimalarial Prescriptions mentioned by $\mathrm{Tu}$ Youyou in her book and the Collection of Antimalarial Recipes and Prescriptions were actually the same. Compiled by the Special Group in Charge of the Daily Work of the "Revolutionary Committee" at the CACMS, Collection of Antimalarial Recipes and Prescriptions probably originated from the collation and research of simple recipes, secret recipes, and effective recipes, which had been carried out by Zhang Shaozhong and his colleagues since 1961 (see the internal document "Several Thoughts concerning the Collation and Research of Simple Recipes, Secret Recipes, and Effective Recipes" in A Special Collection of Materials of the Conference for the Exchange of Experiences in Conducting Traditional Chinese Medicine Research). Moreover, the CACMS ICMM did not join Project 523 until January 1969, which was not long before the traditional Spring Festival (Chinese New Year's Eve on February 16). During the "Cultural Revolution," it was unlikely that someone could start from systematically collecting and collating classical works on traditional Chinese medicine and materia medica, collect over two thousand prescriptions, and select from them more than 640 within a period as short as three months. In fact, prescriptions using qinghao in Collection of Antimalarial Recipes and Prescriptions and References for Research on Effective Recipes for Common Diseases are basically the same. To conclude, none of the Collection of Antimalarial Prescriptions, Collection of Antimalarial Simple Recipes and Effective Recipes (Nüeji dan yan fang ji 疮疾单验方集), and Antimalarial Collections of Effective Recipes and Prescriptions, as Tu Youyou called it in her English work From Artemisia annua L. to Artemisinins, ever existed. The one that did exist is Collection of Antimalarial Recipes and Prescriptions.

28 “处方: 青蒿五钱至半斤; 用法: 捣汁服或水煎服或研细末, 开水兄服; 来源: 福建、贵州、 云南、广西、湖南、江西。” 


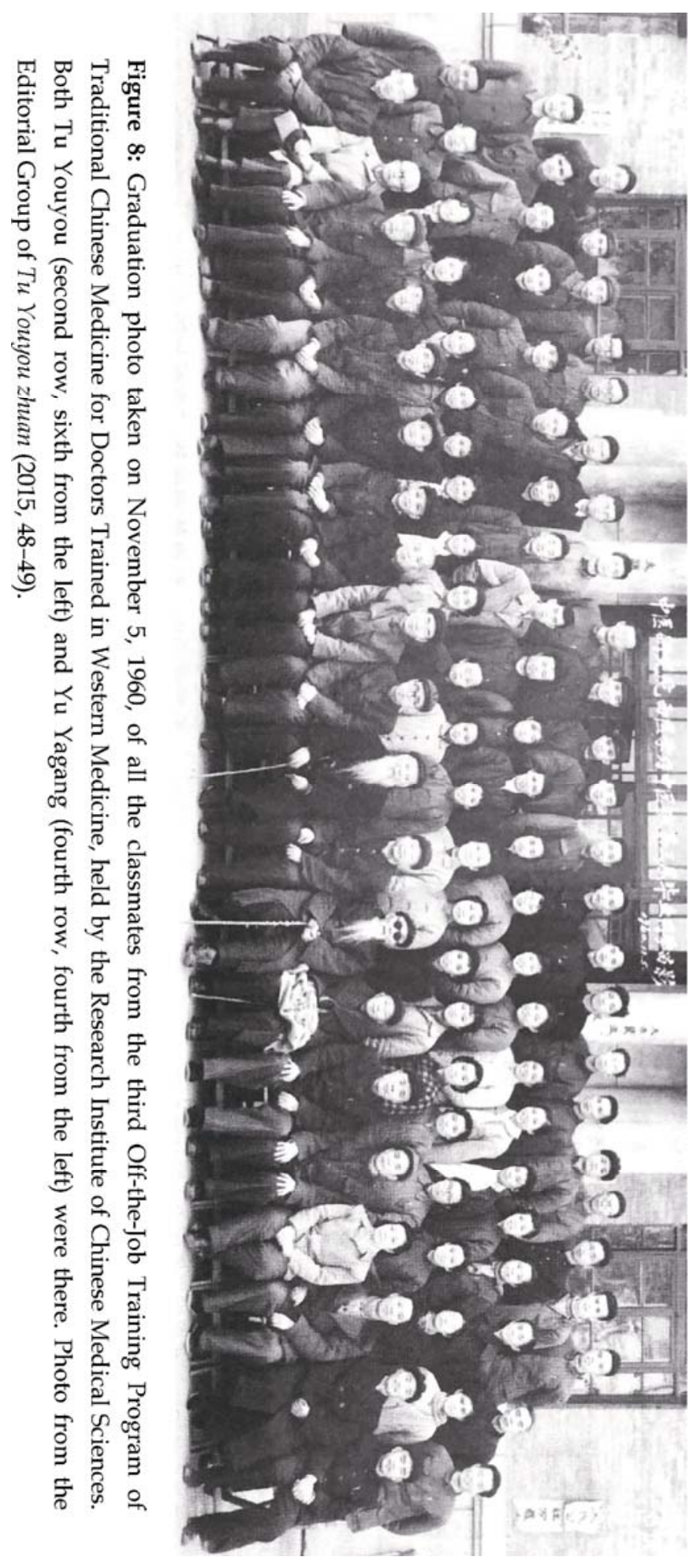




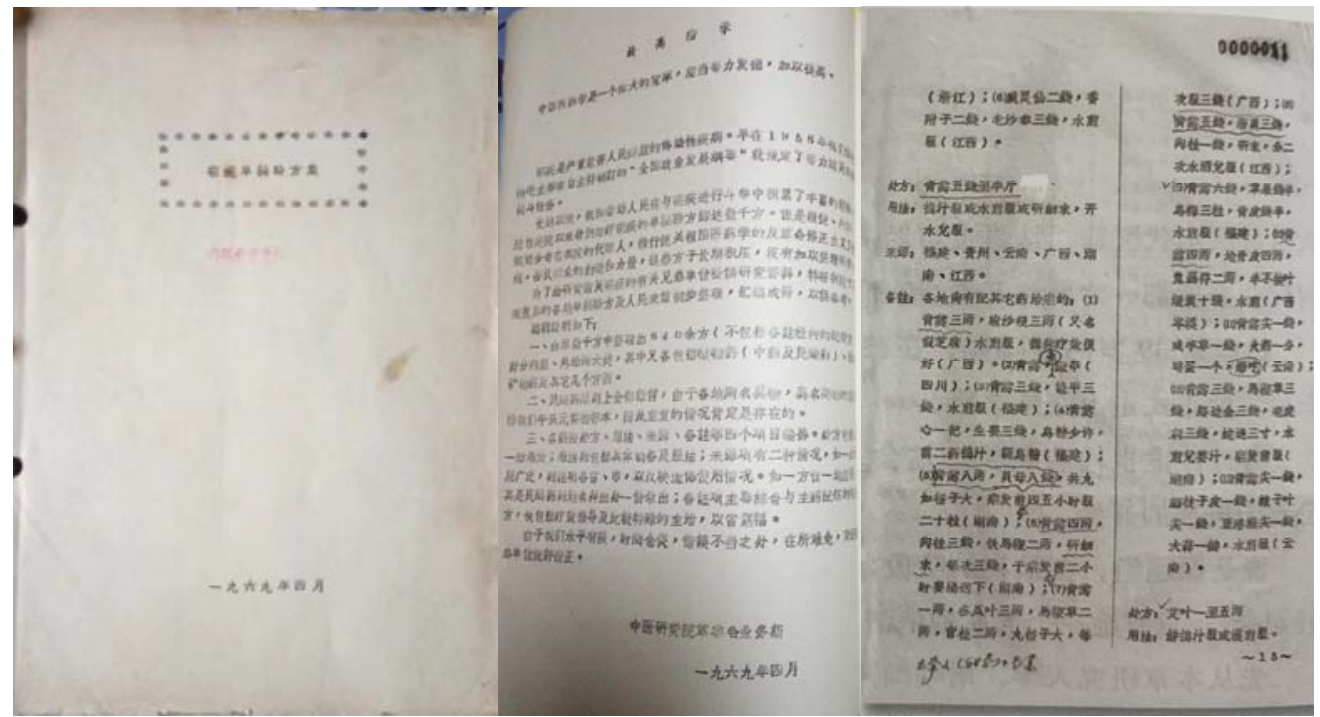

Figure 9: The cover, preface (Kongfz.com), and page 15 (The Editorial Group of $T u$ Youyou zhuan 2015, 64) of Collection of Antimalarial Recipes and Prescriptions, edited by the Special Group in Charge of Daily Work of the CACMS "Revolutionary Committee."

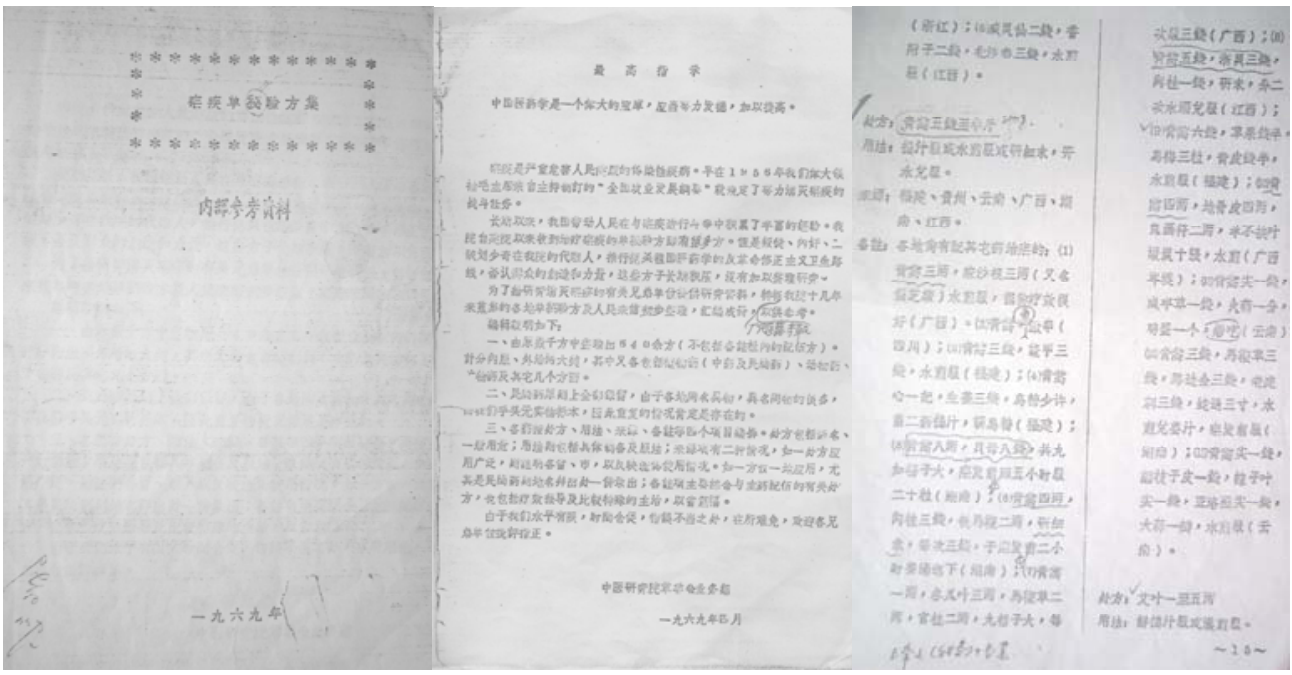

Figure 10: The cover, preface, and page 15 of Collection of Antimalarial Recipes and Prescriptions of the copy kept by Tu Youyou. Photo by Li Runhong.

At that time, due to the very limited conditions for conducting research, the CACMS ICMM was unable to screen antimalarial drugs alone. In May and June 1969, $\mathrm{Tu}$ Youyou and Yu Yagang from the CACMS ICMM initiated cooperation with relevant departments of the AMMS. Records show that only the following drugs were screened: weilingxian 威灵仙 (Chinese clematis root, Clematis chinensis), machixian 马齿苋 (purslane herb, Portulaca oleracea L.), zaojiao 㿝角 (Chinese honeylocust), aiye 艾叶 (argy 
wormwood leaf, Folium Artemisiae Argyi), xixin 细辛 (manchurian wildginger, Herba Asari), chili, white pepper, pepper, huangdan 黄丹 (yellow lead), realgar, and so on.29 Thus it can be seen that although researchers at the CACMS ICMM had the brochure Collection of Antimalarial Recipes and Prescriptions, when it came to the actual screening they did not pay special attention to qinghao, though it was listed in the book. In August and September of that year, when Tu Youyou and Yu Yagang were working in malariaaffected areas in Hainan, they put emphasis on clinically verifying "Drug 52" (pepper extract) and expected to locate the effective component. They were joined by Lang Linfu 郎林福 from the CACMS Research Institute of Acupuncture, who was in Hainan at that time. Nevertheless, the testing of "Drug 52" was terminated as it did not perform well.

In 1970, the National Project Office of Project 523 sent Gu Guoming 顾国明 of the AMMS to the CACMS ICMM to help with the search for antimalarial drugs in traditional Chinese medicine. The institute would send the herb extracts to the AMMS for rodent malaria tests. Believing that screening through thousands of traditional Chinese medicines was too hit-and-miss, Yu Yagang returned to traditional Chinese medical literature. An important work referred to by $\mathrm{Yu}$ at this stage was Collection on Malaria compiled by Shanghai Literature Institute of Traditional Chinese Medicine, published in 1965.

As it was already a common practice to use changshan to treat malaria, Yu decided to turn to other materia medica. He numbered all the recipes recorded in Collection on Malaria, 808 in total. Among these, 519 recipes did not include changshan; additionally, there were 55 other changshan-free recipes that had been included in the "Entry on Malaria" (Nüemen 㾏門) of Complete Records of the Medical Section of the Comprehensive Corpus of Illustrations and Books from Ancient Times to the Present (Gujin tushu jicheng yibu quanlu 古 今图书集成医部全录), 30 compiled by Chen Menglei 陈梦雷 and others, but which were not found in the Collection on Malaria. Yu made a list of all the simple recipes (including those where adjuvant components only play an almost negligible role in the treatment according to the view of traditional Chinese medicine) in these 574 prescriptions, summarizing them into two tables according to whether they appeared before the time of Collection of Prescriptions of the Imperial Medical Service (Taiping Huimin Hejiju fang 太平

29 See the list of drugs that $\mathrm{Tu}$ Youyou sent for screening before she went to Hainan in June 1969. The list was provided by Yu Yagang.

30 Complete Records of the Medical Section of the Comprehensive Corpus of Illustrations and Books from Ancient Times to the Present is a part of the Comprehensive Corpus of Illustrations and Books from Ancient Times to the Present (Gujin tushu jicheng 古今图书集成), the large encyclopaedia compiled during the Kangxi reign of the Qing dynasty. 
惠民和剂局方 $)^{31}$ of the Northern Song dynasty. Yu then selected the repetitions from the two tables and summarized them into another table (Figure 11). According to the account in Collection on Malaria, he specified under the entry for qinghao that the information that it could cure malaria came from the sentence "one handful of qinghao in two sheng 升 of water, mash it and administer the juice" (一握, 水二升, 捣汁服) ${ }^{32}$ in Handbook of Prescriptions for Emergencies. After counting the rate of occurrence of various drugs, $\mathrm{Yu}$ narrowed down a group of materia medica for further focused research according to their efficiency in treating malaria to wutou 乌头 (aconite, Aconitum carmichaeli Debx.), wumei 乌梅 (smoked plum, Fructus Mume), biejia 鳖甲 (turtle carapace, Carapax Trionycis), and qinghao (Figure 12). He asserted that these drugs were worthy of repeated animal screening, as they had not only been used alone in treating malaria, but also appeared repeatedly in compound prescriptions. Judging from this work by him, we can come to the conclusion that, in the CACMS ICMM, it was $\mathrm{Yu}$ Yagang who first proposed the inclusion of qinghao in their screening plan.

While sorting out these materials, Yu Yagang worked with Gu Guoming to extract the above-mentioned prioritized medicines using ethanol. The qinghao that they used was collected from the storehouse of the CACMS ICMM. As Gu recalled, "herbs that appeared more frequently among the traditional antimalarial remedies were selected as objects of study. Among them were qinghao, biejia, and so forth. Extracts were obtained via boiling in water or ethanol extraction, and sent to the screening group for rodent malaria tests. It was found that qinghao had definite antimalarial properties, with an inhibition rate of around 60-80\%."33 Yu Yagang reported the results that he and Gu had obtained in the experiments to Tu Youyou, the group leader, who managed to find time to return to the laboratory during her participation in other work. ${ }^{34}$ Afterwards,

31 Collection of Prescriptions of the Imperial Medical Service was compiled by the Bureau of Medicines, which was affiliated with the Imperial Medical Service, and was the first standard for medicines made by the administration. First published after 1078, this collection of prescriptions consists of 10 chapters and includes 788 prescriptions. For every one of the prescriptions included, the collection records its function, synergy, and preparation. As a collection of prescriptions for clinical use, Collection of Prescriptions of the Imperial Medical Service was widely circulated and regarded as important in traditional Chinese medicine.

32 One sheng in Ge Hong's time (Jin dynasty) was equal to approximately 200 millimeters today. See Qiu, Qiu, and Yang $(2001,281)$.

33 Internal document: Gu Guoming 顾国明, “Reflections on Participating in Qinghao Research" (关于参加部分青蒿研究工作的回顾), June 5, 2004. Jiao Xiuqing 焦岫卿 from the AMMS, who was in charge of screening antimalarial medicines, recalled that "Gu Guoming brought the sample of qinghao extract from the CACMS ICMM for initial screening. The extract turned out to be highly efficient, as the inhibition rate against plasmodium was over $90 \%$. Since the result was good, an experiment report was written and delivered to the Institute of Chinese Materia Medica" (Internal document: Jiao Xiuqing's Reminiscence of the Early Pharmacological Screening of Project 523, December 8, 2012).

34 Yu Yagang, interview by Li Runhong, Beijing, August 12, 2012. Transcript in the database of the Collecting Project. 


\begin{tabular}{|c|c|c|c|c|c|c|}
\hline & क्षे & 致 伍 & 判 剠 & 辣症用产及服法效果 & 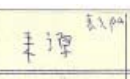 & 俩方 \\
\hline \multirow{3}{*}{ 紋杫 } & 青蒿一梅 & & 水:事梏计服 & 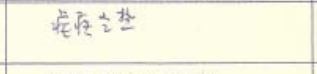 & A 标后方 & 985 \\
\hline & \multirow{2}{*}{ 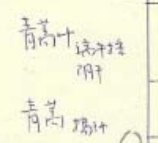 } & 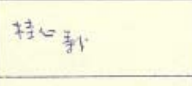 & $\neq$ & 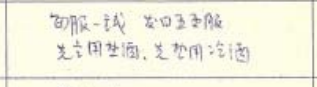 & & 986 \\
\hline & & & 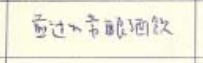 & 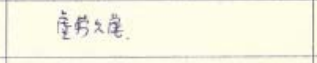 & & 987 \\
\hline$\therefore$ & 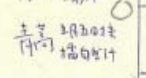 & 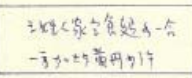 & 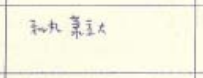 & 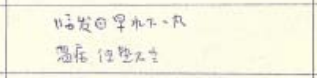 & it 4 초 & 988 \\
\hline i & 菌伡 & & 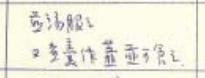 & 情在 & ? & 989 \\
\hline$?$ & 案收商根 & 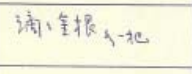 & 聕城一锫 & 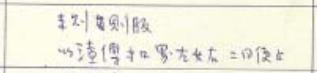 & $i d z=\bar{z}$ & 990 \\
\hline kif & 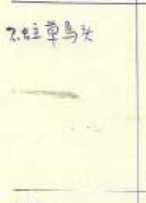 & & 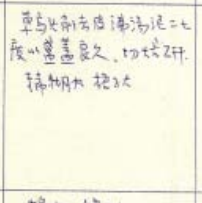 & 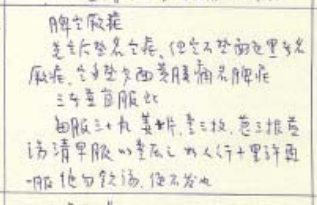 & 车坡3 & 991 \\
\hline 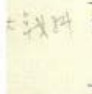 & $e^{E_{2}}-12 \approx 612$ & 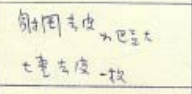 & 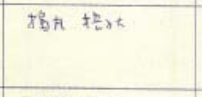 & 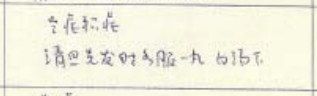 & & 992 \\
\hline ¿ёrq & iat & 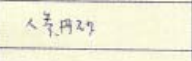 & A Pla . B 1 r.t & 数在 & & 993 \\
\hline thikith & 点特 0 & & 类坊铁 & 舟在顷晒 & & 994 \\
\hline " & $b^{2}+b_{+\infty} 6$ & 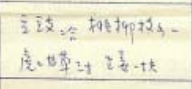 & 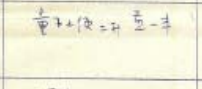 & 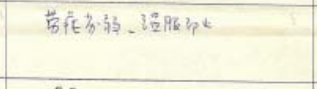 & $12)(z$ & 995 \\
\hline$(2 \pi+174$ & $2113 \cdot-\bar{x}$ & & *kकी & 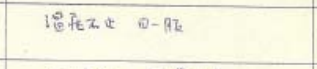 & $\bar{F}_{i} k_{i} i_{k}$. & $\begin{array}{l}(7970) \\
996\end{array}$ \\
\hline$\frac{x}{5} / x^{2} y 4$ & 却却身藏 & 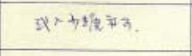 & 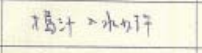 & 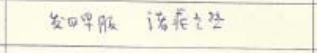 & " & $\begin{array}{l}(\text { (ब⿰871) } \\
9977\end{array}$ \\
\hline 苟? & 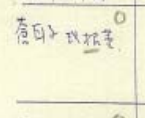 & & 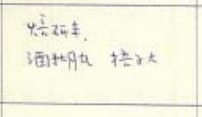 & 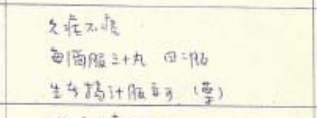 & 禁睡方 & 998 \\
\hline end & 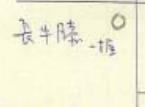 & & 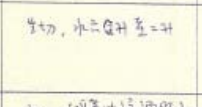 & 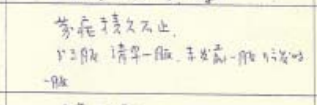 & \$1: & 999 \\
\hline 党计 & Peะ千腾一椎 & & 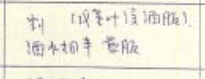 & 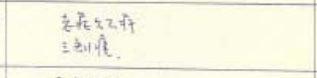 & & 1000 \\
\hline उस्सामें & 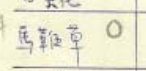 & & 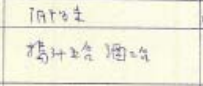 & 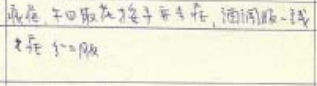 & +23 & $\begin{array}{c}1002 \\
(\text { กิ872) } \\
1003\end{array}$ \\
\hline : & 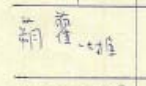 & & 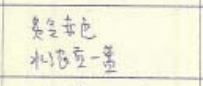 & 教发施服 & 4 पांके & 1004 \\
\hline 3) Nund & 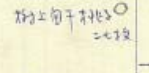 & & 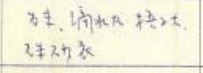 & 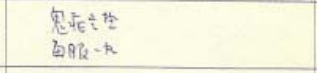 & 哣活 & 1005 \\
\hline 3 & the & 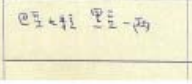 & 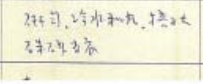 & 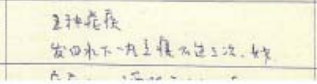 & 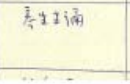 & $\operatorname{toc} 6$ \\
\hline
\end{tabular}

Figure 11: One of the tables made by Yu Yagang in June 1970. Photo by Li Runhong.

$\mathrm{Tu}$ Youyou handed over a list of traditional Chinese materia medica to $\mathrm{Yu}$ for repeat screening. They were classified into medicines of mineral origin, animal origin, or plant origin, and qinghao was among them. At present there are two versions of this screening list available (Figures 13 and 14), both of which are in Tu's handwriting. The 


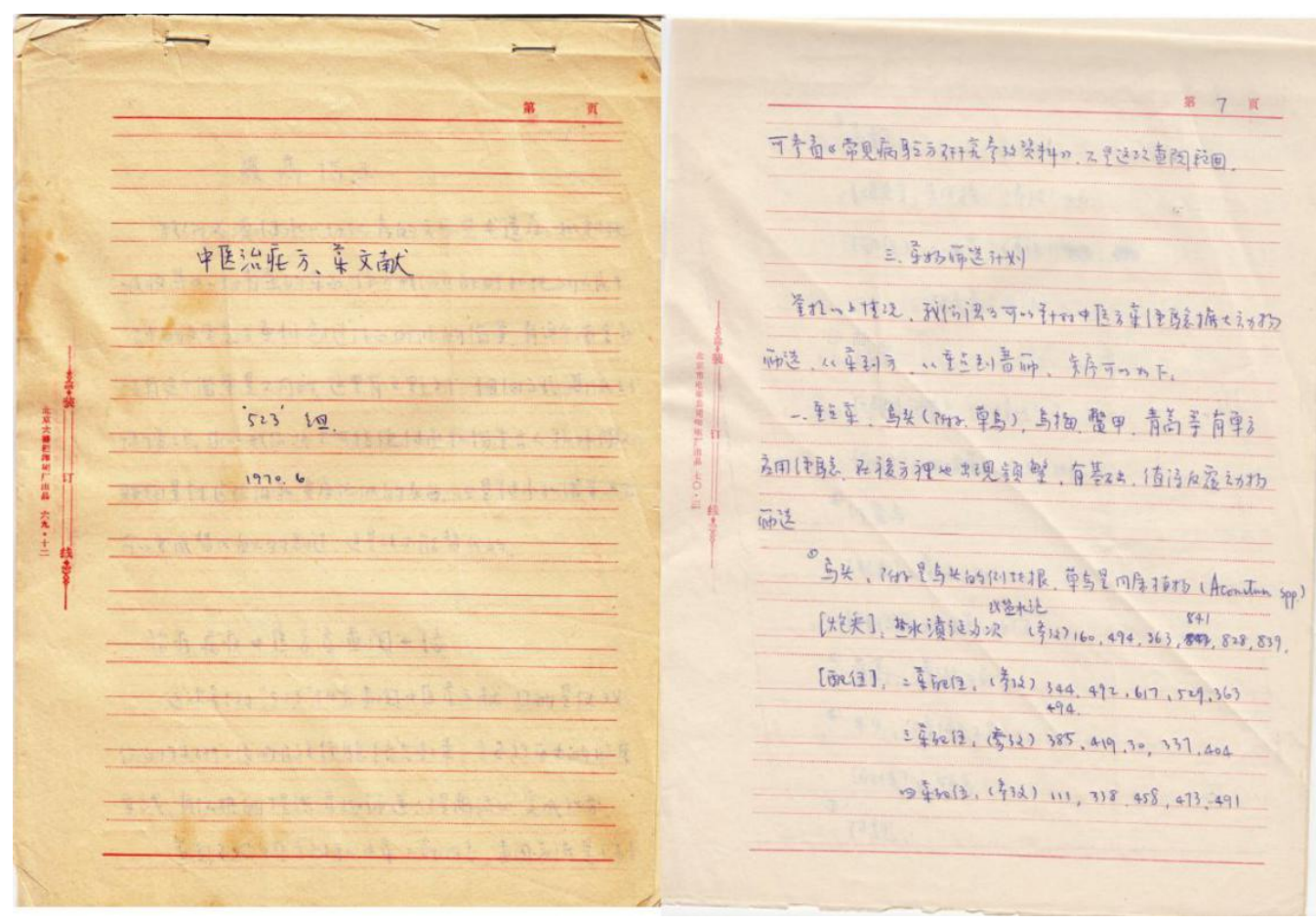

Figure 12: The screening plan composed by Yu Yagang. Photo by Li Runhong.

difference, however, is that the copy stored in the archives of the CACMS ICMM has some additions: 1 . It specifies the date as "9.11"; 2 . it specifies that those of mineral or

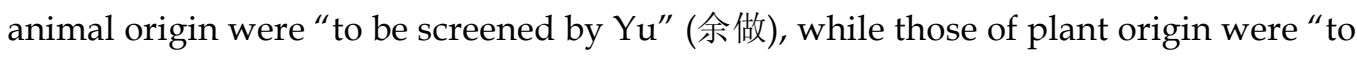
be screened by $\mathrm{Tu}$ " (屠做); 3 . an asterisk is attached to the top left corner of "qinghao" (青蒿). The words “to be screened by $\mathrm{Yu}$ " and "to be screened by $\mathrm{Tu}$ " do not seem to have been written at the same time as the original text. At the bottom of the list preserved by $\mathrm{Yu}$ Yagang, there is also a list of other drugs that he screened.

The ethanol extract obtained by Yu Yagang and Gu Guoming was sent to the AMMS by $\mathrm{Gu}$ for screening with rodent malaria. Records (Figure 15) show that from February 1970, Tu Youyou's research group sent altogether ten batches of samples (prepared by $\mathrm{Yu}$ and $\mathrm{Gu}$ ), totaling 166 kinds of drugs, to the AMMS for testing, and there an inhibition rate was given for each of the sample. Records for most of the first three batches of samples do not include the names of the drugs; only the names of the extractants are included, mainly ethanol, ethyl ether, and petroleum ether. At the end of the records for the fourth batch of samples, it is specified that these samples had been “screened by Tu Youyou" (屠呦呦笁选), while the names of drugs are again omitted. The samples are mainly aqueous solutions of 


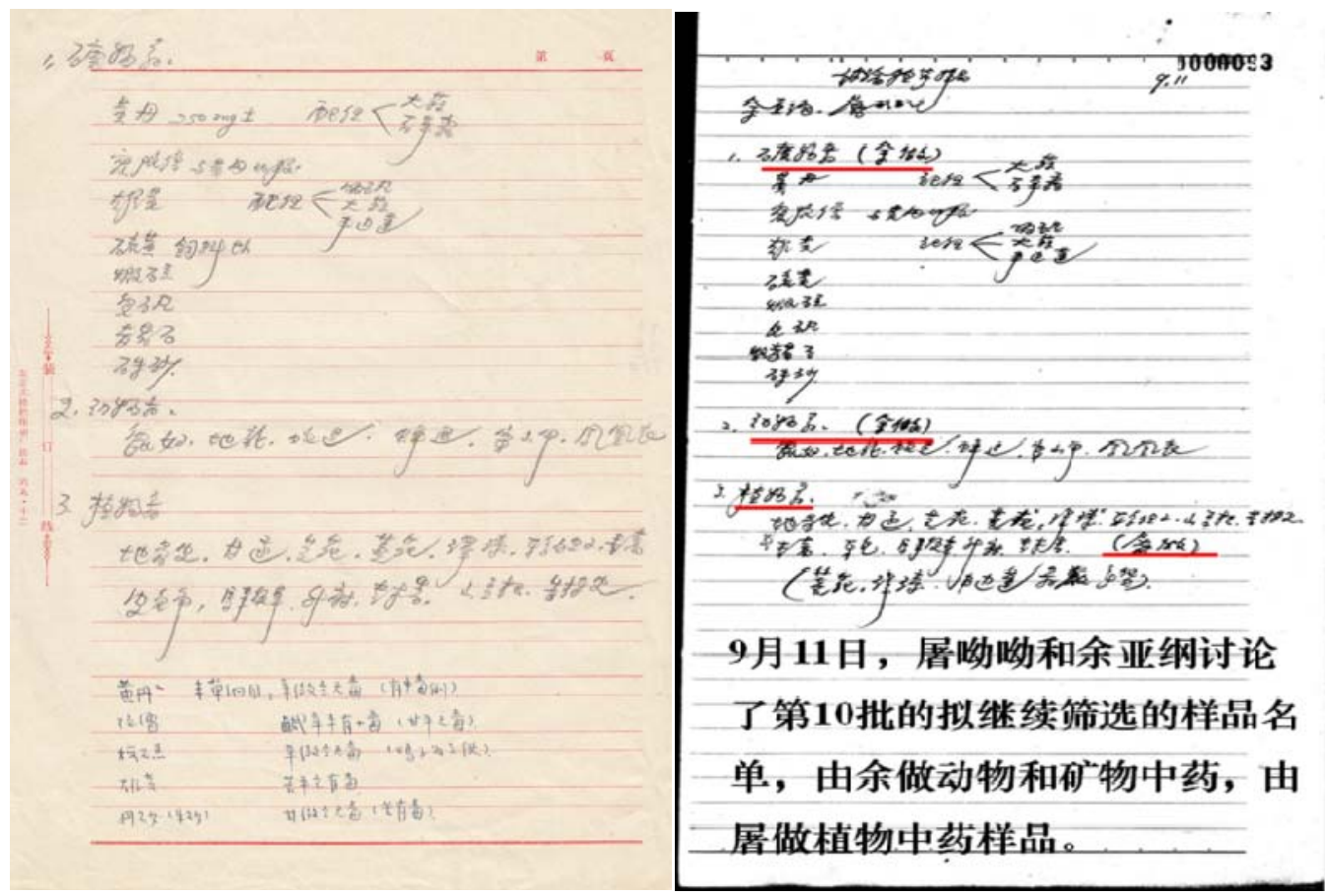

Figure 13: The list of materia medica for screening. This was provided by Tu Youyou for Yu Yagang in 1970 and was preserved by Yu. Photo by Yu Yagang.
Figure 14: The list of materia medica for screening preserved by the CACMS ICMM. The photo was shown by the ICMM during the Shantou meeting of 2012.35

acid or alkali components. No specific remarks are found in records from Batch No. 5 , but the name of each of the materia medica is stated. The last drug of the eighth batch is realgar, which achieved an inhibition rate of $100 \%$. Realgar appears in the ninth batch as well, where the inhibition rate is over $90 \%$. Qinghao appears in the tenth batch. With ethanol as the extractant, the inhibition rate of qinghao turns out to be $68 \%{ }^{36}$ This result conforms with Yu Yagang's recollection. ${ }^{37}$

35 An academic conference commemorating the forty-fifth anniversary of Project 523 was held from October 15 to 16, 2012, at Shantou University in Guangdong. The theme of the conference was "The Development of Artemisinin: From the Traditional Chinese Medicine Qinghao to the International Leading Antimalarial Drug." Scholars from China, the United States, Britain, Vietnam, Thailand, and other countries attended.

36 Research on the Antimalarial Effect of Qinghao. No. 19861002 of the Science and Technology Archives (photocopy), the Institute of Chinese Materia Medica of the China Academy of Chinese Medical Sciences, Beijing.

37 In Yu Yagang's screening, the inhibition rate of realgar once reached 100\%. The inhibition rate of qinghao was not as high as that of realgar; nevertheless, considering that realgar is a compound containing arsenic, which is highly toxic and not suitable for large-scale clinical use, the researchers decided to study the next best according to the inhibition rate-qinghao (Li 2011). 


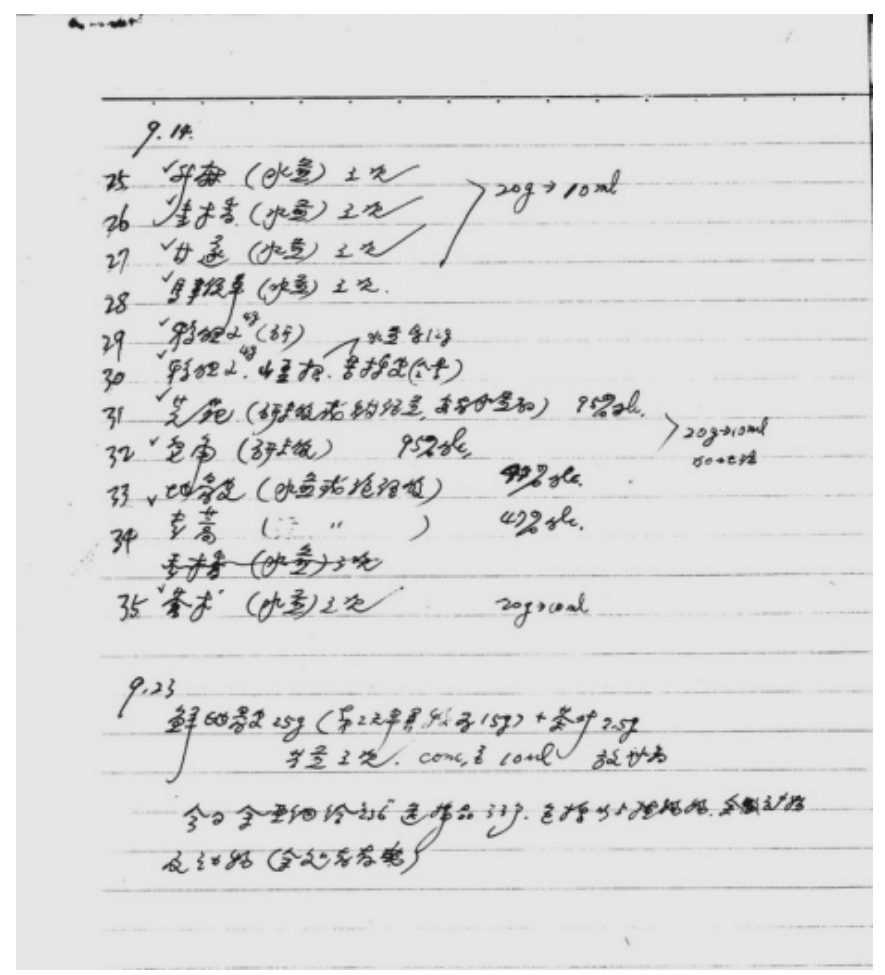

Figure 15: A photocopy of the picture provided by the CACMS ICMM during the 2012 Shantou Meeting (the first line has the date "9.14," while the fifth line from the bottom has "9.23").

Upon finishing the sample screening in September 1970, Gu Guoming was assigned other tasks, which put an end to his collaboration with the CACMS on screening antimalarial Chinese medicines. Yu Yagang also left Tu's group for a project on tracheitis. From then to May 1971, the group's research on antimalarial Chinese herbal medicines was at a standstill. ${ }^{38}$ It can thus be speculated that the test on the tenth batch of samples must have been finished by the end of September $1970 .{ }^{39}$ In his manuscript of 1975, Zhang Guozhen 章国镇, CACMS ICMM vice-director, wrote that “in 1971, as we had been unable

38 Internal document: The Institute of Chinese Materia Medica of the China Academy of Chinese Medical Sciences. 2012. "The Main Process of Discovering Artemisinin in the Academy of Traditional Chinese Medicine (1969-1973)" (中国中医科学院发现青蒿素的主要历程[1969 年～ 1973 年]).

39 Supposing that Tu Youyou did not make this screening list until September 11, 1970, the screening samples were ready on September 14, and that they were given to $\mathrm{Yu}$ Yagang on September 23 to be transferred to the AMMS. In the political atmosphere of that time, it would have been very unlikely for Tu Youyou to have written her comments that "Today Yu Yagang sent thirty-three samples to '236,' including all the plants above. Yu is in charge of screening [medicines originating from] minerals and animals (Yu kept a copy of his list)" (今日余亚纲给 “236” 送样 33 个, 包括以上植物, 余做矿物和动物 [余处有存底]). 
to find (antimalarial drugs, the project was) discontinued." 40 So it seems that the then leadership of the CACMS ICMM had no knowledge of the qinghao screening results. Yu Yagang's material written in 1978 shows that the results that he and Gu Guoming had obtained in screening qinghao and realgar had been reported to $\mathrm{Tu}$ Youyou. It was exactly when they were going to further explore the reasons behind the high efficiency rates of qinghao and realgar that their style of collaboration led to a problem: the AMMS was dissatisfied, thinking that the group was soldiering. At a later meeting, $\mathrm{Tu}$ Youyou suggested giving up this line of research, while Yu Yagang's opinion at that time was to carry on. After the CACMS ICMM Party Secretary Cui Kai 崔凯, Tu Youyou, and Yu Yagang visited the Project Office of Project 523, Yu changed his mind and agreed to stop. $\mathrm{Yu}$ also mentions in his writing that Tu was occupied with other work at the time. ${ }^{41}$ It can thus be speculated that the screening of 1970 was mainly finished by Yu Yagang and Gu Guoming. In a summary report written in 1986, Tu Youyou said, "part of the work was finished in 1970, when Gu Guoming from the AMMS was staying at our institute. It was discontinued later when the AMMS refused to further cooperate on fighting rodent malaria (it was during the climax of the movement to root out 'May 16' counter-revolutionary elements, and the whole of the CACMS was engulfed in political upheaval)." 42

We may safely conclude, therefore, that researchers who studied the extraction and screening of natural plants at that time already had a basic knowledge of studying Chinese herbal medicines with modern scientific methods. The CAMS IMM published Studies on the Effective Components of Chinese Herbal Medicine (Zhongcaoyao youxiao chengfen de yanjiu 中草药有效成分的研究). ${ }^{43}$ These studies showed that choosing the extraction and separation procedure of water-ethanol-ether or etherethanol-water according to the polarity of components in the Chinese herbal medicine was a conventional procedure. Although the results obtained by Yu Yagang and Gu Guoming had not been further confirmed, the two were indeed the first to screen the antimalarial effect of qinghao during "Project 523." Concerning the screening method, Yu Yagang learned of the treatments for malaria in traditional Chinese medicine, and selected a few from the 574 prescriptions and 108 kinds of traditional Chinese medicines that were used to fight malaria. With the help of modern scientific extraction methods and the screening using animal models, after

40 “1971 年, 因为找不到（抗疮药）就下马了。” Zhang Guozhen's manuscript, “Learn from Chairman Mao's Important Instructions on Theoretical Issues and Improve the Work of Project 523" (学习毛主席关于理论问题的重要指示, 把五二三工作促上去), May 16 and July 16, 1975.

41 Internal letter that $\mathrm{Yu}$ Yagang wrote to the CACMS ICMM on its allocation of awards for prize winners of the National Science Conference (photocopy). Provided by Yu Yagang.

42 Research on the Antimalarial Effect of Qinghao. No. 19861002 of the Science and Technology Archives (photocopy), the Institute of Chinese Materia Medica of the China Academy of Chinese Medical Sciences, Beijing.

43 It consists of Institute of Materia Medica, Chinese Academy of Medical Sciences (1972a) and Institute of Materia Medica, Chinese Academy of Medical Sciences (1972b). 
multiple experiments, it was found that qinghao had a high inhibition rate. This provided a valuable clue for future research.

\subsection{The discovery and extraction of artemisinin}

The National Symposium on Research concerning the Prevention and Control of Malaria was held in Guangzhou from May 21 to June 1, 1971. Since the State Scientific Commission had been merged with Chinese Academy of Sciences, during the symposium it was decided that the Leading Group would be headed by the Ministry of Public Health (as the group leader), the Department of Health under the General Logistics Department (as the deputy leader), the Ministry of Chemical Industry, and the Chinese Academy of Sciences. ${ }^{44}$ It was also during this symposium that the CACMS ICMM proposed ending the project; the Ministry of Public Health, the new group leader and the governing unit of CACMS, however, did not approve the proposal.

In July 1971, the CACMS ICMM organized a new research group of four researchers: $\mathrm{Tu}$ Youyou was the group leader, Lang Linfu and Liu Jufu 刘菊福 would be in charge of pharmacological work, and Zhong Yurong 钟裕蓉 would help with extraction. ${ }^{45}$ $\mathrm{Tu}$ Youyou later wrote that "after the screening and experimental research of over one hundred samples, we had to consider some other materia medica while rescreening those that had proved to be highly efficient. As the inhibition rate for qinghao had previously been 68\%, we started to rescreen qinghao" (Tu 2009). ${ }^{46}$ The screening record kept by the CACMS ICMM shows that the inhibition rate of qinghao (sample No. 16) was $12 \%$ on July 26, 1971; on September 1, the inhibition rate of artemisinol was $40 \%$ (sample No. 114); 47 on October 4, the inhibition rate of the ethyl ether extract of qinghao reached $99 \%$ for the first time (sample No. 191). Following that, records Nos. 201, 205, 277, 278, 281, 307, 345, and 347 are all samples of qinghao,

44 Internal document: The Beijing Cooperation Group on Research concerning the Prevention and Control of Malaria, "Liangnian lai Beijing diqu nüeji fangzhi yanjiu gongzuo qingkuang huibao” 两年来北京地区疮疾防治研究工作情况汇报 (Report on Research in Beijing in the Last Two Years concerning the Prevention and Control of Malaria), May 1973; Collection of Materials on Project 523 and Artemisinin.

45 Research on the Antimalarial Effect of Qinghao. No. 19861001 of the Science and Technology Archives (photocopy), the Institute of Chinese Materia Medica of the China Academy of Chinese Medical Sciences, Beijing.

46 “经过 100 多个样品篮选的试验研究工作, 不得不再考虑选择新的药物, 同时又复篎过去显示 效价较高的中药。因为青蒿曾出现过 $68 \%$ 的抑制率, 后来对青高进行复篮。”

47 Research on the Antimalarial Effect of Qinghao. No. 19861001 of the Science and Technology Archives (photocopy), the Institute of Chinese Materia Medica of the China Academy of Chinese Medical Sciences, Beijing. 
the inhibition rates for which were all above $99 \% .48$ Overall, the screening results at first were not that stable, and there were some samples extracted using other solvents, none of which obtained a high rate of inhibition, while the results produced after December 6 were relatively stable.

On March 8, 1972, Tu Youyou gave a presentation titled “Using Mao Zedong Thought to Guide the Exploration of Antimalarial Chinese Herbal Medicines" (Yong Mao Zedong Sixiang zhidao fajue kangnüe Zhongcaoyao gongzuo 用毛泽东思想指导 发掘抗㾏中草药工作) on behalf of the CACMS ICMM at the Nanjing meeting of the Cooperation Group on Traditional Chinese Medicine, hosted by the National Project Office of Project 523 (Figure 16). In her presentation, she represented the ICMM in reporting that the neutral portion of qinghao (Huanghuahao, Artemisia annua L.) ether extract could achieve an inhibition rate of $100 \%$ against rodent malaria and monkey malaria. This attracted the attention of the National Project 523 Head Office and other research units at the meeting. The presentation revealed that during the rescreening, inspired by the instruction of "wringing out the juice' (绞汁) and drinking it" from classical works on traditional Chinese medicine and folk prescriptions, Tu Youyou had realized that the effective ingredient in qinghao might be in the lipophilic part, and thus used ethyl ether as the solvent instead. It was only after this change that the efficacy of qinghao on animals increased from $30 \%-40 \%$ to above $95 \% .49 \mathrm{Tu}$ Youyou was the first person to use ethyl ether, the polarity of which, as a solvent, is lower than that of ethanol and thereby obtained the neutral portion of qinghao ether extract, which demonstrated an inhibition rate of $100 \%$ when tested against the parasite of rodent malaria. This came to be recognized as the most crucial step in the process of the study of artemisinin and the development of relevant drugs, and opened the door for other institutions to study artemisinin.

In January 1972, Tu Youyou's group started to prepare the qinghao ethyl ether extract in large amounts. Toxicity tests on dogs were finished at the end of June the same year, but there was still controversy over the test results. From June to August, Tu Youyou, Lang Linfu, Yue Fengxian 岳风仙, Zhang Guozhen, Yan Shuchang 严述常, Pan Hengjie 潘恒杰, Zhao Aihua 赵爱华, and Fang Wenxian 方文贤 conducted trials

48 Research on the Antimalarial Effect of Qinghao. No. 19861005 of the Science and Technology Archives (photocopy), the Institute of Chinese Materia Medica of the China Academy of Chinese Medical Sciences, Beijing.

49 Internal documents: The Group on Research concerning the Prevention and Control of Malaria from the China Academy of Chinese Medical Sciences, "Using Mao Zedong Thought to Guide the Exploration of Antimalarial Chinese Herbal Medicines," March 4, 1972; "Materials concerning the Dispute over Intellectual Property of Artemisinin," 1994, in Collection of Materials on Project 523 and Artemisinin. 
all three groups. ${ }^{52}$ Comparison of the groups revealed that treatment with high doses of qinghao extract (three grams per dose, four times a day, adding up to thirty-six grams in total for one day) was the most efficacious. ${ }^{53}$ A clinical trial had also been arranged by the National Project Office of Project 523 in Beijing 302 Hospital, where the extract proved to be effective on all nine patients with Plasmodium vivax malaria.

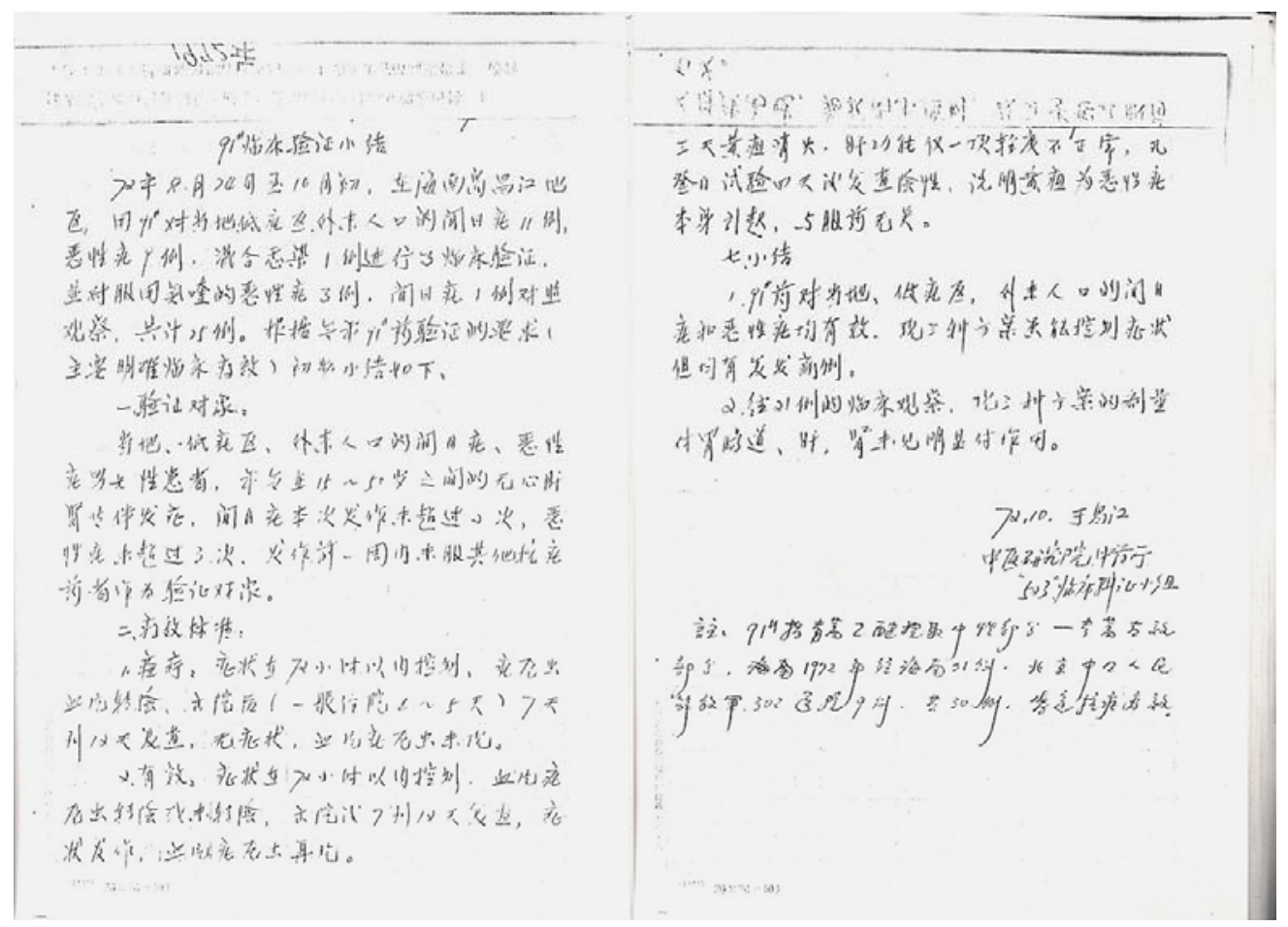

Figure 17: Summary of the clinical experiment using neutral ethyl ether qinghao extract in Changjiang, Hainan Province, in October 1972 (the main part was written by somebody else, while the note at the end is in Tu Youyou's handwriting).

In August 1972, when Tu Youyou and her team were conducting clinical trials in Hainan, Ni Muyun 倪慕云 designed a technique for pre-processing of the column chromatographic separation, which further improved the antimalarial effect of the neutral part ethyl ether extract of qinghao. Having learned from research literature that

52 Clinical Verification Group of Project 523 from the Institute of Chinese Materia Medica, China Academy of Chinese Medical Sciences. 1972. "A Summary of the Clinical Verification of 91\#" (91\#临床验证小结). (Tu Youyou's written comment reads: 91\# refers to the neutral part of the ethyl ether extract of qinghao, which is the effective part of qinghao [91\#指青高乙醚提取中性成 分——青蒿有效部分].)

53 Internal document: The Institute of Chinese Materia Medica, China Academy of Chinese Medical Sciences. 1978. Research on the Antimalarial Effect of Qinghao (1971-1978) (青蒿抗疮研究 [1971 1978]), 26. 
it would be more effective to separate neutral compounds using silica gel columns, on the basis of Ni Muyun's pre-processing, Zhong Yurong worked with her assistant Cui Shulian 崔淑莲 to separate neutral ethyl ether extract with silica gel column chromatography following the method described in the literature, and used petroleum ether and ethyl ether (which was later changed to petroleum ether and ethyl acetate) in gradient elution. From November 8, 1972, the silica gel columns used in the separation was changed to those produced by the Shanghai Chemical Reagent Works. The product would then be eluted multiple times with petroleum ether and ethyl acetate-petroleum ether (in different proportions). The first thing obtained was a small amount of needlelike crystals called "Needle Crystal I" (No. 1 or Needle 1). The second product of elution was the needle-like crystal called "Needle Crystal II" (No. 2 or Needle 2), and the next, which was in the shape of cubical crystal, was "Crystal III" (No. 3 or the Cubical Crystal). At the time the crystals obtained were given many names and the nomenclature had not been unified. At the beginning of December that year, an experiment in treating rodent malaria proved that "Needle Crystal II" was the only monomer to be antimalarial. Later on, when the CACMS ICMM reported to the National Project Office of Project 523, the name for the antimalarial component "Needle Crystal II" was changed to "artemisinin II," and sometimes "artemisinin"; the two names were usually used interchangeably. After 1975, the CACMS ICMM used "artemisinin" in most cases.

\subsection{The successive discovery of huanghuahaosu and huanghaosu}

After researchers from the Shandong Institute of Parasitic Diseases who had participated in the Nanjing meeting returned to Shandong, they drew on the lessons from the CACMS ICMM discovery to extract components from local qinghao using ethyl ether and alcohol. As the product proved to be effective in animal experiments, ${ }^{54}$ the Shandong researchers submitted a written report to the National Project Office of Project 523 on October 21, 1972. The conclusion that this institute had reached was that in fighting rodent malaria, the extract of huanghuahao 黄花高 was as effective as the qinghao extract prepared by the CACMS. 55 Subsequently, in October 1973, the Shandong Institute of Parasitic Diseases started to work with the Shandong Institute of Chinese Medicine in separating effective monomers. In November, seven kinds of crystals were separated and extracted from huanghuahao from Taian 泰安, Shandong Province, by the Shandong Institute of Chinese Medicine. The fifth of the crystals was

54 Letter from the Shandong Institute of Parasitic Diseases to the Institute of Chinese Materia Medica of the China Academy of Chinese Medical Sciences, March 14, 1973. Provided by Tu Youyou.

55 Internal document: National Project Office of Project 523. "On the Research into the Antimalarial Effect of Qinghao" (关于青蒿抗㾏研究的情况), October 1977. In Collection of Materials on Project 523 and Artemisinin. 
named huanghuahaosu 黄花蒿素 and was antimalarial.

At the end of 1972, Fu Liangshu 傅良书, vice-director of the Yunnan Project Office of Project 523, went to Beijing to attend the annual meeting of directors of provincial 523 offices. ${ }^{56}$ On returning to Kunming, he went to the Yunnan Institute of Materia Medica to convene a meeting of researchers. Fu Liangshu reported the findings about qinghao by the CACMS ICMM, and suggested making full use of the rich plant resources in Yunnan by comprehensively screening plants of the genus Artemisia in the Asteraceae family.57 During the Spring Festival in 1973, Luo Zeyuan 罗泽渊 discovered the strong-smelling kuhao 苦蒿 on the campus of Yunnan University. He brought the sample back to the institute for extraction and found that the ethyl ether extract of kuhao was antimalarial. ${ }^{58}$ In April of that year, he separated the antimalarial monomer "Kuhao Crystal III," which would be renamed "huanghaosu 黄蒿素." Not long afterwards, Wu Zhengyi 吴征镒 from the Kunming Institute of Botany, Chinese Academy of Sciences helped to identify that the scientific name of this kuhao was Artemisia annua L. f. macrocephala Pamp (Figure 18) (Luo 1980). In September 1973, Zhan Eryi 詹尔益 and Qi Yufang 戚育芳 from the Yunnan Institute of Materia Medica bought some huanghuahao 黄花蒿 (Artemisia annua L.) that was native to Youyang 酉 阳, Sichuan Province, to make up for the lack of raw materials. A larger amount of huanghaosu was extracted from it. ${ }^{99}$

All three institutions used Artemisia annua L. to extract crystals. Differences in the plants' origin and extraction techniques, however, led to differences in the quantities of crystals obtained. After 1974, the early method used by the CACMS ICMM, which was to extract artemisinin with ethyl ether and $\mathrm{NaOH}_{1}{ }^{60}$ was replaced by the Yunnan Institute of Materia Medica's method of extracting with gasoline, the method of Sichuan Institute of Chinese Materia Medica (now Chongqing Academy of Chinese Materia Medica) of extracting with 95\% ethanol (Liu 2017), and the Shandong Institute of Chinese Medicine's method of extracting with acetone. Starting from 1975, having

56 This was the meeting of directors of provincial 523 offices held between November 20 and November 30, 1972, in Beijing. The persons-in-charge of the departments and institutions in Beijing that participated in Project 523, and representatives of the professionals involved in the research, also attended the meeting. Fu Liangshu did not attend the Nanjing meeting in March 1972; he did not learn about this progress in research on qinghao until November at this meeting at Beijing. He saw the qinghao extract at the CACMS ICMM as well at this time.

$57 \mathrm{Fu}$ Liangshu, interview by Li Runhong, Kunming, September 24, 2009. Transcript in the database of the Collecting Project.

58 Huang Heng and Luo Zeyuan, interview by Li Runhong, Chengdu, September 18, 2009. Transcript in the database of the Collecting Project.

59 This was consistent with the record in Zhang Guozhen's journal for February 1974.

60 Internal document: The Institute of Chinese Materia Medica, China Academy of Chinese Medical Sciences. 1978. Research on the Antimalarial Effect of Qinghao (1971-1978), 36 and 38. 


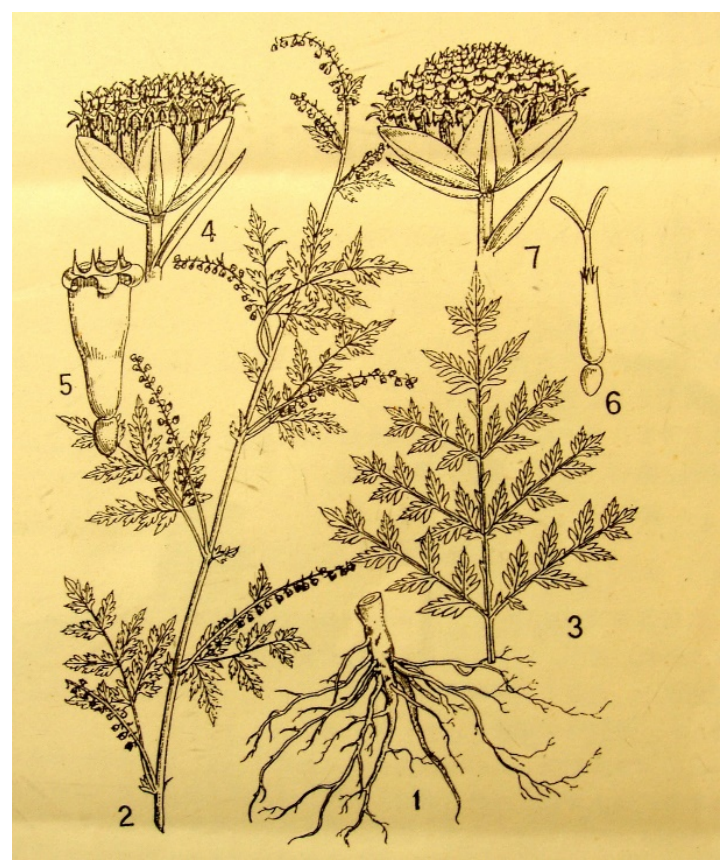

Figure 18: Artemisia annua L. f. macrocephala Pamp in the 1980 paper by Luo Kaijun 罗开均 from the Yunnan Institute of Materia Medica (Luo 1980).

visited their counterparts in Yunnan and Sichuan ${ }^{61}$ to learn their extraction methods, scholars at the CACMS ICMM started to buy qinghao from Youyang in Sichuan and extract either by themselves or by passing it on to third parties. That is to say, from 1975, the CACMS ICMM extracting method was no longer used; artemisinin II was henceforth also replaced by huanghaosu or huanghuahaosu. Today, the method of using gasoline as the solvent to extract artemisinin is used for industrial-scale production.

\section{Clinical verification and structural determination of artemisinin through national collaboration}

\subsection{Clinical verification}

The ultimate goal of Project 523 was to find effective antimalarial drugs, especially those that were effective against malaria $p . f$., so the experiments conducted had to serve clinical purposes. Only after a certain drug has been proved to be clinically effective and without toxicity or side effects can it be regarded as effective in a real sense. The crystal monomers independently obtained from qinghao (huanghuahao) by the CACMS ICMM, the Shandong Institute of Chinese Medicine, and the Yunnan Institute of

61 Internal document: The Institute of Chinese Materia Medica, China Academy of Chinese Medical Sciences. 1978. Research on the Antimalarial Effect of Qinghao (1971-1978), 39. 
Materia Medica all yielded positive results, yet there were great differences regarding the significance and reliability of the clinical verification of each.

From the first half of 1973 to the second half of 1974, the CACMS ICMM encountered several setbacks in their efforts to extract artemisinin II. Zhang Guozhen, vice-director of the institute, wrote that in the first half of 1973 "(we) used 3000 jin of qinghao to extract Crystal II and preliminarily obtained around 60 grams of the crystal" (this was later revised to "100 grams" using a pencil); 62 " $47 \%$ ethanol was used to extract and ethyl ether was then used to dissolve and extract." 63 For some reason, they failed to "extract 300-500 grams of drug by the end of May to further expand the scope of clinical verification" 64 as planned. 65 The 100 grams of artemisinin II obtained by the CACMS ICMM was sent to Hainan in September 1973 for clinical trials (Pharmacology Research Laboratory of the Institute of Chinese Materia Medica, China Academy of Chinese Medical Sciences 1979). It was used in altogether eight cases, including three cases of Plasmodium vivax malaria and five cases of malaria p.f. The drug was proved to be effective on patients of Plasmodium vivax malaria, but case numbers were too few. On malaria p.f. patients, on the other hand, the drug failed to prove itself. ${ }^{66}$ In order to further verify the drug's clinical efficacy, from February 28 to March 1, 1974, the National Project Office of Project 523 assigned four institutes from Beijing, Shandong, and Yunnan to complete clinical trials of qinghao crystal on 150-200 patients by October 1974 . The CACMS ICMM only obtained around a dozen grams of artemisinin II and thus failed in the tasks of both production and clinical verification. ${ }^{67}$ In early and mid-May 1974, the Shandong Cooperation Group on huanghuahao conducted clinical trials on ten patients with Plasmodium vivax malaria in Guandong Commune 关东公社, Juye 巨野 County, Shandong Province; the drug turned out to be remarkably effective. ${ }^{68}$

62 “提取 3000 斤青蒿初步得到结晶 II 号约 60 克。”

63 “4 $47 \%$ 乙醇提取后乙醚转溶。”

64 “在五月底提取 300 500 (克) 药品进一步扩大临床验证。”

65 Internal documents: Zhang Guozhen's manuscript, “Summary of the (Plan's Implementation for) Research Done by the Institute of Chinese Materia Medica in (the First Half of) 1973" (中药研 究所一九七三年 [上半年]科研 [计划执行情况]工作总结); Zhang Guozhen's manuscript, “Learn from Chairman Mao's Important Instructions on Theoretical Issues and Improve the Work of Project 523," May 16 and July 16, 1975.

66 Internal document: The Institute of Chinese Materia Medica, China Academy of Chinese Medical Sciences. 1978. Research on the Antimalarial Effect of Qinghao (1971-1978), 26.

67 Internal documents: Zhang Guozhen's manuscript, “Summary of the (Plan's Implementation for) Research Done by the Institute of Chinese Materia Medica in (the First Half of) 1973"; Zhang Guozhen's manuscript, "Learn from Chairman Mao's Important Instructions on Theoretical Issues and Improve the Work of Project 523," May 16 and July 16, 1975.

68 Internal document: The Shandong Cooperation Group on Huanghuahao. 1974 or 1975. "A Preliminary Observation on Treating Patients of Plasmodium Vivax Malaria with Huanghuahaosu and the Simple Dosage Form of Huanghuahao's Acetone Extract" (黄花蒿素及黄花蒿丙酮提取简易 剂型治疗间日疮现症病人初步观察). 
The Yunnan Clinical Cooperation Group fulfilled their tasks using huanghaosu, specifically testing its efficacy against malaria p.f. ${ }^{69}$ On September 8, 1974, group members Lu Weidong 陆伟东 and Wang Xuezhong 王学忠 took huanghaosu to the Yun County 云县 and Chafang 茶坊 areas to observe its clinical effects. Liu Pu 刘溥 was dispatched by the CACMS ICMM as an observer to join the Yunnan group. As at that time there were few malaria patients in Yunxian and Chafang, Lu, Wang, and Liu turned to Gengma 耿马 County, which had more malaria p.f. patients, and arrived on October 13. In Gengma, they met the medical team led by Li Guoqiao 李国桥 from the Guangzhou College of Chinese Medicine. With the approval of their superiors, the group provided drugs to the Guangdong medical team to conduct clinical trials together. ${ }^{70}$ The Yunnan group and the Guangdong medical team tested huanghaosu on twenty-one patients in total (three from Yunnan and eighteen from Guangdong), including six cases of Plasmodium vivax malaria and fifteen cases of malaria $p$.f. It was found to be effective in all of these cases. Liu Pu returned to Beijing on December 3, and on December 9, he presented a report at the CACMS ICMM concerning the clinical trials conducted in Yunnan. ${ }^{71}$

At the end of February 1975, a meeting of leaders of all the regional Project Offices of Project 523 and some institutions that were charged with tasks was held in Beijing. Liu Xiangping 刘湘萍, the person in charge from the Ministry of Public Health, listened to the report before the meeting and criticized the CACMS ICMM for once again proposing to stop the research on qinghao. ${ }^{72}$ During the meeting, the Guangdong Project Office of Project 523 presented "A Summary on Treating Eighteen Malaria Patients with Huanghaosu” (黄蒿素治疗㾏疾 18 例小结), which concerned the clinical trials that the Guangzhou College of Chinese Medicine had conducted in Gengma, Yunnan Province. In view of the results from research and trials on qinghao (huanghuahao) since 1972, especially the remarkable effect that huanghaosu had had against malaria p.f. in Yunnan, qinghaosu 青蒿素 and huanghuahaosu were included in the Project 523 research priorities in 1975.

In early 1975, when the CACMS ICMM was worrying about their lack of supply of artemisinin II, Chen Miaohua 陈妙华 from the Department of Chemistry visited the Yunnan Institute of Materia Medica, and found that they had obtained a large amount of huanghaosu of high purity, from huanghuahao originating in Youyang using gasoline as the solvent. Liu Jingming 刘静明 and Pan Jiongguang 潘畑光 traveled

69 Internal document: The Yunnan Clinical Verification Group on Huanghaosu and the 523 Group of Guangzhou College of Chinese Medicine. "A Summary on Treating Eighteen Patients of Malaria with Artemisinin” (青蒿素治疗疮疾 18 例总结), February 1975.

70 Lu Weidong's journal, 1974.

71 Zhang Guozhen's journal, December 9, 1974.

72 Shi Linrong 施凛荣, interview by Li Runhong, Beijing, September 23, 2009. Transcript in the database of the Collecting Project. 
to the Yunnan Institute of Materia Medica at once to learn from their experience. Having learned how to extract artemisinin using 120\# gasoline as the solvent and $50 \%$ ethanol for recrystallization, Liu and Pan bought 8100 jin of huanghuahao from Chongqing and entrusted it to a pharmaceutical factory, which extracted approximately 500 grams of crystal from it. This solved the urgent need for artemisinin to carry out the so-called "battle for clinical verification" that year, and to conduct experimental research.73 At the end of 1975, under the coordination of the National Project Office of Project 523, the CACMS ICMM entrusted the task of extracting artemisinin to the Sichuan Institute of Chinese Materia Medica. The ICMM provided a special fund and dispatched to Chongqing Tan Honggen 谭鸿根, Cui Shulian, and Zhang Yongli 张永利 (Zhang went there later than other two) to participate in the extraction. Using diluted alcohol, they obtained more than 600 grams of artemisinin. ${ }^{74}$

In April 1975, a symposium of the Cooperation Group on Traditional Chinese Medicine was held in Chengdu. Since Li Guoqiao and his colleagues had obtained good results treating malaria p.f. patients with huanghaosu originating from Yunnan, the symposium proposed expanding the "national battle" for clinical verification. As a result, the number of institutions and people participating in research on qinghao and artemisinin increased significantly. In order to unify diagnosis and clinical trials standards, before sending working staff to malaria-affected areas, the Project Office of Project 523 organized experts, including Li Guoqiao, to provide training in Hainan for those who would participate in clinical trials on aspects such as the ways to observe the plasmodium, the time to measure body temperature, and so on. ${ }^{75}$

Till November 1978, when the assessment meeting of scientific research achievements of using artemisinin (huanghuahaosu, huanghaosu) to treat malaria was held, participating institutions throughout the country used simple preparations of qinghao extract and artemisinin (huanghuahaosu, huanghaosu) in clinical trials involving a total of 6555 cases of malaria, of which 2099 cases were treated with artemisinin (huanghuahaosu, huanghaosu), including 588 cases of malaria p.f. (141 of which were cerebral malaria patients) and 1511 cases of Plasmodium vivax

73 Xu Tiansheng 徐天生. 1975. “Zhongyao Yanjiusuo keyan gongzuo jianbao” 中药研究所科研 工作简报 (A Brief Report of the Institute of Chinese Materia Medica's Scientific Research), issue 3. 74 Internal document: Qi, Shangbin 齐尚斌, and Wan Yaode 万尧德. “Restoring the Historical Truth: Rarely-Known Stories in the Development of Artemisinin” (还历史于本来面目一一青蒿素 研制中鲜为人知的故事). November 1, 2005.

75 Internal document: "A Brief Report on the Symposium of the 523 Cooperation Group on Traditional Chinese Medicine" (五二三中医中药专业座谈会简报), April 24, 1975, Chengdu. In Collection of Materials on Project 523 and Artemisinin. 
malaria. ${ }^{76}$ From 1971 to 1978, scholars from the ICMM "cooperated in Hainan, Hubei, Gaoyou in Jiangsu, and Henan to observe the clinical efficacy of the crude extract of qinghao, artemisinin, and others, in total involving around ten dosage forms, on 529 patients." 77

\subsection{Structural determination}

During the symposium of the people-in-charge of the Leading Group for Research on the Prevention and Control of Malaria, which was held in Shanghai from May 28 to June 7, 1973, the leading group of Project 523 gave clear instructions concerning determining the chemical structure of the antimalarial components of qinghao: "While improving the dosage form and popularizing the use of artemisinin, organize researchers, facilitate cooperation, and strive to determine the chemical structure in 1974 and carry out research on chemical synthesis."78

At the beginning of 1973, the CACMS ICMM began work on determining the structure of artemisinin II. Based on research that huanghuahao contains sesquiterpene (Institute of Materia Medica, Chinese Academy of Medical Sciences 1972a, 418), at the suggestion of Professor Lin Qishou 林启寿 from the Department of Pharmaceutics of Beijing Medical College, Ni Muyun and her colleagues from the CACMS ICMM let artemisinin II react with reagents, including potassium borohydride, to explore whether there are ketones and aldehydes carbonyl groups in the molecule. They determined that artemisinin appears as white, needle-shaped crystals, and has a melting point between $156^{\circ} \mathrm{C}$ and $157^{\circ} \mathrm{C}$. Chemical reactions verified that the substance contains neither nitrogen nor double bonds, the result of elemental analysis being $\mathrm{C}$ $63.72 \%, \mathrm{H} 7.86 \%$. Using instruments from both their own and other institutes to carry out infrared spectroscopy (IR), ultraviolet spectroscopy (UV), mass spectrometry (MS), and nuclear magnetic resonance spectroscopy (NMR), they determined that artemisinin's molecular formula is $\mathrm{C}_{15} \mathrm{H}_{22} \mathrm{O}_{5}$ and its molecular weight $282 .{ }^{79}$ However, according to the commissioned elemental analysis report of artemisinin II (Figure 19)

76 Internal document: The National Leading Group for Research on the Prevention and Control of Malaria. “The Identification of Artemisinin” (青蒿素鉴定书), November 28, 1978.

77 “在海南、湖北、江苏高邮、河南等地共同协作, 对青蒿粗制剂, 青蒿素等约 10 剂型, 进行了 529 例临床疗效观察。” The Institute of Chinese Materia Medica, China Academy of Chinese Medical Sciences. 1978. Research on the Antimalarial Effect of Qinghao (1971-1978), 34.

78 “青蒿素在改进剂型推广使用的同时, 组织力量加强协作, 争取 1974 年定出化学结构, 进行化 学合成的研究。” Internal document: The Conference Team for the Symposium of Persons-inCharge of the National Leading Group for Research on the Prevention and Control of Malaria. "Major Tasks for the Last Three Years in the Five-Year Plan Period for Research on the Prevention and Control of Malaria [Draft]" (关于症疾防治研究五年规划后三年主要任务 [讨论稿]). In Collection of Materials on Project 523 and Artemisinin.

79 The melting point and the molecular formula were consistent with Tu Youyou's speech, as recorded in Zhang Guozhen's journal on February 28, 1974. 
finished by the CAMS IMM, provided by Tu Youyou in her 2015 Nobel lecture, the C\% measurements were 63.86 and 63.59 , and the $\mathrm{H} \%$ measurements 8.52 and 8.54 . If we use these data to calculate, the molecular formula of artemisinin will be closer to $\mathrm{C}_{15} \mathrm{H}_{24} \mathrm{O}_{5}$ rather than $\mathrm{C}_{15} \mathrm{H}_{22} \mathrm{O}_{5}$, which is the widely-acknowledged molecular formula of artemisinin. Nevertheless, these elemental analysis results never attracted attention.

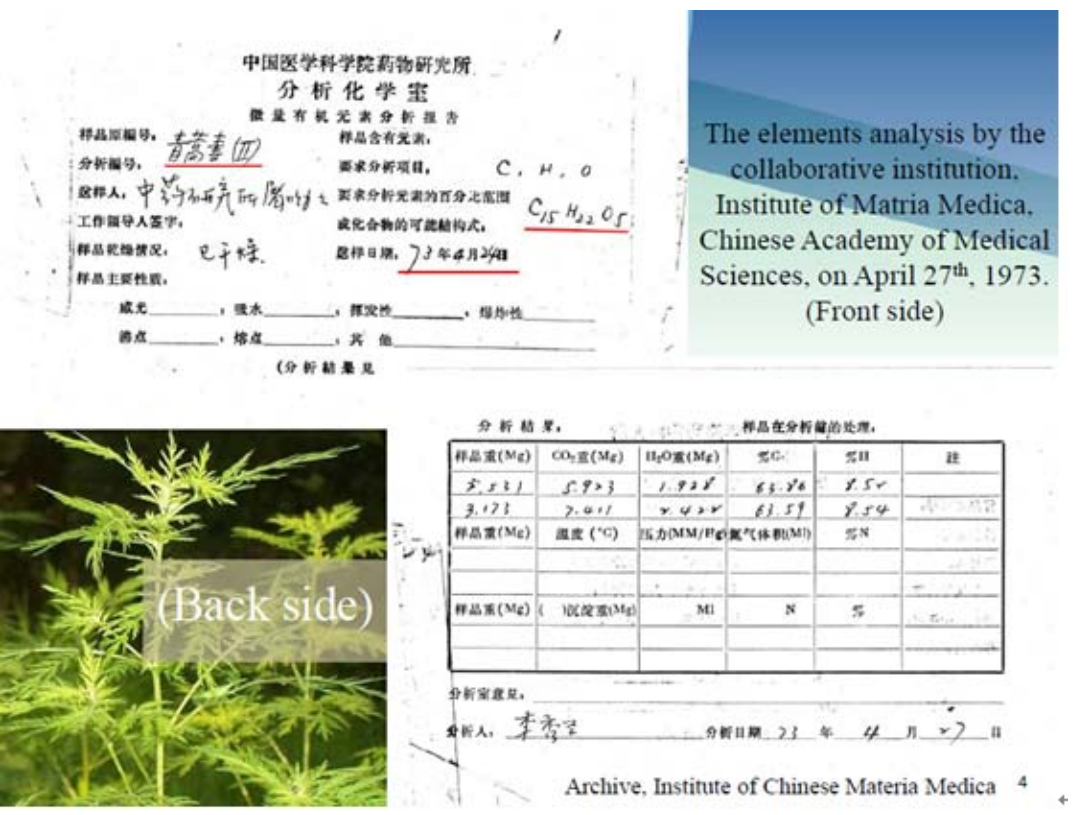

Figure 19: One page of the slide that $\mathrm{Tu}$ Youyou used in 2015 during her Nobel lecture (The Nobel Prize Organization 2015, page 4 of the PDF attachment titled "ArtemisininA Gift from Traditional Chinese Medicine to the World: Lecture slides").

The authors of this paper have also seen an elemental analysis report in the scientific research archives of the CACMS ICMM. This analysis was done on April 18, 1973 by two scholars from the Institute of Chemistry of the Chinese Academy of Sciences, using a different method. The results that they obtained were $\mathrm{C} 64.27 \%, \mathrm{H}$ $7.89 \%, \mathrm{C} 63.97 \%, \mathrm{H} 7.96 \%, \mathrm{~N}<0.3 \%$, which seem to be closer to the recognized molecular formula of artemisinin $\mathrm{C}_{15} \mathrm{H}_{22} \mathrm{O}_{5}$. Another elemental analysis report from November 16, 1973, however, presents theoretical values for the artemisinin sample as C 63.39\%, $\mathrm{H} \mathrm{8.45 \% ,} \mathrm{while} \mathrm{experimental} \mathrm{values} \mathrm{are} \mathrm{C} \mathrm{61.99 \% ,} \mathrm{H} \mathrm{7.27 \% .} \mathrm{Also} \mathrm{appearing}$ on this analysis report is " $\mathrm{C}_{15} \mathrm{H}_{24} \mathrm{O}_{5}$ or $\mathrm{C}_{15} \mathrm{H}_{22} \mathrm{O}_{5} \cdot \mathrm{H}_{2} \mathrm{O}$," presumably molecular formulas derived from theoretical values. ${ }^{80}$

80 Research on the Antimalarial Effect of Qinghao. No. 19861002 of the Science and Technology Archives (photocopy), the Institute of Chinese Materia Medica of the China Academy of Chinese Medical Sciences, Beijing. 
As it only had a limited number of researchers and lacked equipment, the CACMS ICMM was unable to finish the entire structural identification process alone. Having learned that Professor Liu Zhujin 刘铸晋 from the Shanghai Institute of Organic Chemistry, Chinese Academy of Sciences (hereafter "Institute of Organic Chemistry" for short) specialized in terpenoid, a component of huanghuahao (Institute of Materia Medica, Chinese Academy of Medical Sciences 1972a), the CACMS ICMM reached out to the Institute of Organic Chemistry in the hope that the two institutes might collaborate. In late August 1973, Tu Youyou brought relevant materials to the Institute of Organic Chemistry to discuss their collaboration on determining the structure of artemisinin,, 11 where she was received by Chen Yuqun 陈毓群. In January 1974, Chen wrote back, agreeing that the CACMS ICMM should send one of their members to Shanghai to work with them (Tu 2009, 44). Wu Zhaohua 吴照华 from the research group on contraceptives of Department One of the Institute of Organic Chemistry undertook the task of determining artemisinin's structure. ${ }^{82}$ During her work, she very often consulted $\mathrm{Wu}$ Yulin 吴毓林 for help with reading the spectra. ${ }^{83}$ Zhou Weishan 周维善, vice-director of the "Revolutionary Committee" of Department One, also participated in the discussions.

In February 1974, the CACMS ICMM sent Ni Muyun to the Institute of Organic Chemistry to conduct experiments with $\mathrm{Wu}$ Zhaohua. Ni brought along research materials and an unknown amount of artemisinin II. At first $\mathrm{Ni}$ and $\mathrm{Wu}$ repeated some experiments that had been carried out before in Beijing. Later on, they mainly conducted research on relevant chemical reactions and wave spectrum data. ${ }^{84}$ Zhong Yurong, Fan Jufen 㚞菊芬, and Liu Jingming were also sent by the CACMS ICMM to the Institute of Organic Chemistry to participate in the work of structural determination. Researchers working at the Institute of Organic Chemistry would send progress reports on the structural determination to $\mathrm{Tu}$ Youyou in Beijing. Tu would then consult with Professor Lin Qishou (in the early period) and Professor Liang Xiaotian (in the later period) to provide feedback to the researchers in Shanghai, offering suggestions to contribute to the work.

$\mathrm{Wu}$ Zhaohua started off by re-purifying the samples provided by the CACMS ICMM, and then carried out elemental analysis. The results that she obtained were consistent with the molecular formula of $\mathrm{C}_{15} \mathrm{H}_{22} \mathrm{O}_{5}$. Later she conducted experiments together with members of the CACMS ICMM to explore if there were any double

81 Research on the Antimalarial Effect of Qinghao. No. 19861014 of the Science and Technology Archives (photocopy), the Institute of Chinese Materia Medica of the China Academy of Chinese Medical Sciences, Beijing.

$82 \mathrm{Wu}$ Yulin to Li Runhong, July 26, 2013.

$83 \mathrm{Wu}$ Zhaohua's reminiscence on the structural determination of artemisinin, March 16, 2011.

84 Ni Muyun, interview by Li Runhong, Beijing, March 9, 2011. Transcript in the database of the Collecting Project. 
bonds, ketone carbonyl groups, and lactone groups, eventually determining that artemisinin is a kind of sesquiterpene lactone that contains neither nitrogen nor double bonds. Wu Zhaohua recrystallized the sample of artemisinin II that had been brought by Ni Muyun again and again until the melting point became stable, and then carried out the elemental analysis. The results were $\mathrm{C} 63.84 \%$ and $\mathrm{H} 7.53 \%$. The molecular formula of artemisinin II would thus be $\mathrm{C}_{15} \mathrm{H}_{22} \mathrm{O}_{5}$. With hydrogen- and carbon-proton nuclear magnetic resonance spectrometry and high-resolution mass spectrometry, $\mathrm{Wu}$ and her collaborators further confirmed this deduction. According to Wu Zhaohua's results, it can be speculated that the artemisinin II sample on which the CAMS IMM did elemental analysis commissioned by the CACMS ICMM was probably not pure. From February 28 to March 1, 1974, the National Project Office of Project 523 convened an artemisinin research symposium, involving participation by the four institutes from Beijing, Shandong, and Yunnan. During the meeting, Jing Houde 景厚德, an expert on pharmacology from the CACMS ICMM, highlighted the four differences of the crystals provided by the three institutes, proposing that the crystals they had obtained might not be identical. ${ }^{85}$ Participants from all three institutes responded to this point. Shi Linrong 施凛荣 from the Project Office of Project 523 pointed out that chemical experiments should be done under identical conditions and further analysis should follow if the results prove to be different. He suggested that each institute do experiments on their own, and then contrast the result with that of chloroquine to explore if there is toxicity. According to the symposium's bulletin, without doing eutectic experiments, members of the participating institutes decided that the effective crystals they had extracted successively were probably the same. In retrospect, this conclusion was not very well grounded.

In early 1975, Zhou Weishan visited the Yunnan Institute of Materia Medica on his way to attend a meeting in Kunming. He commented that there were three difficulties in the structural determination of artemisinin: Firstly, the research was difficult in itself; secondly, artemisinin was in short supply; thirdly, their collaborators from the CACMS ICMM had returned to Beijing, and it was unclear whether they would like to continue. Fortunately, through the coordination of the National Project Office of Project 523, the Yunnan Institute of Materia Medica and the Shandong Institute of Chinese Medicine helped to provide a quantity of high purity crystals for the Institute of Organic Chemistry to continue their work on determining the chemical structure of artemisinin (Zhang J. 2018). Starting from 1975, the crystals provided by the Yunnan and the Shandong institutes were huanghaosu or huanghuahaosu, rather than the artemisinin II originally obtained by the CACMS ICMM. As has been mentioned above, since 1975, there was no longer any artemisinin II available to the CACMS ICMM; all the crystals

85 Zhang Guozhen's journal, March 1, 1974. 
that they obtained using the methods of the Yunnan and Sichuan institutes after that were huanghaosu or huanghuahaosu.

With the results of elemental analysis, mass spectrum, infrared spectrum, and nuclear magnetic resonance, it was not especially laborious to determine that artemisinin's molecular formula is $\mathrm{C}_{15} \mathrm{H}_{22} \mathrm{O}_{5}$, and that it belongs to sesquiterpene compounds. Further determination of its structure, however, encountered many difficulties, the main problem being how to arrange the five oxygen atoms in the framework consisting of fifteen carbon atoms. Researchers from the Institute of Organic Chemistry had speculated that artemisinin probably belongs to peroxide. Nevertheless, artemisinin is relatively stable, so this speculation would contradict the common knowledge that peroxides decompose easily.

In April 1975, Li Ying 李英86 from the Shanghai Institute of Materia Medica, Chinese Academy of Sciences (hereafter "Shanghai Institute of Materia Medica" for short) heard a presentation from Yu Dequan of the CAMS IMM on the chemical structure of yingzhaosu A (another antimalarial monomer that contains the peroxy group) during the Chengdu symposium. Inspired by Yu Dequan's report, upon returning to Shanghai, Li Ying introduced Yu's finding to $\mathrm{Wu}$ Yulin from the Institute of Organic Chemistry, who thus speculated that artemisinin might also belong to the peroxide group. He did a simple qualitative experiment the next day to confirm his guess. Wu Zhaohua's quantitative analysis then followed, which finally proved that artemisinin was indeed a kind of peroxide. Taking into account the phenomena of some chemical reactions that they had observed and wave spectrum analysis results, researchers inferred part of artemisinin's molecular structure (The Cooperation Group on Research of Artemisinin's Structure 1977; Liu et al. 1979).

At the same time, while researchers of the CACMS ICMM and the Institute of Organic Chemistry were trying to determine artemisinin's chemical structure with chemical methods, taking the advice of Liang Xiaotian, the National Project Office of Project 523 contacted the Institute of Biophysics, Chinese Academy of Sciences, which had participated in determining the structure of insulin, to bring them into the cooperation (Liang 2017). The Institute of Biophysics, CAS, used the X-ray diffraction method, a very advanced technique in the country at the time, to work out the chemical structure of artemisinin (Tu 2009, 44). Li Pengfei 李鹏飞, Liang Li 梁丽, and their colleagues from the institute obtained a group of diffraction intensity data of artemisinin crystals using the method of X-ray crystal diffraction analysis and a fourcircle X-ray diffractometer. After that, in the period between the end of 1975 and 1976, by adopting a mathematical method of acquiring phase data from the diffraction intensity data according to probability relations, and using computers of the Beijing

$86 \mathrm{Wu}$ Yulin and Li Ying were husband and wife. 
Computing Center for calculation, the researchers determined the absolute configuration of artemisinin (Liang 2017). The complete and precise structure of artemisinin was thus finally worked out. This work also received guidance and support from Tang Youqi 唐有祺, Liang Xiaotian, and Zhu Xiuchang 朱秀昌 ( Wu 2009; The Cooperation Group on Artemisinin of the Institute of Biophysics, CAS 1979). Artemisinin has a chemical structure that is completely different from any antimalarial drug known previously; it is a kind of sesquiterpene lactone containing the peroxy group. The molecule has seven chiral centers, a structural unit that contains 1, 2, 4trioxacyclohexane, and a special chain where carbon atoms and oxygen atoms alternate. It was later learned that the peroxy group is significant, as it is the active antimalarial component in artemisinin.

After the CACMS, the Institute of Biophysics of CAS, and the Institute of Organic Chemistry discussed together and sought for opinions from relevant institutes including the CAMS IMM, a consensus was reached that this determination of artemisinin's structure was reliable. In order to avoid this discovery being published preemptively by scholars in foreign countries, a preliminary decision was made to publish the result as a brief report in Chinese Science Bulletin (Kexue tongbao 科学通报). The first draft, written by Liang Li from the Institute of Biophysics, CAS, was finished in mid-January 1976 (Tu 2009, 44). After the draft had been discussed by researchers and had been approved by the Project Office of Project 523, at the beginning of February 1976, the CACMS reported to the Ministry of Public Health, ${ }^{87}$ asking for permission to publish the report. On February 16, a written reply from the Bureau of Medical Science, Technology, and Education under the Ministry of Public Health agreed to publish it in the name of "The Cooperation Group on Research of Artemisinin's Structure." After Chinese Science Bulletin had prepared the proof, however, the bureau made a phone call, withdrawing its consent. 88 One person concerned recalled later that the reason for not allowing publication was that there had been criticism at the time claiming that scholars were competing to be the first to publish, and that this was driven by a desire for personal fame and gain.

The arrest of the "Gang of Four" on October 6, 1976 marks the actual termination of the "Cultural Revolution." On February 5, 1977, the CACMS ICMM brought the issue of publishing the report to the CACMS,89 which in turn once again asked the Ministry of Public Health for permission. Their request was approved; "Artemisinin: A New Type of Sesquiterpene Lactone" (Yizhong xinxing de beibantie neizhi: Qinghaosu 一种

87 Research on the Antimalarial Effect of Qinghao. No. 19861017 of the Science and Technology Archives (photocopy), the Institute of Chinese Materia Medica of the China Academy of Chinese Medical Sciences, Beijing (hereafter "Research on the Antimalarial Effect of Qinghao. No. 19861017").

88 Research on the Antimalarial Effect of Qinghao. No. 19861017.

89 Research on the Antimalarial Effect of Qinghao. No. 19861017. 
新型的倍半萜内酯——青蒿素) was then published in the third issue of Chinese Science Bulletin of 1977 (Figure 20). This was the first publication ever on research about artemisinin (The Cooperation Group on Research of Artemisinin's Structure 1977). Concerned about giving away the secret of antimalarial drugs, the authors of this article only reported that they had separated a kind of crystal called artemisinin from Artemisia annua. L, a plant of the Asteraceae family, and briefly introduced the crystal's structure; the finding that artemisinin could fight malaria was left out.

Also, since the final form of the publication had not been reviewed by the Institute of Biophysics of CAS, the CACMS ICMM used the relative configuration rather than the absolute configuration (Figure 21).

In March 1978, the National Project Office of Project 523 convened a preparatory meeting for evaluation of the scientific research achievement of using qinghao (huanghuahao) to treat malaria at the Fragrant Hill Hotel in Beijing. The participants wrote a first draft of the evaluation of the achievement, and basically reached a consensus regarding the ranking of participants' contributions to it. The formal Meeting for Evaluation of the Scientific Research Achievement of Using Qinghao (Huanghuahao, Huanghaosu) to Treat Malaria was held in November of the same year in Yangzhou 扬州, Jiangsu Province. The meeting was hosted by the National Leading Group for Research on the Prevention and Control of Malaria, and attended by as many as forty-five institutions from all over the country. There was a heated discussion during the meeting concerning whether to name the antimalarial monomer as qinghaosu or huanghuahaosu without agreement being reached. This was not a purely academic debate, but also related to priority in accomplishing the achievement. The CACMS ICMM insisted on calling the monomer "qinghaosu," which would indicate that it was first obtained by the ICMM. Calling it "huanghaosu" or "huanghuahaosu," however, would imply that it was the Yunnan or the Shandong institute that first obtained this crystal. In the end, the name was settled as qinghaosu, as "qinghao" was the name of the traditional Chinese materia medica.

The Chinese national award system for scientific and technological achievements had had its work suspended from 1965 to 1976. On December 28, 1978, an edited Regulations of the People's Republic of China on Awards for Inventions (Zhonghua Renmin Gongheguo faming jiangli tiaoli 中华人民共和国发明奖励条例) was issued by the State Council and the selection of state awards for inventions was restarted. In September 1979, the State S\&T Commission's Invention Awards Selection Committee convened its third meeting to review fifteen inventions. "Artemisinin: The New Antimalarial Drug" (抗疮新药——青蒿素) was on the list, and won the second prize of the State 


\section{一种新型的倍半萜内酯一一青勱素}

\section{青蒿素告构研究协作组}

我们从菊科植物 Aremisia annua L. 中, 分离出的一种结晶. 定名为青蒿素, 是无色 针状结晶, 熔点 $156-157^{\circ} \mathrm{C},[\alpha]_{D}^{17}=+66.3^{\circ}$ $(\mathrm{C}=1.64$, 氯仿), 高分辨质谱 $(\mathrm{m} / \mathrm{e}$ $\left.282.1472 \mathrm{M}^{+}\right)$及元素分析(C63.72\%, 7.86\%)

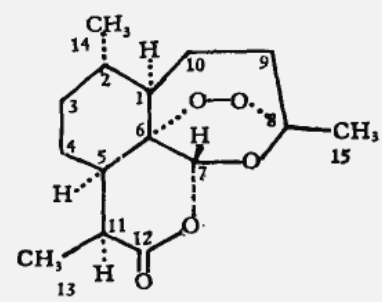

表示其分子式 为 $\mathrm{C}_{15} \mathrm{H}_{22} \mathrm{O}_{5}$. 根 据光谱数据和 $\mathrm{X}$-射线分析以 及化学反应, 证明其为一种 新型的倍半萜 内酯, 具有左

列的相对构型.

红外光谱(澳化钾)具有一个六元环内酯 (1745 厘米 $\left.{ }^{-1}\right)$ 和过氧基团 $(831,881,1115$ 厘 $\left.*^{-1}\right)$. 不含双键. 无紫外吸收.

质子 $\left({ }^{1} \mathrm{H}\right.$ ) 共振谱(四氯化碳, $100 \mathrm{M} \mathrm{Hz}$, 六甲基二硅醚， $\delta$-值） 0.93 (双峰， $3 \mathrm{H}$, $\mathrm{J}={ }^{*} 6 \mathrm{~Hz}, 14-\mathrm{CH}_{3}$ )，1.06 (双峰，3H，J= $6 \mathrm{~Hz}, 13-\mathrm{CH}_{3}$ ), 1.36 (单峰, $3 \mathrm{H}, 15-\mathrm{CH}_{3}$ ), 3.08-3.44 (多峰, 11-H), 炤射此峰, 则 1.06 由双峰变为单峰, 5.68 (单峰, $7-\mathrm{H}$ ).

${ }^{13} \mathrm{C}$ 共振谱(氯仿, $22.63 \mathrm{M} \mathrm{Hz}, \delta$-值) $12,19,23$ (四重峰, 14, 13, 15- $\mathrm{CH}_{3}$ ) , 25, $25.1,37,35.5$ (三重峰, 4, 3, 10, 9- $\mathrm{CH}_{2}$ ), $32.5,33,45,50,93.5$ (双峰, 2, 5, 1, 11, 7-CH), $79.5,105,172$ (单峰, $6,8-\mathrm{C}, 12-\mathrm{C}=0$ ).

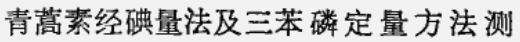
定,证明分子内存在过氧基团. 用钯一碳酸钙 在常温常压下催化氢化或用碱处理即失去过 氧基团. 内酯中的羰基, 能被嗍氢化钠或二 异丁基铝氢还原成差基, 此羟基用铬䣶氧化
又成为原来的羭基.

青蓠素经采用 X-射线单晶衍射方法, 确 定了其晶体结构.

结晶学参数: 空间群 $\mathrm{D}_{2}^{4}-\mathrm{P}_{2_{1}{ }_{1}{ }_{1}{ }_{1}}$, 晶胞参 数 $a=24.098 \AA, b=9.468 \AA, c=6.399 \AA$, 密度: 实验 $d_{0}=1.30$ 克/厘米 ${ }^{3}$, 计算 $d_{c}$

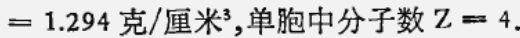

衍射强度数据是由 phillips 四圆衍射仪 收集, 采用石墨单色器 $\left(2 \theta_{M}=26.6^{\circ}\right), \mathrm{CuK}_{2}$ 辐射 $(\lambda=1.5418 \AA)$, 收到了 $\theta$ 小于 $58^{\circ}$ 的 全部强度数据, 独立的衍射点为 810 个, 可观 察的衍射点 619 个.

利用符号附加法得到相角,经 $\operatorname{tg}$ 公式修 正, 由此获得 $\mathrm{E}$ 图, 应用傅里叶综合法作电子 密度函数的逼近, 获得了全部非氢原子的结 构信息，确定了青蓠素的分子结构 (图 1).

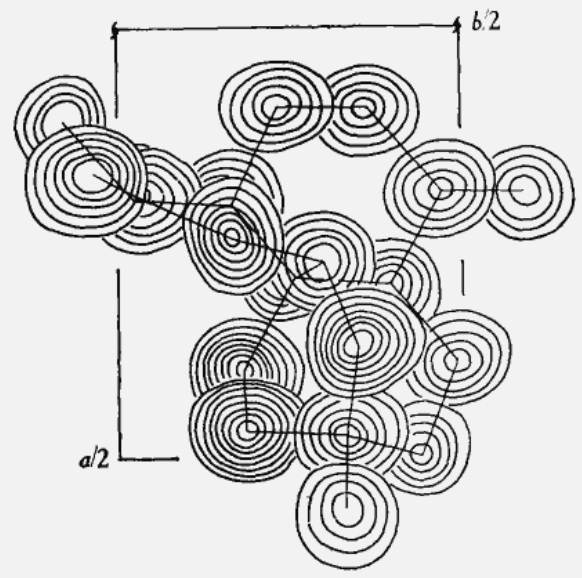

图 1 青蓠素晶体结构三维电子密度叠合图

本文 1976 年 2 月 20 日收到.

- $250 \mathrm{MHz}$ 数据, $100 \mathrm{MHz}$ 时, 裂距较小.

$\cdot 142$.

Figure 20: The article published in Chinese Science Bulletin in 1977, under the name of "The Cooperation Group on Research of Artemisinin's Structure." 


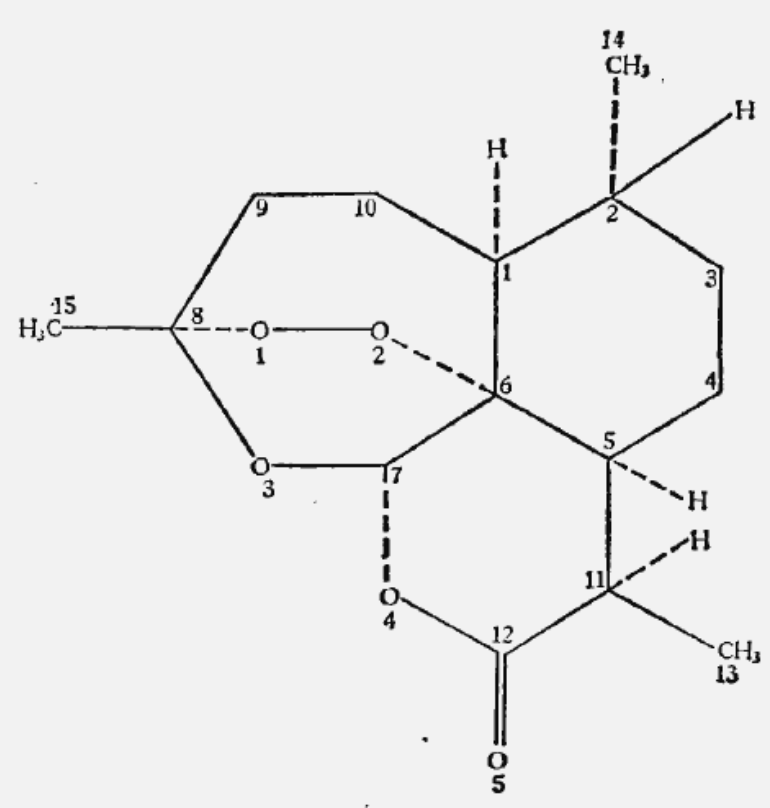

Figure 21: The absolute configuration of artemisinin (The Cooperation Group on Artemisinin of the Institute of Biophysics, CAS 1979, 1114).

Technological Invention Award (Figures 22 and 23). Six inventors were recognized on the certificate, namely the CACMS ICMM, which belongs to the Ministry of Public Health, the Shandong Institute of Chinese Medicine, the Yunnan Institute of Materia Medica, the Institute of Biophysics of CAS, the Institute of Organic Chemistry, and the Guangzhou College of Chinese Medicine. The "etc." (deng 等) that follows probably refers to the Sichuan Institute of Chinese Materia Medica and the Medical Research Group of the Health Bureau of Gaoyou, Jiangsu Province, the two organizations that had been admitted onto the list submitted during the March 1978 meeting held at the Fragrant Hill Hotel (Zhang J. 2018, 63).

\section{The R\&D and marketization of Chinese new antimalarial drugs}

\subsection{R\&D supported by "Project 523" and the Steering Committee on Artemisinin}

Newly synthesized antimalarial drugs that have new chemical structures have produced even more remarkable results compared to drugs based on artemisinin and its derivatives (Zhang J. 2018, 140; Zhang, Li, and Rao 2017, 216-217). In 2000, the United Nations proposed the Millennium Development Goals (MDG). In 2015, the malaria MDG target (The World Health Organization and the United Nations 


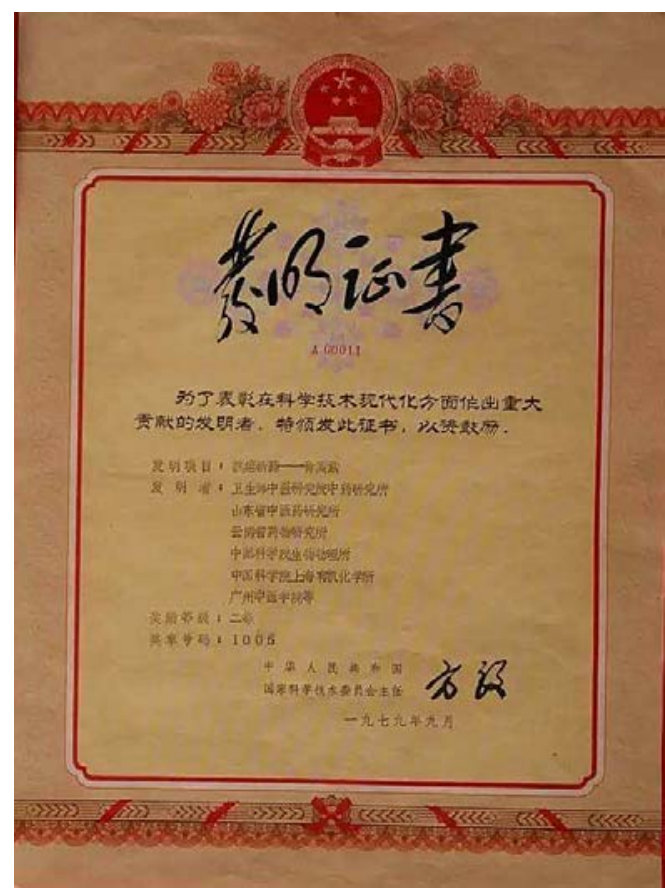

Figure 22: The certificate of artemisinin's State Technological Invention Award, which was won in September 1979. Provided by $\mathrm{Tu}$ Youyou; photo by $\mathrm{Li}$ Runhong.

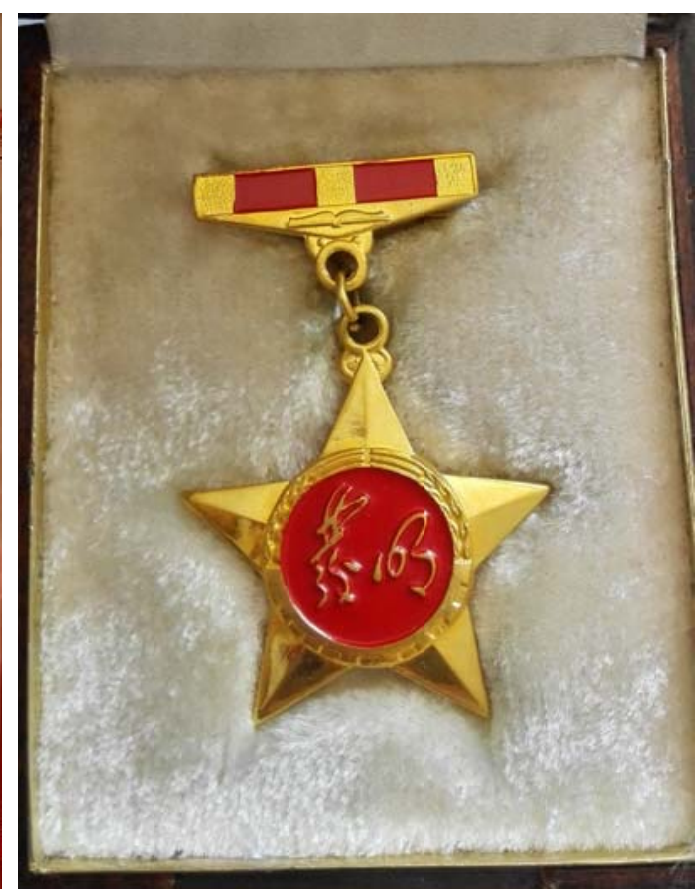

Figure 23: The medal that came with the State Technological Invention Award won by artemisinin. Provided by Tu Youyou; photo by Li Runhong.

Children's Fund 2015) was successfully reached, which was described as "one of the great public health success stories" (The World Health Organization 2015). The artemisinin-based combination therapy (ACT, the compound drugs consist of artemisinin and its derivatives, and chemically-synthesized drugs) made outstanding contributions towards this goal. If we look at its effect in averting clinical malaria cases, ACT contributed around 22\% (Bhatt et al. 2015). In compound drugs, there is a synergistic effect from the two categories of drugs, both of which are indispensable. China's Project 523 and the work of the subsequent Steering Committee of Research and Development on Artemisinin and Its Derivatives in China (hereafter referred to as "Steering Committee on Artemisinin") laid a solid foundation for this. ${ }^{90}$

We can divide China's research and utilization of artemisinin into three phases, namely period of Project 523 (1967-1981), the period of the Steering Committee on Artemisinin (1982-1988), and the period of marketization (1989-present). The achievements of the original research in China played, and have continued to play, an

90 The committee was officially founded after the Ministry of Public Health and the National General Administration of Medicine jointly issued the document [(82) WKZ No. 15]. 
indispensable role in global action to control malaria throughout these three periods $(\mathrm{Li}$ et al. 2015; Li et al. 2018).

The main new antimalarial drugs developed during Project 523 are listed in Table 1.

Table 1: New antimalarial drugs developed through original research in China during the period of Project 523 (1967-1981)

\begin{tabular}{|c|c|c|}
\hline Drug name & R\&D institution and manufacturer & Time of evaluation (in China)* \\
\hline Pyronaridine & $\begin{array}{l}\text { The National Institute of Parasitic Diseases of Chinese Center } \\
\text { for Disease Control and Prevention, Hangzhou Minsheng } \\
\text { Pharmaceutical Factory }\end{array}$ & 1975 \\
\hline Artemisinin & $\begin{array}{l}\text { CACMS ICMM, Shandong Institute of Chinese Medicine, } \\
\text { Yunnan Institute of Materia Medica, Guangzhou College of } \\
\text { Chinese Medicine }\end{array}$ & 1978 \\
\hline Piperaquine phosphate & $\begin{array}{l}\text { State Institute of Pharmaceutical Industry in Shanghai, } \\
\text { Second Military Medical University }\end{array}$ & $1978^{* *}$ \\
\hline Artesunate injection & $\begin{array}{l}\text { Guilin Pharmaceutical Factory (nowadays Guilin } \\
\text { Pharmaceutical Corporation [Fosun]), Guilin No. } 2 \\
\text { Pharmaceutical Factory (nowadays Guilin Pharmaceutical } \\
\text { Corporation [Fosun]), Guangxi Medical College, Guangxi } \\
\text { College of Chinese Medicine }\end{array}$ & 1980 \\
\hline Artemether injection & $\begin{array}{l}\text { Shanghai Institute of Materia Medica, Kunming } \\
\text { Pharmaceutical Factory (nowadays Kunming Pharmaceutical } \\
\text { Inc. [Holley]) }\end{array}$ & 1981 \\
\hline Lumefantrine & $\begin{array}{l}\text { AMMS Institute of Microbiology and Epidemiology } \\
\text { (hereafter "the AMMS IME"). R\&D started in } 1976 .\end{array}$ & Unevaluated \\
\hline
\end{tabular}

* In the 1970s and the 1980s, the R\&D and regulation system for drugs in China was not as rigorous as the present day, and international standards, such as those of FDA, GMP, or GLP, were not enforced. Many drugs would be put into production having only been evaluated by invited professionals in the province or institute from which they originated, and then put into use. Such remedies were accepted as "drugs" in the Chinese context.

** Piperaquine phosphate $(\mathrm{PQP})$ was first developed by China. It was used for long-term malaria prevention in the late 1960s and had wholly replaced chloroquine by 1978 in regions throughout the country where malaria p.f. was endemic. Hydroxypiperquine phosphate was evaluated in 1975 (in the Meeting for the Evaluation and Certification of Chemically-Synthesized Drugs in Project 523, held on December 24, 1975).

The English paper on the study of artemisinin's antimalarial effect in China attracted international attention after its publication in 1979 (Qinghaosu Antimalarial Coordinating Research Group 1979). This was also the year when China renewed its relations with the World Health Organization (WHO). From September 29 to October 15, 1978, China's Minister of Health, Jiang Yizhen 江一真, and the WHO DirectorGeneral Dr. Halfdan T. Mahler met in Beijing to discuss expanding cooperation between China and the WHO. They signed the "Memorandum on Technical Cooperation on Health between the Ministry of Public Health of the PRC and the WHO" in Beijing, which included "research on artemisinin's antimalarial activity and mechanism of action in animal models." In 1980, Dr. Mahler wrote to the Minister of Public Health of China, requesting to hold a special meeting of the Scientific Working 
Group on the Chemotherapy of Malaria (SWG-CHEMAL) on artemisinin-based antimalarial drugs. In October 1981, the fourth meeting of TDR/SWG-CHEMAL was held in Beijing, sponsored by the United Nations Development Programme (UNDP), the World Bank, and the WHO Special Programme for Research and Training in Tropical Diseases. ${ }^{91}$ The theme was "Antimalarial Research on Artemisinin and Its Derivatives." At the meeting, the efficacy of various medicines based on artemisinin and its derivatives was summarized according to the research materials produced in China.

Table 2: The efficacy of various drugs based on artemisinin and its derivatives 92

\begin{tabular}{lccccc}
\hline \multirow{2}{*}{ Dosage form } & $\begin{array}{c}\text { Daily dose } \\
\text { (grams per day) }\end{array}$ & Cases & \multicolumn{2}{c}{ Hours until } & Cure rate \\
\cline { 4 - 6 } Artemisinin tablet & 3.2 & 43 & 34 & 41 & $22 \%$ \\
\hline Artemisinin tablet & 5.0 & 14 & 36 & 27 & $55 \%$ \\
\hline Artemisinin suppository & 0.9 & 68 & 32 & 30 & $89 \%$ \\
\hline Artemether & 0.6 & 180 & 22 & 29 & $94 \%$ \\
\hline Artesunate & 0.4 & 159 & 26 & $48 \%$ \\
\hline
\end{tabular}

After this meeting, on October 12, 1981, another meeting called "Cooperation between Chinese Research Institutions and TDR/SWG-CHEMAL on Antimalarial Research of Artemisinin and Its Derivatives" was held in Beijing. It pointed out that the major problem in China's research on artemisinin and its derivatives was the lack of data on pharmacokinetics and toxicology. The meeting also discussed the priorities in cooperative research with TDR/SWG-CHEMAL, so as to lay a foundation for China's potential international registration of artemisinin and its derivatives. The meeting proposed that the Chinese government establish a small steering committee (i.e. the subsequent Steering Committee on Artemisinin) as the counterpart of the WHO/TDR organization to execute the plan and ensure effective organization and coordination. ${ }^{93}$ The Steering Committee on Artemisinin set up in 1982 decided that the purpose and emphasis of the research were "prioritizing collecting preclinical pharmacological and toxicological data through experiments on artesunate for injection, artemether oil injection, and artemisinin oral preparation, according to the requirement of internationally registered new drugs, so as to lay a foundation for the three drugs to be

91 After Project 523 had been brought to an end in March 1981, principal members of the Project Office were temporarily seconded to the Department of Science and Technology of the Ministry of Public Health to prepare for this meeting.

92 Internal document: The Preparatory Group, ed. "A Brief Report on the Preparatory Work for the Meeting of Development of Antimalarial Artemisinin and Its Derivatives (No. 1)" (青蒿素及 其衍生物的发展会议筹备工作简报 [第一期]), July 10, 1981.

93 Internal minutes of the meeting "Cooperation between Chinese Research Institutions and TDR/SWG-CHEMAL on Research of Antimalarial Artemisinin and Its Derivatives," October 12, 1981. 
commercialized and internationally registered."94 The R\&D and domestic registration of the three new antimalarial preparations, namely artesunate injection, artemether injection, and artemisinin suppositories, were completed under the leadership of the Steering Committee on Artemisinin. The committee also subsidized the development of other new antimalarial drugs in China (Table 3), and the industrial production of artemisinin in Youyang, Sichuan Province. Despite this work, the committee was wound up before the new antimalarial drugs entered the market. 95

\subsection{R\&D of artemisinin-based combination therapy}

From January 5 to January 8, 1982, a meeting concerning research on artemisinin and its derivatives, convened by the Ministry of Public Health and the National General Administration of Medicine, was held in Beijing. In addition to establishing the Steering Committee on Artemisinin, the meeting mainly discussed the plan for international cooperation that would be discussed with the TDR/SWG-CHEML experts who would visit Beijing between February 1 and February 14. Teng Xihe 滕翕和 from the AMMS drafted the research plan that would be put forward, which included looking into the use of combination therapies to delay the emergence of artemisinin resistance. This was the first suggestion to study compound drugs from the point of view of delaying the emergence of drug resistance.

In the early stage of the R\&D of artemisinin, with regard to clinical use, there was a relatively high relapse rate for patients in the short term. In order to improve the cure rate, researchers experimented with compounding artemisinin and chemical antimalarial drugs already in use, which turned out to have good effects. Zhou Yiqing 周义清 and Teng Xihe from the AMMS submitted an application for further research, entitled "Research on Drug Combinations that Delay Drug-Resistance against Artemisinin” (合并用药延缓青蒿素抗性产生的探索研究), to the Steering Committee on Artemisinin in the second half of 1982, seeking to further improve efficacy, shorten the course of treatment, and delay the emergence of drug-resistance. The application resulted in start-up capital of 20,000 yuan, and another 15,000 yuan the following year.

Traditionally, antimalarial compound drugs selected components that could work together to achieve a synergistic effect, the components being similar in their metabolic half-life. Zhou Yiqing went beyond the traditional practice to compound artemisinin with pyronaridine, lumefantrine, ${ }^{96}$ and mefloquine, and discovered that these kind of

94 “按照国际新药注册标准要求, 优先完成青蒿酯钠水注射剂、蒿甲醚油注射剂和青蒿素口服制 剂的临床前药理毒理实验资料, 为进一步实现三药商品化和国际注册确立基础。”

95 The Ministry of Public Health and the National General Administration of Medicine issued a document officially winding up the Steering Committee on Artemisinin on June 13, 1988.

96 Lumefantrine was developed by Deng Rongxian 邓蓉仙, Teng Xihe 滕翕和, and their colleagues from the AMMS. This was one of the achievements from the period of Project 523. 
Table 3: New antimalarial drugs developed through original research in China that received financial aid from the Steering Committee on Artemisinin between 1982 and 1988

\begin{tabular}{|c|c|c|}
\hline Drug name & R\&D institution and manufacturer & Year of certification \\
\hline $\begin{array}{l}\text { Pyronaridine phosphate } \\
\text { tablets and injection }\end{array}$ & $\begin{array}{l}\text { National Institute of Parasitic Diseases of Chinese Center for Disease } \\
\text { Control and Prevention, Hangzhou Minsheng Pharmaceutical Factory }\end{array}$ & 1985 \\
\hline $\begin{array}{l}\text { API (Active } \\
\text { pharmaceutical } \\
\text { ingredient) of artemisinin }\end{array}$ & CACMS ICMM $^{*}$ & 1986 \\
\hline Artemisinin suppository & $\begin{array}{l}\text { CACMS ICMM, Guangzhou Baiyunshan Pharmaceutical Factory, } \\
\text { Guangzhou College of Chinese Medicine }\end{array}$ & 1986 \\
\hline API of artesunate & $\begin{array}{l}\text { Guilin Pharmaceutical Factory (nowadays Guilin Pharmaceutical } \\
\text { Corporation [Fosun]), State Institute of Pharmaceutical Industry in } \\
\text { Shanghai, AMMS IME, CACMS ICMM, CAMS IMM, Shanghai } \\
\text { Institute of Materia Medica, Guangxi Medical College, Guangxi } \\
\text { College of Chinese Medicine }\end{array}$ & 1987 \\
\hline Artesunate for injection & $\begin{array}{l}\text { State Institute of Pharmaceutical Industry in Shanghai, Guilin No. } 2 \\
\text { Pharmaceutical Factory (nowadays Guilin Pharmaceutical } \\
\text { Corporation [Fosun]), Guangzhou College of Chinese Medicine }\end{array}$ & $1987\left(2010^{* *}\right)$ \\
\hline Artesunate tablets & Guilin Pharmaceutical Factory & 1988 \\
\hline API of artemether & Shanghai Institute of Materia Medica, Kunming Pharmaceutical Factory & 1987 \\
\hline Artemether for injection & Kunming Pharmaceutical Factory & 1987 \\
\hline $\begin{array}{l}\text { API and gel pills of } \\
\text { lumefantrine }\end{array}$ & AMMS IME, Kunming Pharmaceutical Factory & 1987 \\
\hline $\begin{array}{l}\text { API and tablets of } \\
\text { dihydroartemisinin }\end{array}$ & CACMS ICMM, Beijing No. 6 Pharmaceutical Factory & 1992 \\
\hline $\begin{array}{l}\text { Tablets of compound } \\
\text { artemether (Lumefantrine } \\
+ \text { Artemether) }\end{array}$ & AMMS IME, Kunming Pharmaceutical Factory & 1992 \\
\hline $\begin{array}{l}\text { Naphthoquine phosphate } \\
\text { tablets }\end{array}$ & AMMS IME & 1993 \\
\hline
\end{tabular}

* The application documents for the active pharmaceutical ingredient (API) of artemisinin included the work accomplished by many institutions during Project 523. The certification for the new drug, however, was given exclusively to the CACMS ICMM, which is now regarded as a mistake of the government. Permissions to produce artemisinin were only granted to the Guangzhou Baiyunshan Pharmaceutical Factory, which never actually produced any artemisinin, and the Kunming Pharmaceutical Factory. Control over the production of artemisinin was lifted after 2000; as a consequence, the number of manufacturers of artemisinin in China reached over eighty at one time. In contrast, less than five enterprises have permission to produce the API of artemisinin.

* Guilin Pharmaceutical Corporation [Fosun] passed the WHO's prequalification for suppliers in 2010.

prescriptions were rapid-acting, could achieve a high curative effect, and delayed the drug-resistance of artemisinin and its derivatives. Ning Dianxi 宁殿胥 from the AMMS processed various experimental data of using new Chinese antimalarial drugs against rodent malaria and monkey malaria, and in the end came up with the optimal ratio of 1:6 in the compound consisting of artemether and lumefantrine. Compound artemether tablet was thus developed with the financial support of the Kunming Pharmaceutical Factory and Ning Dianxi as the project leader. In 1992, it passed the national new drug review. In 1990, through CITIC Technology Inc.'s cooperation with 
the Swiss company CIBA-Geigy (now Novartis AG), compound artemether tablet took the lead in entering the international market, to be followed by other new antimalarial ACTs (Table 4).

Table 4: ACTs currently in use throughout the world that contain new chemical antimalarial drugs developed through original research in China

\begin{tabular}{|c|c|c|c|}
\hline ACT name & Brand & Manufacturer & $\begin{array}{c}\text { Year of } \\
\text { international } \\
\text { registration }\end{array}$ \\
\hline Lumefantrine-Artemether & Coartem, Riamet & Novartis AG & 1998 \\
\hline $\begin{array}{l}\text { Piperaquine }\left(\mathrm{PO}_{4}\right)- \\
\text { Dihydroartemisinin }\end{array}$ & Duo-Cotecxin (Artekin) & $\begin{array}{l}\text { Kunming Pharmaceutical Inc. } \\
\text { (Holley) }\end{array}$ & $2002^{*}$ \\
\hline $\begin{array}{l}\text { Naphthoquine }\left(\mathrm{PO}_{4}\right) \\
\text {-Artemisinin }\end{array}$ & Arco & $\begin{array}{l}\text { Kunming Pharmaceutical Inc. } \\
\text { (Holley) }\end{array}$ & $2003^{*}$ \\
\hline Piperaquine-Artemisinin & Artequick & Artepharm Co., Ltd. & $2006^{*}$ \\
\hline $\begin{array}{l}\text { Piperaquine }\left(\mathrm{PO}_{4}\right)- \\
\text { Dihydroartemisinin }\end{array}$ & Eurartesim & Alfasigma S.p.A (Sigma-Tau) & 2011 \\
\hline Pyronaridine-Artesunate & Pyramax & $\begin{array}{l}\text { Shin Poong Pharmaceutical Co., Ltd. } \\
\text { (South Korea) }\end{array}$ & 2012 \\
\hline
\end{tabular}

${ }^{*}$ Time of new drug certification in China.

Li Guoqiao's team from the Guangzhou University of Chinese Medicine was probably the first in the world to start studying and using compounds of artemisinin and its derivatives. As early as 1978 (Zhang, Zhu, and Li 2019), taking advantage of their cooperation with Keith Arnold (the head of the Roche Far East Research Foundation) on the antimalarial mefloquine, they began randomized controlled clinical trials using combinations of artesunate and mefloquine to treat malaria p.f. In August 1982, an article titled "Antimalarial Activity of Mefloquine and Qinghaosu" was published in The Lancet (Jiang et al. 1982) (Figure 24), probably the first paper published internationally on the combination of artemisinin and other drugs. Based on this research, the combination of artesunate and mefloquine became widely used in Southeast Asia. Li Guoqiao's team started to promote the method of Fast Elimination of Malaria by Source Eradication (FEMSE) in 1996 in Vietnam, Cambodia, and Comoros, and achieved significant results.

After the Steering Committee on Artemisinin was wound up, the State S\&T Commission took charge of coordinating international cooperation concerning new artemisinin-based antimalarial drugs. In the second half of 1989, the Department of Social Development of the State S\&T Commission signed the "Contract regarding the Exploitation of the International Market for Artemisinin-Based Antimalarial Drugs" (开 拓青蒿素类抗疮药国际市场合同) with more than ten large Chinese state-owned 


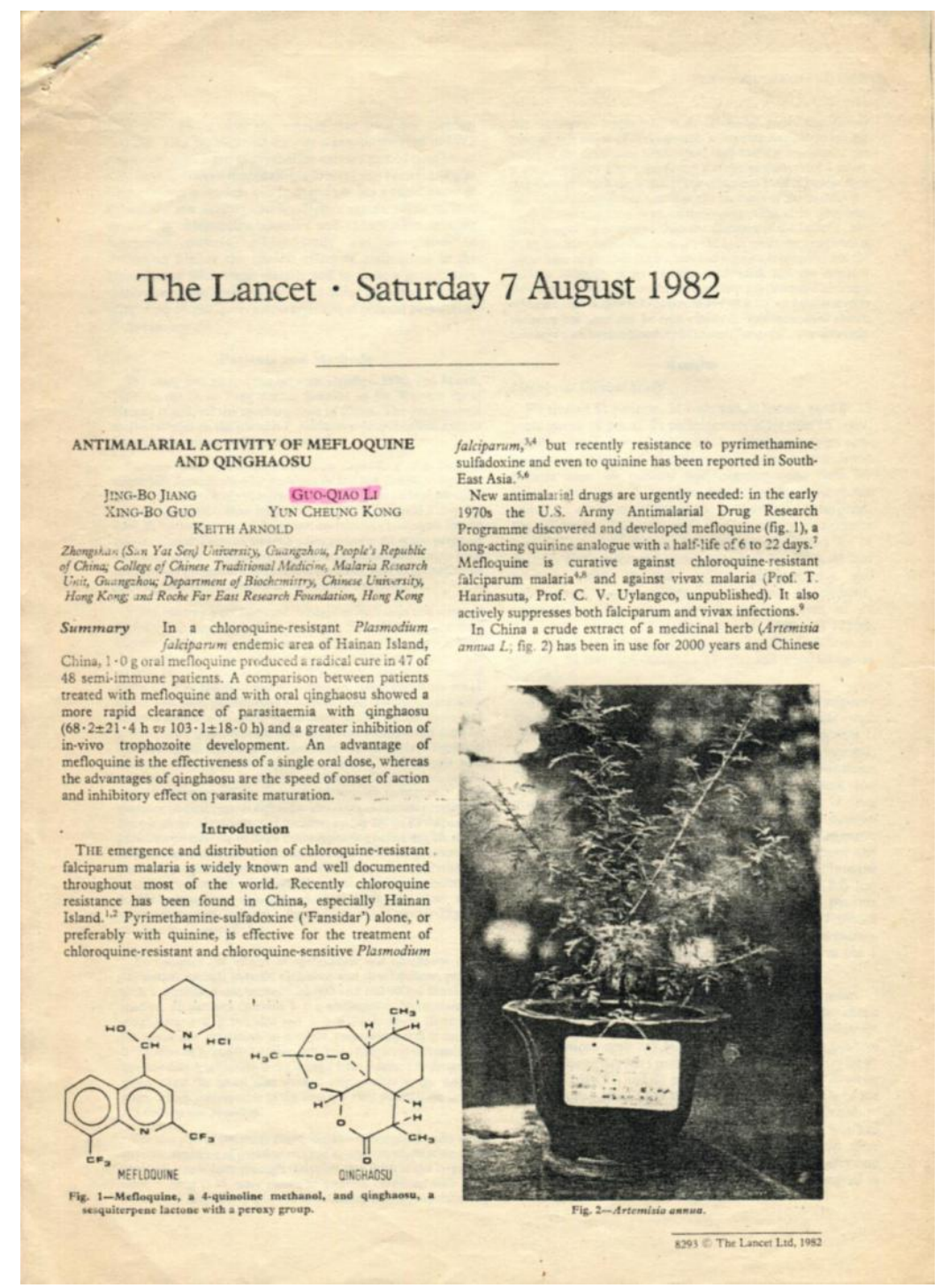

Figure 24: The article titled "Antimalarial Activity of Mefloquine and Qinghaosu" published in The Lancet (Jiang et al. 1982, 285).

foreign trade companies including CITIC Technology Inc. On September 20, 1994, CIBA-GEIGY (one of the predecessors of Novartis AG), CITIC Technology Inc., the AMMS IME, and the Kunming Pharmaceutical Factory signed a "License \& Development Agreement" for cooperative development of the new artemisinin-based antimalarial medicines. On October 17, the agreement was approved by the Department of Social Development, which marked the first multi-component drug developed by independent original research in China to enter the international market. To date, more than three billion treatments of the branded drug from Novartis AG 
(Coartem) and the generic drug from India have been supplied (The World Health Organization 2019, 45). In addition, with the support of the Medicines for Malaria Venture (MMV), the artesunate injection produced by Guilin Pharmaceutical Factory, which was domestically registered in 1986, also passed the WHO drug prequalification in 2010. It is used to save the lives of severe malaria patients, with more than 150 million vials supplied worldwide (Medicines for Malaria Venture 2019, 24).

Now ACT drugs and artesunate injection have been selected as essential medicines for the treatment of malaria p.f. and severe malaria. For many years, Li Guoqiao's team from Guangzhou University of Chinese Medicine have been combining artemisininbased drugs and small doses of primaquine to treat patients and halt the transmission of parasites. Their method has been clinically verified in the Comoros with good results.

\section{Conclusion}

The year 1967 saw the peak convulsions of the "Cultural Revolution," when most scientific research in China was suspended. As a special national program linked to war preparation, Project 523 was shielded from many of the distractions resulting from the turbulent social environment and was able to carry out its tasks relatively smoothly. All the participating institutions and researchers followed the instructions of the national government, so that different departments, places, institutions, and their researchers, as well as the military and local government, could unite as one to collaborate closely. They shared scientific equipment and technology freely, and when one of the participating units met difficulties, others would provide help. This ensured the final completion of Project 523. The project not only satisfied the nation's diplomatic and political needs, but also effectively promoted research and development of new drugs. Artemisinin and its derivatives, as well as many other chemical drugs that prevent or control malaria, were all developed through such large-scale cooperation.

The discovery of artemisinin followed the rules and processes for discovering effective medicinal components in plants (Dong 2019, 149). What made this case special was the availability of rich resources of traditional Chinese medical literature, as well as a cooperation mechanism whereby the state was prioritized, and politics and scientific research intersected. It is an example of combining collecting and reviewing literature on traditional Chinese medicine and modern research methods of pharmacy. It is also a typical example of tasks leading scientific research. Project 523 was an extraordinary achievement of the collective wisdom and efforts of Chinese scientists. It concentrated large amounts of human, material, and financial resources, achieved the expected goal in a short period of time, and trained a large number of skilled personnel who specialized in research on antimalarial drugs. Tu Youyou is thus a prominent representative of a special period of doing experiments through "large-scale 
cooperation." Political needs, scientific research, and the Chinese administrative system all had their role to play in the implementation of such a project. Having characteristics specific to both China and that era, the project is historically significant and difficult for other countries to replicate. This demonstrates the uncertainties inherent in scientific research projects, and that they are usually shaped by intertwining factors.

The construction of scientific knowledge is influenced by social factors. Problems and divergences of opinion, both institutional and personal, concerning the ownership of intellectual property reared up in the context of the extensive scientific cooperation of Project 523. When it came to differences concerning concepts, terms, and theoretical explanations, the construction of knowledge appears to have been negotiable. The research on artemisinin demonstrates that when divergences emerge, it is necessary that there is someone to hold on to an objective perspective and do the right thing. Nevertheless, it is not very easy for such an individual to step forward in China even today.

Artemisinin and its derivatives have proved to be highly effective, rapid-acting, of low toxicity, and without cross resistance in treating malaria. The artemisinin-based compound drugs have become the first choice internationally in the treatment of malaria, and have made significant contributions to relieving the suffering of patients across the world. The discovery of artemisinin is thus rightly regarded as "one of the great collaborative scientific activities in the latter half of the twentieth century" (Lague 2002). ${ }^{97}$

\section{Acknowledgments}

The author would like to thank Zeng Meiyi 曾美怡, Wu Yulin 吴毓林, Liu Tianwei 刘 天伟, and Su Jingjing 苏静静 for their valuable suggestions.

\section{References}

Bhatt, S., et al. 2015. "The Effect of Malaria Control on Plasmodium Falciparum in Africa Between 2000 and 2015." Nature 526 (7572): 207-211.

Chen, Haifeng 陈海峰. 2002. Chen Haifeng ying wen ji 陈海峰影文集 [Collection of Chen Haifeng's Photography and Writings]. Shijiazhuang: Editorial Office of Zhongguo yixue lilun yu shijian 中国医学理论与实践 [Theories and Practice of Medical Science in China].

Chen, Xiu 陈修. 1957. Yadanzi kangnüe liaoxiao yu duxing fanying de linchuang shiyan 鸦胆子抗疮疗 效与毒性反应的临床实验 [Clinical Experiments on Yadanzi's Antimalarial Effect and Toxic Reaction]. Zhonghua yixue zazhi 中华医学杂志 [National Medical Journal of China] (9): 721-724. Chou, T. Q., Fu F. Y., and Kao Y. S. 1948. "Antimalarial Constituents of the Chinese Drug Ch'ang Shan, Dichroa febrifuga Lour." Journal of the American Chemical Society 70 (5): 1765-1767.

97 Said by Professor Richard K. Haynes, Hong Kong University of Science and Technology. 
Chou, T. Q., Jang C. S., Fu F. Y., Kao Y. S., and Huang K. C. 1947. "Antimalarial Element, Dichroine, Contented in Dichroa fabrifuga." Chinese Medical Journal 65:189.

The Cooperation Group on Artemisinin of the Institute of Biophysics, CAS. 1979. “Qinghaosu de jingti jiegou jiqi juedui gouxing” 青蒿素的晶体结构及其绝对构型 [The Crystal Structure and Absolute Configuration of Artemisinin]. Zhongguo kexue 中国科学 [Scientia Sinica] (11): 11141128.

The Cooperation Group on Research of Artemisinin's Structure. 1977. "Yizhong xinxing de beibantie neizhi: Qinghaosu” 一种新型的倍半萜内酯——青高素 [Artemisinin: A New Type of Sesquiterpene Lactone]. Kexue tongbao 科学通报 [Chinese Science Bulletin] 22 (3): 142.

Dong, Jielin 董洁林. 2019. Renlei keji chuangxin jianshi: Yuwang de liliang 人类科技创新简史: 欲望 的力量 [A History of Human Beings' Scientific Innovation: The Power of Desire]. Beijing: China CITIC Press.

The Editorial Committee of Zhongguo nüeji de fangzhi yu yanjiu. 1991. Zhongguo nüeji de fangzhi yu yanjiu 中国疮疾的防治与研究 [Prevention, Control, and Study of Malaria in China]. Beijing: People's Medical Publishing House.

The Editorial Group of Tu Youyou zhuan. 2015. Tu Youyou zhuan 屠呦呦传 [A Biography of Tu Youyou]. Beijing: People's Publishing House.

Fan, Wanfu 樊万福. 1952. “Yadanzi zhiliao nüeji 27 li baogao” 鸦胆子治疗疮疾 27 例报告 [Report on 27 Cases of Malaria Treated with Yadanzi]. Yiyaoxue 医药学 [Medical Science] 5 (1): 28-29.

Fu, Fengyong 傅丰永, et al. 1956. “Changshan ye zhong quanshengwujian hanliang ceding fa de yanjiu” 常山叶中全生物碱含量测定法的研究 [Research on the Method to Determine the Content of Total Alkaloids in Changshan Leaves]. In Zhongguo Yixue Kexueyuan 1956 nian lunwen baogaohui lunwen zhaiyao 中国医学科学院 1956 年论文报告会论文摘要 [Selection of the Papers Presented during the 1956 Symposium of Chinese Academy of Medical Sciences], vol. I:18-20.

Fu, F. Y., and Jang C. S. 1948. “Chemotherapeutic studies on Ch'ang Shan dichroa febrifuga. III. Potent antimalarial alkaloids from Ch'ang Shan." Science and Technology in China 1 (3): 56-61.

Hong, Xin 洪欣, Li Huairong 李怀荣, et al. ed. 2005. Zhongguo Zhongyi Yanjiuyuan wushinian licheng (1955-2005) 中国中医研究院五十年历程 (1955 2005) [Five Decades of the China Academy of Chinese Medical Sciences (1955-2005)]. Beijing: Ancient Chinese Medical Books Publishing House.

Hsu, Elisabeth. 2009. "Diverse Biologies and Experiential Continuities: Did the Ancient Chinese Know That Qinghao Had Anti-Malarial Properties?" Canadian Bulletin of Medical History 26 (1): 203-213.

$\mathrm{Hu}$, Xiaofeng 胡晓峰. 2008. “'Wenge' shiqi Zhongcaoyao zhuzuo gaishu” 文革时期中草药著作概 述 [A Summary of Works on Chinese Herbal Medicine during the "Cultural Revolution"]. Zhongguo Zhongyao zazhi 中国中药杂志 [Chinese Journal of Chinese Materia Medica] 33 (24): 2988-2991.

Hu, Zhimin 胡治民. 1958. “Shiyong Zhongyao Mabiancao zhiliao 31 li nüeji liaoxiao baogao" 试 用中药马鞭草治疗 31 例疮疾疗效报告 [Report on 31 Cases of Malaria Treated with Mabiancao]. Zhongyi zazhi 中医杂志 [Journal of Traditional Chinese Medicine] (3): 188-190.

Huang, Songping 黄松平, and Zhu Yazong 朱亚宗. 2012. “Keji faming quan yu Tu Youyou 
Qinghaosu faxian zhengduan de huajie” 科技发明权与屠呦呦青蒿素发现争端的化解 [Science and Technology Inventor's Rights and Resolution of the Debate over Tu Youyou's Discovery of Artemisinin]. Ziran bianzhengfa tongxun 自然辩证法通讯 [Journal of Dialectics of Nature] 28 (1): 86-90.

Institute of Materia Medica, Chinese Academy of Medical Sciences. 1972a. Tiqu, fenli, jianding he hanliang ceding 提取、分离、鉴定和含量测定 [Extraction, Separation, Identification, and Content Determination]. Vol. 1 of Zhongcaoyao youxiao chengfen de yanjiu 中草药有效成分的研究 [Studies on the Effective Components of Chinese Herbal Medicine]. Beijing: People's Medical Publishing House.

Institute of Materia Medica, Chinese Academy of Medical Sciences. 1972b. Yaowu shaixuan fangfa 药物筛选方法 [Methods of Drug Screening]. Vol. 2 of Zhongcaoyao youxiao chengfen de yanjiu. Beijing: People's Medical Publishing House.

Jang, C. S., Fu F. Y., Huang K. C., and Wang C. Y. 1948. “Pharmacology of Ch'ang Shan (Dichroa febrifuga), a Chinese Antimalarial Herb." Nature 161:400-401.

Jang, C. S., Fu F. Y., Wang C. Y., Huang K. C., Lu G., and Chou T. C. 1946. “Ch'ang Shan, A Chinese Antimalarial Herb." Science 103 (2663): 59.

Ji, Weiping 季伟萍, ed. 2016. Fengyu liushi nian: Shanghaishi Zhongyi Wenxianguan guanshi (19562015) 风雨六十年：上海市中医文献馆馆史 （1956 2015） [Six Decades of Ups and Downs: History of the Shanghai Literature Institute of Traditional Chinese Medicine (1956-2015)]. Guilin: Guangxi Normal University Press.

Jiang, Jing-Bo, Xing-Bo Guo, Guo-Qiao Li, Yun Cheung Kong, and Keith Arnold. 1982. “Antimalarial Activity of Mefloquine and Qinghaosu." The Lancet 320 (8293): 285-288.

Jiang, Xiangchun 蒋祥春. 2016. “Qinghaosu faxian zhong de wenxianxue siwei” 青蒿素发现中的 文献学思维 [Thinking Model of Philology in the Discovery of Artemisinin]. Keji guangchang 科 技广场 [Science Mosaic] (7): 107-109.

Lague, David. 2002. "Chinese Medicine: Revolutionary Discovery." Far Eastern Economic Review, March 14, 2002, 34-37.

Lei, Sean Hsiang-lin. 1999. "From Changshan to a New Anti-Malarial Drug: Re-networking Chinese Drugs and Excluding Chinese Doctors." Social Studies of Science 29 (3): 323-358.

Li, Guoqiao 李国桥, Li Ying 李英, Li Zelin 李泽琳, and Zeng Meiyi 曾美怡. 2015. Qinghaosu lei kangnüe yao 青蒿素类抗疮药 [Artemisinin-Based Antimalarial Drugs]. Beijing: Science Press.

Li, Guoqiao, Li Ying, Li Zelin, and Zeng Meiyi, ed. 2018. Artemisinin-Based and Other Antimalarials. London: Academic Press.

Li, Runhong 黎润红. 2011. “523 Renwu' yu Qinghao kangnüe zuoyong de zaifaxian” “523 任 务”与青高抗疮作用的再发现 [The “523 Project” and the Rediscovery of Sweet Wormwood's Antimalarial Effect]. Zhongguo kejishi zazhi 中国科技史杂志 [The Chinese Journal for the History of Science and Technology] 32 (4): 488-500.

Li, Runhong, and Zhang Daqing 张大庆. 2019. “Qinghaosu: Cong Zhongguo chuantong yaowu dao quanqiu kangnüe liangyao" 青蒿素: 从中国传统药物到全球抗疮良药 [Artemisinin: From Traditional Chinese Medicine to Global Antimalarial Drug]. Zhongguo Kexueyuan yuankan 中国 科学院院刊 [Bulletin of Chinese Academy of Sciences] 34 (9): 1046-1057.

Li, Weipu 李蔚普. 1954. “Qinghao de kangnüe liaoxiao” 青蒿的抗疮疗效 [The Effect of Qinghao 
in Treating Malaria]. Beijing Zhongyi 北京中医 [Beijing Journal of Traditional Chinese Medicine] (9): 17-18.

Liang, Li 梁丽. 2017. “Qinghaosu fenzi he liti jiegou ceding de lishi huigu” 青蒿素分子和立体结 构测定的历史回顾 [Historical Reflection on the Determination of the Molecular and Stereo Structure of Artemisinin]. Shengwu huaxue yu shengwu wuli jinzhan 生物化学与生物物理进展 [Progress in Biochemistry and Biophysics] 44 (1): 6-16.

Liang, Xiaotian 梁晓天, Yu Dequan 于德泉, Wu Weiliang 吴伟良, and Deng Huaichun 邓槐春. 1979. “Yingzhaojiasu de huaxue jiegou" 鹰爪甲素的化学结构 [The Structure of Yingzhaosu A]. Huaxue xuebao 化学学报 [Acta Chimica Sinica] 37 (3): 215-230.

Literature Research Office of the CPC Central Committee, ed. 1992. Jianguo yilai Mao Zedong wengao 建国以来毛泽东文稿 [Mao Zedong's Writings Since the Founding of the People's Republic of China], vol. 7. Beijing: Central Party Literature Press.

Liu, Jingming 刘静明, Ni Muyun 倪慕云, Fan Jufen 㚞菊芬, Tu Youyou 屠呦呦, Wu Zhaohua 吴照华, Wu Yulin 吴艈林, and Zhou Weishan 周维善. 1979. “Qinghaosu de jiegou he fanying” 青蒿素的结构和反应 [Structure and Reaction of Arteannuin]. Huaxue xuebao 37 (2): 129-140.

Liu, Jitang 刘雾堂, and Ling Ziping 凌子平. 2018. “Qinghaosu faming de lishi zhuizong ji qishi” 青蒿素发明的历史追踪及启示 [Tracing the History of the Invention of Artemisinin and Its Inspiration]. Xin Zhongyi 新中医 [Journal of New Chinese Medicine] 50 (3): 1-5.

Liu, Shihe 刘世和. 2017. “Nuobeier Jiang beihou de gushi” 诺贝尔奖背后的故事 [Stories behind the Nobel Prize]. Chongqing Zhongcaoyao yanjiu 重庆中草药研究 [Chongqing Journal of Research on Chinese Drugs and Herbs] (2): 56-58.

Luo, Kaijun 罗开均. 1980. “Kangnüe xinxing yaowu Huanghuahaosu yuan zhiwu de yanjiu” 抗 疮新型药物黄花蒿素原植物的研究 [A Study on the Source Plant of a New Antimalaria Substance Huanghuahaosu]. Yunnan zhiwu yanjiu 云南植物研究 [Acta Botanica Yunnanica] 2 (1): 33-41.

Malaria Prevention Station of Dehong Dai and Jingpo Autonomous Prefecture in Yunnan Province. 1959. “Nüeji fen wenyao zhiliao nüeji he kang fufa de xiaoguo guancha” 疮疾粉闻药 治疗㾏疾和抗复发的效果观察 [Observations on Treating Malaria and Preventing its Relapse by Nasal Delivery of Antimalarial Medicinal Powder]. Zhongyi zazhi (4): 27-29.

Medicines for Malaria Venture. 2019. Annual Report 2019. Last modified July 30, 2020. https://www.mmv.org/sites/default/files/uploads/docs/publications/MMV_AR2019_EN_ 20200730_WEB.pdf.

The Medical Research Group of Gaoyou in Jiangsu Province, and the Epidemic Prevention Station of Gaoyou in Jiangsu Province. 1975. "Qinghao zhiliao nüeji 125 li liaoxiao guancha" 青蒿治疗疮疾 125 例疗效观察 [Observations on Treating 125 Malaria Patients with Qinghao], written by Wang Qi 王琦, Qian Daohong 钱道宏, and Xia Zhiping 夏治平. Shaanxi xin yiyao 陕西新医药 [New Medical Science in Shaanxi] (3): 19-20.

Ministry of Public Health of the People's Republic of China. 1957. Nüeji fangzhi shouce 㾏疾防治手 册 [Handbook of the Prevention and Control of Malaria]. Beijing: Ministry of Public Health of the People's Republic of China.

The Nobel Prize Organization. 2015. “Tu Youyou: Nobel Lecture." Accessed May 18, 2019. https://www.nobelprize.org/prizes/medicine/2015/tu/lecture/. 
Pharmacology Research Laboratory of the Institute of Chinese Materia Medica, China Academy of Chinese Medical Sciences. 1979. “Qinghao de yaoli yanjiu” 青蒿的药理研究 [Pharmacologic Study of Qinghao]. Xin yiyaoxue zazhi 新医药学杂志 [Magazine for New Medicine and Pharmacology] (1): 23-33.

Qinghaosu Antimalarial Coordinating Research Group. 1979. “Antimalaria Studies on Qinghaosu." Chinese Medicine Journal 92 (12): 811-816.

Qiu, Guangming 丘光明, Qiu Long 邱隆, and Yang Ping 杨平. 2001. Zhongguo kexue jishu shi: Duliangheng juan 中国科学技术史 - 度量衡卷 [History of Science and Technology in Premodern China: Weights and Measures]. Beijing: Science Press.

Rao, Yi 饶毅. 2015. “Zhongyao tiqu kangnüe huaxue fenzi diyiren” 中药提取抗疮化学分子第一 人 [The First Person to Extract Antimalarial Chemical Molecules from Traditional Chinese Medicine]. Keji daobao 科技导报 [Science \& Technology Review] (20): 127-131.

Rao, Yi, Li Runhong, and Zhang Daqing. 2016. Xinsuan yu rongyao: Zhongguo kexue de Nuojiang zhilu 心酸与荣耀一一国科学的诺奖之路 [Bitterness and Glory: The Road of Chinese Science towards a Nobel Prize]. Beijing: Peking University Press.

The "Revolutionary Committee" of the China Academy of Chinese Medical Sciences. 1970a. Changjian bing yanfang xuanbian 常见病验方选编 [Selection of Effective Recipes for Common Diseases]. Beijing: People's Medical Publishing House.

The "Revolutionary Committee" of the China Academy of Chinese Medical Sciences. 1970b. Changjian bing yanfang yanjiu cankao ziliao 常见病验方研究参考资料 [References for Research on Effective Recipes for Common Diseases]. Beijing: People's Medical Publishing House.

Shanghai Literature Institute of Traditional Chinese Medicine, ed. 1965. Nüeji zhuanji 疮疾专辑 [Collection on Malaria]. Shanghai: Shanghai Scientific and Technical Publishers.

Su, Xinzhuan 苏新专, and Louis H. Miller. 2015. “Qinghaosu de faxian yu Nuobeier Shenglixue Huo Yixue Jiang” 青蒿素的发现与诺贝尔生理学或医学奖 [The Discovery of Artemisinin and the Nobel Prize in Physiology or Medicine]. Zhongguo kexue: Shengming kexue 中国科学: 生命 科学 [Science China: Life Science] 45 (11): 1148-1152.

Sun, Qingwei 孙清伟. 2015. “Zhongguo Zhongyi Kexueyuan zhuyao jigou yange gaishu” 中国中 医科学院主要机构沿革概述 [A Brief History of the Main Institutions in the China Academy of Chinese Medical Sciences]. Zhonghua yishi zazhi 中华医史杂志 [Chinese Journal of Medical History] 45 (6): 352-355.

Tu, Youyou, ed. 2009. Qinghao ji Qinghaosu lei yaowu 青蒿及青蒿素类药物 [Qinghao and Artemisinin-Based Medicines]. Beijing: Chemical Industry Press.

Wang, Jinying 王进英. 1950. “Yadanzi you kangnüe xiaoneng” 鴉膽子有抗瘧效能 [Yadanzi is Antimalarial]. Kexue tongbao 1 (7): 460.

Wang, Jinying, Fu Fengyong, and Zhang Changshao. 1945. “Guochan kangnüeyao Changshan zhi yanjiu (chubu baogao zhier): Huaxue zhiliao shijian” 国产抗疮药常山之研究 (初步报告之 二) 一一化学治疗实践 [Research on the Domestic Antimalarial Drug Changshan (Preliminary Report No. 2): The Practice of Chemotherapy]. Zhonghua yixue zazhi (Chongqing edition) 31 (2): 159-174.

Wang, Shunyi 王顺义. 2012. “Kexue faxian de youxianquan: Cong Tu Youyou huojiang shuoqi" 科学发现的优先权: 从屠呦呦获奖说起 [Priority in Scientific Discovery: Talking about Tu 
Youyou and the Lasker Award]. Kexue 科学 [Science] 64 (3): 29-33.

The World Health Organization. 2015. “WHO/UNICEF Report: Malaria MDG Target Achieved amid Sharp Drop in Cases and Mortality, but 3 Billion People Remain at Risk." Last modified September 17, 2015. https://www.who.int/news-room/detail/17-09-2015-who-unicef- reportmalaria-mdg-target-achieved-amid-sharp-drop-in-cases-and-mortality-but-3-billion-peopleremain-at-risk.

The World Health Organization. 2019. World Malaria Report 2019. Geneva: World Health Organization.

The World Health Organization, and the United Nations Children's Fund. 2015. Achieving the Malaria MDG Target: Reversing the Incidence of Malaria 2000-2015. Geneva: The WHO Document Production Services. https://www.unicef.org/publications/files/Achieving_the_Malaria_ MDG_Target.pdf.

Wu, Yulin 吴毓林. 2009. “Qinghaosu: Lishi he xianshi de qishi” 青蒿素—一历史和现实的启示 [Qinghaosu (Artemisinin): Revelations from History and Reality]. Huaxue jinzhan 化学进展 [Progress in Chemistry] 21 (11): 2365-2371.

Wu, Yunyi 吴云翼, et al. 1956. “Huang Changshan jian de kangnüe zuoyong he duxing” 黄常山 碱的抗症作用和毒性 [The Antimalarial Effect and Toxicity of Changshan]. In Zhongguo Yixue Kexueyuan 1956 nian lunwen baogaohui lunwen zhaiyao, vol. I, 29-31.

Xie, Li 谢力. 2015. “2015 nian Nuobeier Yixue Jiang zhi santi (san)” 2015 年诺贝尔医学奖之三体 (三) [A Trilogy on the 2015 Nobel Prize in Physiology or Medicine, Part 3]. Last modified October 28, 2015. http:/ / blog.sciencenet.cn/blog-669170-931740.html.

Yuan, Yanan 袁亚男, Jiang Tingliang 姜廷良, Zhou Xing 周兴, and Liu Ying 刘盈. 2017. “Qinghaosu de faxian he fazhan” 青蒿素的发现和发展 [The Discovery and Development of Artemisinin]. Kexue tongbao 62 (18): 1914-1927.

Zhang, Changshao, and Huang Qizhang 黄琪章. 1956. “Changshan jian de yaoli” 常山碱的药理 [The Pharmacology of Dichroine]. Shengli xuebao 生理学报 [Acta Physiologica Sinica] 20 (1): 30-36.

Zhang, He 张融. 2018. “Qinghaosu faxianshi yanjiu de huigu he sikao” 青蒿素发现史研究的回顾 和思考 [Reflections and Thoughts about the Research on the History of Artemisinin's Discovery]. Zhonghua yishi zazhi 48 (2): 114-118.

Zhang, Jianfang 张剑方. 2018. Chidao de baogao: Zhongguo 523 xiangmu wushi zhounian jinianban 迟 到的报告一一国 523 项目五十周年纪念版 [A Belated Report: For the Fiftieth Anniversary of Project 523]. Chengdu: Sichuan People's Publishing House.

Zhang, Daqing, Li Runhong, and Rao Yi. 2017. Jicheng yu chuangxin: Wuersan renwu yu Qinghaosu yanfa 继承与创新一一五二三任务与青蒿素研发 [Inheritance and Innovation: Project 523 and the R\&D of Artemisinin]. Beijing \& Shanghai: Science and Technology of China Press \& Shanghai Jiao Tong University Press.

Zhang, Wei 张卫, and Zhang Ruixian 张瑞贤. 2009. “'Wenhua Dageming' qijian Zhongcaoyao yundong tedian ji biaoxian xingshi” “文化大革命” 期间中草药运动特点及表现形式 [Features and Forms of the Movement of Promoting Chinese Herbal Medicines during the "Cultural Revolution"]. Zhonghua yishi zazhi 39 (1): 25-29.

Zhang, Wenhu 张文虎. 2009. “Chuangxin zhong de shehui guanxi: Weirao Qinghaosu de jige zhenglun” 创新中的社会关系: 围绕青蒿素的几个争论 [Social Relations in Innovation: Several 
Arguments about Artemisinin]. Ziran bianzhengfa tongxun 31 (6): 32-39.

Zhang, Xiaohong 张晓红, Zhu Shizhe 朱世哲, and Li Jian 李剑. 2019. Bange shiji de jianshou yu huihuang: Li Guoqiao Qinghao kangnüe tuandui guangying jiyi 半个世纪的坚守与辉煌——李国桥 青高抗疮团队光影记忆 [Perseverance and Glory of Half a Century: Photographic Records of Li Guoqiao's Research Team on the Antimalarial Qinghao]. Guangzhou: Guangdong Science and Technology Press.

Zhao, Chengxia 赵承瑕, Zhang Changshao, Fu Fengyong, Gao Yisheng, and Huang Qizhang. 1947. “Changshan zhi kangnüe chengfen: Changshanjian” 常山之抗㾏成分一一常山碱 [The Antimalarial Component of Changshan: Dichroine]. Kexue 科学 [Science] 29 (2): 49.

Zhou, Cheng 周程. 2016. “Tu Youyou yu Qinghao kangnüe gongxiao de faxian” 屠呦呦与青蒿高 抗疮功效的发现 [Tu Youyou and the Discovery of the High Antimalarial Potency of Sweet Wormwood]. Ziran bianzhengfa tongxun 38 (1): 1-18. 